\title{
Comparative study of post pneumonectomy compensatory lung response in growing male and female rats
}

by

Sekhon Harmanjatinder Singh

B.Sc.. Punjab University. Chandigarh. INDIA. 1971

M.B.B.S.. Magadh University. Gaya, INDIA, 1980

\section{A THESIS SUBMITTED IN PARTIAL FULFILMENT OF THE REQUIREMENTS FOR THE DEGREE OF MASTER OF SCIENCE \\ in \\ THE FACULTY OF GRADUATE STUDIES \\ Department of Academic Pathology}

We accept this thesis as conforming to the required standard

THE UNIVERSITY OF BRITISH COLUMBIA November. 1987

(c) Sekhon Harmanjatinder Singh. 1987 
In presenting this thesis in partial fulfilment of the requirements for an advanced degree at the The University of British Columbia, I agree that the Library shall make it freely available for reference and study. I further agree that permission for extensive copying of this thesis for scholarly purposes may be granted by the Head of my Department or by his or her representatives. It is understood that copying or publication of this thesis for financial gain shall not be allowed without my written permission.

Department of Academic Pathology

Faculty of Medicine

The University of British Columbia

2211 Wesbrook Mall

Vancouver. BC, Canada

V6T 1 W5

Date: November. 1987 


\section{ABSTRACT}

Male and female Sprague-Dawley rats matched for litter and body weight. were subjected to left pneumonectomy and sham operations at four weeks of age. Three weeks following surgery, rats were sacrificed, and somatic and lung growth, pressure-volume curves, biochemical, and morphometric parameters were measured.

Females weighed $48 \%$ less than males at the end of the experiment. Somatic growth of neither sex was effected by pneumonectomy. Following pneumonectomy. lung weight and lung volume increased significantly and matched that of both lungs of the sham-operated group in both sexes. The absolute amount of DNA and protein content also increased but was significantly less than that of both lungs of shams. Since females weighed less, absolute lung weight, lung volume. DNA and protein content increased more in males but specific parameters (i. e. values/ $100 \mathrm{~g}$ body weight) increased significantly less compared to females. This occurred because specific lung weight and volume decreased with increasing body weight. Mean linear intercept and mean chord length of alveoli were increased. Alveolar surface area increased by $51 \%$ in males and $31 \%$ in females, and matched that of both lungs of shams in males but not in females. The total number of alveoli increased $15 \%$ and $18 \%$ in males and females respectively and was significantly less compared to both lungs of shams in both sexes.

After pneumonectomy, the post-caval lobe increased in volume $70 \%$ and $73 \%$ in males and females respectively as compared to a $60 \%$ and $47 \%$ increase in total lung volume. The mean linear intercept and mean chord length of alveoli increased less in the upper and lower lobes compared to the middle and post-caval lobes in males as 
well as in females. The number of alveoli per unit volume decreased more in middle and post-caval lobes compared to the upper and lower lobes in both sexes. In shamoperated male rats the upper and lower lobes had a smaller mean linear intercept and mean chord length of alveoli compared to the post-caval lobe. Postpneumonectomy, loss of elastic lung recoil at mid-volumes was observed in females.

It was inferred that compensatory response following pneumonectomy was in general similar in males and females. While there was an evidence of alveolar multiplication. simple dilation of airspaces occurred and this was the dominant effect especially in females. In certain aspects (weight, volume) compensatory growth was complete but in most (DNA. protein. morphometry) was not. Male and female differences could not account for differing results in the literature concerning completeness or otherwise of lung compensatory growth. 


\section{Contents}

ABSTRACT

LIST OF TABLES viii

LIST OF FIGURES Ni xi

ACKNOWLEDGEMENTS . Xii

1 INTRODUCTION 1

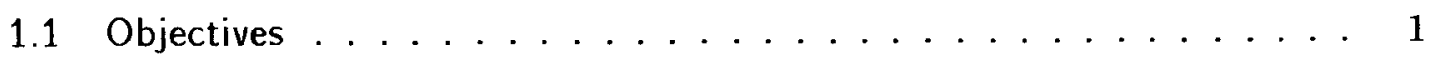

1.2 Normal postnatal lung growth ................ . 1

1.3 Compensatory growth .................. 4

1.4 Pneumonectomy and compensatory growth ............ 5

1.4.1 Extent of compensatory lung response . . . . . . . . . 5

1.4.2 Nature of response ............... 6

1.4.3 Alveolar multiplication .............. 8

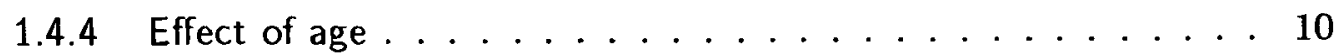

1.4.5 Duration of response ................. 11

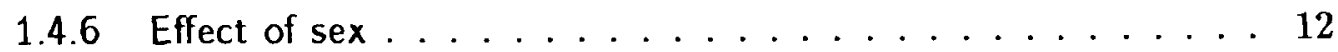

1.4.7 Lobar response ................... 12

1.4.8 Location of response ................. 14

1.4.9 Physiological studies .................. 14 
1.4.10 Control of compensatory lung growth . . . . . . . . . 16

a. Mechanical stretch .................. 16

b. Hypoxia and hypoxemia ................. 17

c. Oxygen consumption ................... 18

d. Specific growth factors . . . . . . . . . . . . . . . 19

e. Hormones .................... . . 20

f. Ozone $\left(O_{3}\right) \ldots \ldots \ldots \ldots \ldots \ldots$

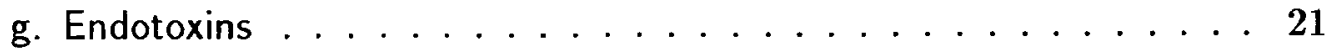

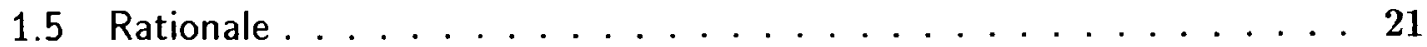

2 MATERIALS AND METHODS 22

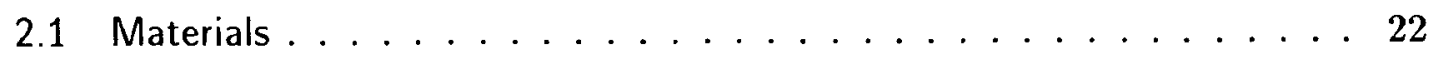

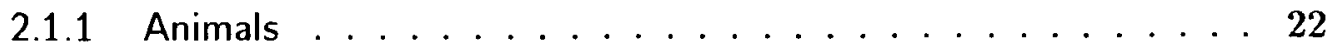

2.1 .2 Chemicals ................... 22

2.2 Methodology..................... 22

2.2.1 General experimental design . . . . . . . . . . . . 22

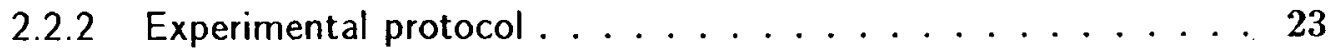

a. Surgery ........................ 23

b. Termination ........................ 24

2.2.3 Pressure-volume curve manuever . . . . . . . . . . . . 24

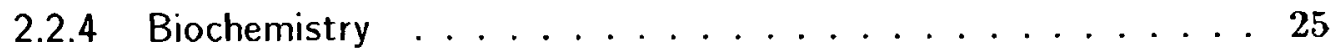

a. DNA and protein extraction .................. 25

b. Alkali soluble protein estimation . . . . . . . . . . . 26

c. Deoxyribonucleic acid (DNA) estimation ........... 26

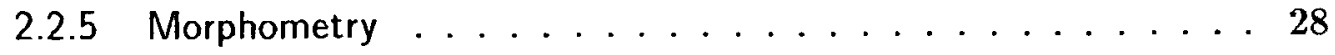

a. Lung fixation and volume determination . . . . . . . . . . 28

c. Tissue shrinkage factor . . . . . . . . . . . . . . 29 
2.3 Statistical analysis of data . . . . . . . . . . 32

3 RESULTS $\quad 36$

3.1 Expression of results $\ldots \ldots \ldots \ldots \ldots \ldots$

3.2 Somatic growth $\ldots \ldots \ldots \ldots \ldots \ldots \ldots \ldots$

3.3 Compensatory response . . . . . . . . . . . . . . . 39

3.3.1 Extent of response $\ldots \ldots \ldots \ldots \ldots \ldots \ldots \ldots$

a. Males . . . . . . . . . . . . . . . . . 39

b. Females . . . . . . . . . . . . . . 39

c. Difference in males and females . . . . . . . . . 42

3.3.2 Nature of response (Lobar response) . . . . . . . . . 42

a. Males . . . . . . . . . . . . . . . . . 42

b. Females ...................... 43

3.3.3 Nature of response (Global response). . . . . . . . . . 46

a. Males . . . . . . . . . . . . . . . 46

b. Females . . . . . . . . . . . . . 46

c. Difference in males and females . . . . . . . . 47

3.3.4 Biochemical changes. . . . . . . . . . . . . 48

3.4 Lung mechanics. . . . . . . . . . . . . . . . 49

$3.5^{\prime \prime}$ Morphometric interlobar differences in shams $\ldots . . . \ldots . . .52$

3.5 .1 Males. . . . . . . . . . . . . . . . 52

3.5 .2 Females. . . . . . . . . . . . 52

4 DISCUSSION $\quad 56$

4.1 Somatic growth ..................... 57

4.2 Extent of response ................... 57

4.3 Nature of response .................. 59 


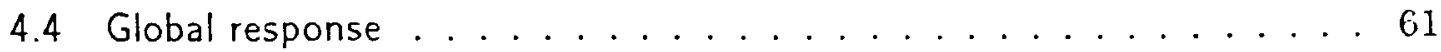

4.4 Males .................... 61

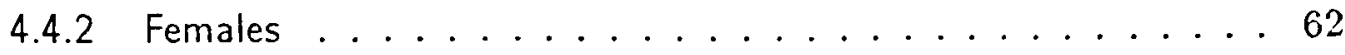

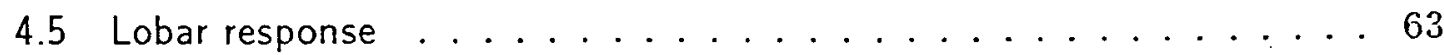

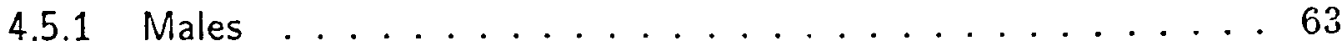

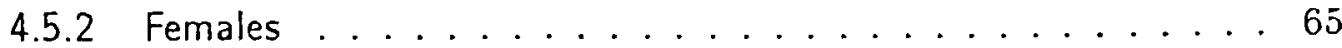

4.6 Lung mechanics ... . . . . . . . . . . . . . 65

4.7 Lung structure at age 7 weeks ................. . . 67

4.8 Difference between males and females following pneumonectomy . . . . 70

4.9 Intersex response and differences in the literature ........ 71

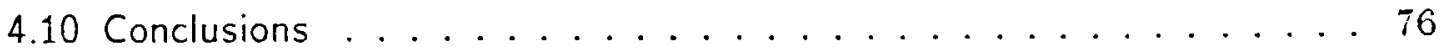

$\begin{array}{ll}\text { BIBLIOGRAPHY } & 78\end{array}$

$\begin{array}{lr}\text { A APPENDDX } & 89\end{array}$ 


\section{List of Tables}

2.1 Number of animals used per group per analysis (morphometric and biochemical.) ..................... 23

2.2 Morphometric calculations . . . . . . . . . . . 35

3.1 Abbreviations ...................... 37

3.2 Somatic growth results for male sham-operated vs female sham-operated group. and male pneumonectomy vs female pnuemonectomy group. . . 38

3.3 Extent of compensatory lung growth results for male pneumonectomy group compared to male sham-operated group. . . . . . . . . 40

3.4 Extent of compensatory lung growth results for female pneumonectomy group compared to female sham-operated group. . . . . . . . 41

3.5 Lobe volumes $(\mathrm{ml})$ : Male pneumonectomy group compared to male sham-operated group and female pneumonectomy group compared to female sham-operated group. . . . . . . . . . . . . . . 4 4

3.6 Lobar morphometric response results for male pneumonectomy group compared to male sham-operated group. . . . . . . . . . . . 44

3.7 Lobar morphometric response results for female pneumonectomy group compared to female sham-operated group. . . . . . . . . 45

3.8 Global morphometric response results for male pneumonectomy group compared to male sham-operated group. . . . . . . . . . . 47

3.9 Global morphometric response results for female pneumonectony group compared to female sham-operated group. . . . . . . . . 48 
3.10 Nature of lung growth, a biochemical aspect: Male sham-operated vs male pneumonectomy group. and female sham-operated vs female pneumonectomy group. ................... 49

3.11 Static pressure-volume curve results for male sham-operated vs male pneumonectomy group. and female sham-operated vs female pneumonectomy group. .................. 52

3.12 Morphometric results for interlobar difference . . . . . . . . . . 54

4.1 Global morphometric response in males following pneumonectomy. . . . 62

4.2 Global morphometric response in females following pneumonectomy. . . 63

4.3 Lobar morphometric response in males following pneumonectomy. . . . 64

4.4 Lobar morphometric response in females following pneumonectomy. . . 66

4.5 Results for hypothetical experiment [A] using data from the present study. ..................... 72

4.6 Results for hypothetical experiment [B] using data from the present study.

A.1 Somatic growth results for male sham-operated vs male pneumonectomy. female shame-operated vs female pneumonectomy groups. . . . 89

A.2 Extent of compensatory lung growth results for male sham-operated group compared to female sham-operated group. . . . . . . . . 90

A.3 Extent of compensatory lung growth results for male pneumonectomy group compared to female pnemonectomy group. . . . . . . . . . . 90

A.4 Lobar morphometric results for male sham-operated group compared to female sham-operated group. .............. 91

A.5 Lobar morphometric results for male pneumonectomy group compared to female pnemonectomy group. . . . . . . . . . . . . . 92

A.6 Global morphometric response for male sham-operated group compared to female sham-operated group. ............... 93 
A.7 Global morphomteric response results for male pneumonectomy group compared to female pnemonectomy group. . . . . . . . . . . 93

A.8 Nature of lung growth, a biochemical aspect: male sham-operated vs female sham-operated group, and male pnemonectomy vs female pnemonectomy group. . . . . . . . . . . . . . . 93

A.9 Static pressure-volume curve results for male sham-operated vs female sham-operated group, and male pneumonectomy vs female pneumonectomy group. . . . . . . . . . . . . . . . . . 94 


\section{List of Figures}

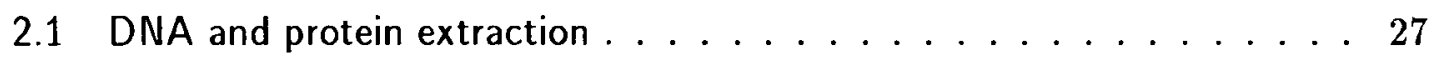

2.2 Test grid used for light microscopic morphometry. . . . . . . . . . 31

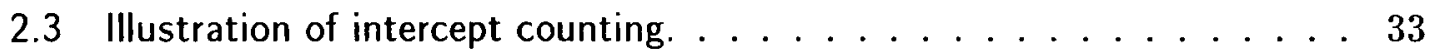

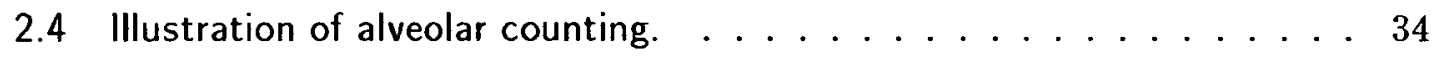

3.1 Static pressure-volume curve of female pneumonectomy group plotted against female sham-operated group. . . . . . . . . . 50

3.2 Static pressure-volume curve of male pneumonectomy group vs. male sham-operated group. . . . . . . . . . . . . . . . . 51

3.3 Static pressure-volume curve of male sham-operated group vs. female sham-operated group. . . . . . . . . . . . . . . 53

4.1 Lung weight in males at the time of $177 \mathrm{~g}$ body weight. . . . . . 68

4.2 Lung volume in males at the time of $177 \mathrm{~g}$ body weight. . . . . . . . 69 


\section{Acknowledgements}

I specially and sincerely thank my supervisor, Dr. W. M. Thurlbeck for his endless support, enormous encouragement and precious time which he spent to guide me throughout my graduate studies. His invaluable advice, utmost patience and constructive criticism helped me to solve the riddles to made this work possible.

Also my sincere gratitudes to my supervisory committee. Dr. J. B. Hudson, Dr. D. E. Brooks. Dr. D. F. Smith and Dr. J. Emerman for their invaluable time to understand my unique situation and invaluable guidance and suggestions.

I would like to express my deep appreciation of the friendship, support and encouragement I have received while doing my research, from Craig Smith. Felix Ofulue. Hassan Khadampour, Jan Larson. Kamala Sudhakar and Mary Battell. Especially. I am indebted to Dr. Sudhakar Cherukupalli for his invaluable assistance in processing this work on the computer.

Finally I would like to extend my gratitude to Ominder and Narinder Chauhan . Manohar Patara. Lakhbir. Satnam and Mypinder for encouragement, endless warmth and appreciation. 
Dedicated

to

\section{MY PARENTS}

Gulzara Singh and Manjit Kaur Sekhon $A N D \quad T O \quad M Y \quad I N-L A W S$

Avtar Singh and Gurmeet Kaur Nahal 


\section{Chapter 1}

\section{INTRODUCTION}

\subsection{Objectives}

The intent of this experiment was to study structural, physiological and biochemical aspects of compensatory response following pneumonectomy in growing male and female rats. The specific objectives of this investigation were:

1. To test the hypothesis that the postpneumonectomy compensatory response in young male and female rats, is different.

2. To test the hypothesis that all lobes of the right lung are morphologically similar.

3. To study the difference in the interlobar compensatory response after left pneumonectomy in growing males and females.

\subsection{Normal postnatal lung growth}

The transition of the fetus from intra-uterine to extra-uterine life is sudden, the fetalplacental circulation is interrupted and adaptation to extra-uterine life is crucial. At this stage the gas exchanging surface in many species is immature without the definitive components of the adult lungs. It has been agreed that at the time of birth rodents such as rats (Newhauser and Dingler, 1962; Weibel, 1967; Burri et al., 1974). mice (Wilson. 1928; Amy et al., 1977) and mammals such as rabbits (Engel. 1953). cats (Engel. 1953: Dingler. 1958) and dogs (Boyden and Tompsett, 1961) do not possess 
alveoli, the terminal air exchanging units in adult lungs. They contain almost exclusively primitive thick walled primary saccules (Weibel, 1967: Burri, 1974) or terminal sacs (Boyden and Tompsett. 1961), which undergo rapid subdivision postnatally by secondary crests which results in structural rearrangement to form true alveoli. These smooth walled primary saccules are large and lack surface complexity. The wall has double capillary network which runs on either side of the connective tissue framework (Burri et al..1974).

In humans, some investigators (Emery and Mithal. 1960; Mithal and Emery. 1961; Boyden and Tompsett, 1965: Boyden. 1967: Wilcock. 1966; Reid, 1967; Hislop and Reid, 1974) have stated that alveoli are absent in the fetus at the time of birth and suggested that the structures in question were saccules (Hislop and Reid, 1974). However, Loosli and Potter (1959) observed that from seven and one-half months gestation until term. there was further development of respiratory channels into alveolar ducts which produced small but definitive alveoli. Langston and Thurlbeck (1982) found a mean of 55 million and a range of 10-149 million alveoli at the time of birth. Dunhill (1962) reported 20 million in one infant. Hieronymi $(1960 ; 1961)$ found 70 million and Thurlbeck and Angus (1975) counted 71 million alveoli at birth. It has been pointed out that by 32 weeks gestation, alveoli-like structures can be found in the fetal lungs and definitive alveoli are present at 36 weeks of gestational age (Brody and Thurlbeck, 1986). The conflicting results could be due to biological variations. difference in tissue preparation or difficulty of defining and recognizing alveoli (Thurlbeck, 1975). Whether the complement of acini at birth, increases postnatally by simple enlargement (Kolliker. 1881) or due to formation of additional structures (Browman, 1923: Heiss, 1923) has been a matter of controversy for the past century. In adults, there is a range of 200-600 million alveoli (Angus and Thurlbeck, 1972). The alveolar surface area increases twelve fold and lung volume twenty-eight fold from birth to adult life. The constant number of alveoli per unit volume and alveolar size up to 2-4 years of postnatal age in children is an indication of alveolar multiplication and subsequent to that no or little increase in total alveolar number occurs (Thurlbeck, 1982). Later in childhood, it is thought that alveolar multiplication continues but at a slower rate and does not cease until somatic growth stops (Thurlbeck. 1975). However. some investigators have suggested that alveolar multiplication ceases between age of 4 and 
11 years (Dunhill. 1962; Davies and Reid, 1970). After 8-9 years of age, minimal multiplication of alveoli occurs and change in lung structure is related to chest wall growth and body stature (Thurlbeck and Haines, 1976). Boys have bigger lungs in comparison to girls of same age and height (Thurlbeck. 1982).

Postnatal lung growth in animals has been studied in detail (Engel, 1953: Dingler. 1958; Weibel, 1967: Burri, 1974: Burri et al., 1974: Kauffman et al., 1974; Amy et al.. 1977). In rats and mice during the first day of life there is little change in lung weight (Amy et al., 1977) or lung volume (Short. 1951). Tritiated thymidine incorporation into DNA for the first 24 hours is also negligible (Kauffman et al.. 1974). The lungs then increase rapidly in weight (Amy et al., 1977; Nijjar, 1979) and the rate of tritiated thymidine incorporation into DNA is also increased (Das and Thurlbeck, 1979). In rats, postnatal lung growth has been divided into three distinct phases (Burri, 1974). During the first phase (lung expansion phase, days 1-4), the lung primarily grows by expansion due to a gain in the volume of airspaces. The second phase (tissue proliferation phase, days 5-13) is identified with an increase in lung weight and lung volume. Lung weight doubles and lung volume triples during this period. DNA synthesis increases intensively (Kauffman et al., 1974). The third phase (equilibriated lung growth, day 14- ) comprises a slow but proportional increase in lung weight and lung volume. New alveoli continue to be added but the rate of cellular proliferation decreases (Kauffman et al., 1974). Alveolar surface area increases directly with lung volume. The number of alveolar type I cells increase 3-4 times up to 6 weeks (Brody and Thurlbeck, 1986), and the thickness of the alveolar wall decreases primarily due to diminished cellular components of the interstitial compartment.

A fourth phase (Thurlbeck. 1975) of simple expansion is present in some species. It starts when alveolar multiplication ceases between 6 and 10 weeks of age (Holmes and Thurlbeck, 1979), but it has been reported that alveolar multiplication continues even up to 133 days of age of rats (Weibel. 1967).

In the past century, various techniques have been employed to manipulate the lungs to alter or stimulate lung growth in postnatal life. Several maneuvers i.e. pneumonectomy, adrenalectomy, exposure to hypobaric hypoxic conditions, administration of growth hormone etc.. have been used to study altered lung growth. However, interpretation of results of these manipulations is hard to extrapolate to normal postnatal 
lung growth, yet could serve as a useful model to understand this complex process.

\subsection{Compensatory growth}

Partial extirpation of an organ is a common surgical procedure to limit or cure a disease. Organs such as kidney, liver, adrenal, gut, and lung show compensatory growth of the remaining tissue after partial resection. However, this occurrence is not true in all organs and organs that do not show compensatory growth include ovaries. testes, brain, or the medullary portion of the adrenals (Addis, 1928). Restoration of the organ mass may take place by cellular proliferation (hyperplasia) as in the liver. or by increase in cell size (hypertrophy) as in heart. or both as in the kidney. A hyperplastic cellular response is observed by rapid increase in amount of DNA content without apparent change in cell size, while hypertrophic changes are characterized by increase in protein per nucleus and RNA to DNA ratio. In most organs, the original morphology is maintained with slight alteration in the architecture.

In rats after resection of $2 / 3$ of liver mass, the residual tissue restores the original mass within 10 days (Becker. 1969: Tsanev, 1975). Cellular proliferation is more rapid in younger animals and mitotic activity starts in the liver cells within 24 hours of hepatectomy. The lobes after resection are not reformed. The new functional units are formed by proliferation of new acini within the old lobules which ultimately increase the size of the liver. The architecture of the restored liver differs slightly from the original tissue (Lewan, 1977).

Similarly in rats after nephrectomy soon after birth. compensatory response in the contralateral kidney is hyperplastic, but if resection is done after 40 days of age. hypertrophic changes take place (Krap et al.. 1971) Complete renal function restoration takes place within 6 weeks after $75 \%$ ablation of renal mass at birth in puppies, while surgery performed at the age of 8 weeks results in only $45 \%$ restoration over the same time period (Archinberg, 1978). Unilateral nephrectomy results in an increase of glomerular number, if resection is done before the age of 50 days in rats, but not thereafter (Bonvalet et al., 1972). In growing rats, removal of $50 \%$ and $70 \%$ of renal mass resulted in an increase of $81 \%$ and $168 \%$ respectively in comparison to $31 \%$ in control rats (Kauffman et al., 1974). Thus, it is evident that compensatory growth 
of kidney is qualitatively and quantitatively age dependant and also depends upon the quantity of the mass removed.

\subsection{Pneumonectomy and compensatory growth}

After resection of a lung (pneumonectomy) or a part of a lung (lobectomy), a significant space is created within the thoracic cavity. How does the residual lung respond and how is the interdependence of function and structures maintained. were the questions put forth by Hassler in 1892. He suggested that in young developing rats after ablation of a lung, the contralateral lung grew by hyperplastic regeneration. Later Mohlgaard and Rovsing (1910) and Kawamura (1914) stated that compensatory lung growth in the adults occurs by dilatation of existing structures. Since then, controversy has existed whether the postpneumonectomy or postlobectomy compensatory response in the contralateral or ipsilateral lung is complete (equal to both lungs of the controls), or incomplete (less than both lungs of the controls), and if it occurs by formation of additional new structures or by enlargement of the already existing ones.

\subsubsection{Extent of compensatory lung response}

Lungs are different in comparison to the other organs of the body which have been studied for compensatory growth. They receive the entire cardiac output and after pneumonectomy or lobectomy, the whole blood flow is directed to the residual lung tissue. Thus, increased blood volume load and loss of lung volume and parenchyma has enormous impact on the remaining tissue. After pneumonectomy, a marked increase in the lung size of rats (Addis, 1928: Cohn, 1939; Romanova, 1960; Buhain and Brody. 1973: Nattie et al.. 1974: Holmes and Thurlbeck. 1979: Burri and Sehovic. 1979). rabbits (Sery et al.. 1969; Boatman. 1977: Langston et al.. 1977: Boatman et al.. 1983). guinea pigs (Gnavi et al.. 1970), cats (Bremer. 1936). and dogs (Rienhoff. 1935; Fisher and Simnett, 1973; Thurlbeck et al.. 1981: Arnup et al. 1984) has been described. However, the extent of the postpneumonectomy response of lung is still controversial. Previous studies have shown that after pneumonectomy or lobectomy. equal or near equal (differences which were statistically insignificant) values (lung weight, lung volume. DNA and protein content) were achieved in comparison to both 
lungs of controls (Sery et al.. 1969: Romanova, 1971: Nattie et al., 1974: Langston et al., 1977: Boatman. 1977: Burri ad Sehovic. 1979: Thurlbeck et al.. 1981: Yee and Hyatt. 1983: Rannels et al., 1984). Hence, the restitution was considered to be complete.

On the other hand. some investigators have documented an incomplete response. McBride (1985) found that in ferrets, the volume of the contralateral lung after pneumonectomy was $17 \%$ less than controls. Long-Evans rats after left pneumonectomy attained only $85 \%$ lung volume and lung weight in comparison to the controls (Buhain and Brody, 1973). Holmes and Thurlbeck (1979) observed that Sprague-Dawley rats pneumonectomized at 4,8 , and 12 weeks of age achieved equal lung weight but a smaller lung volume than controls.

Brody et al. (1978) reported that in mice, increase in lung weight preceeded the increase in lung volume, but Das and Thurlbeck (1979) observed these changes in reverse order in rabbits. Increase in lung volume may not be due to an increase of tissue volume. It may be due to overexpansion of the lung, a unique characteristic of that organ (Thurlbeck, 1975). In rats, the response appears to be complete by about one week, in mice by two weeks and in rabbits by three weeks (Cagle and Thurlbeck. 1988).

\subsubsection{Nature of response}

The increase in tissue mass of the remaining lung after pneumonectomy may be due to hypertrophy (increase in cell size as assessed by an increased Protein/DNA ratio and/or RNA/DNA ratio), hyperplasia (as assessed by an increase in DNA content), of the parenchyma, or a combination of both. The lung has the unique characteristic that it may be able to increase in volume by overexpansion of airspaces to reach a new size without an increase in tissue volume. This increase in size should not be interpreted as hypertrophy and the terms hypertrophy and hyperplasia should be confined to the cellular response within the lung. In the early postoperative period, increase in lung weight is also observed due to edema and congestion (Romanova et al., 1967). She also found a small increase in the wet/dry lung weight ratio ascribed to edema. Addis (1928) reported that, based on nitrogen content, the $40 \%$ increase in the weight of the 
remaining lung in albino female rats 61 days after pneumonectomy, was not due to the presence of blood (he removed the blood by flushing the lungs). but due to increase in the actual tissue mass. In rats (Fisher and Simnett, 1973; Rannels et al.. 1979). mice (Simnett. 1974; Brody et al.. 1978) and rabbits (Cowan and Crystal, 1975; Das and Thurlbeck. 1979) after pneumonectomy, cellular hyperplasia has been noticed by observing increased mitotic indices or increased tritiated thymidine incorporation of parenchymal cells and total DNA content. Romanova et al. (1967) observed that the mitotic index doubled on the 3rd or 4th day postpneumonectomy and 5 fold on day 5. By day 7 , it returned to a 2 fold increase. DNA synthesis was found to be significantly increased in alveolar wall cells by day 5 and peaked on day 11 in rabbits. After 21 days, the total DNA content was equal to control (both lungs) values. and DNA synthesis were the same as in controls (Das and Thurlbeck, 1979).

RNA and protein content increase in parallel to lung weight and cease to increase as soon as the restoration is complete (Rannels et al., 1984). An increase in RNA synthesis reached maximum on day 4 and 5 in contralateral lungs of rats (Romanova et al.. 1967). In rats after pneumonectomy, an increase in DNA and RNA content was noticed but no increase in RNA/DNA ratio was observed. Thus, it was considered that a hyperplasia took place (Buhain and Brody. 1973). Rannels et al. (1979) found an increase in protein to DNA ratio (statistically insignificant) and a significant increase in RNA/DNA ratio. They postulated that the increase of RNA/DNA ratio might be due to newly synthesized protein for collagen formation. Ultrastructural morphometric studies have demonstrated an increase in cell number of type $1 /$ pneumocytes and interstitial cells, and an increase in cell size of type I pneumocytes and endothelial cells (Thet and Law, 1984).

In rabbits there was rapid accumulation of collagen in the lung which was preceded by an increase in the rate of collagen synthesis (Cowan and Crystal, 1975). During the second week following pneumonectomy, the rate of collagen synthesis (calculated as nmoles of ${ }^{14} \mathrm{C}$-proline incorporation into ${ }^{14} \mathrm{C}$-hydroxyproline per $\mathrm{mg}$ of DNA per hour) increased 3 times that of controls and after 4 weeks the collagen content per dry lung weight was constant (Cowan and Crystal, 1975). An increase of $216 \%$ in lysyl oxydase activity (an enzyme responsible for initiating the extracellular crosslinking of collagen and elastin) within 24 hours after pneumonectomy was observed in Golden 
Syrian hamsters (Brody et al., 1979). Light microscopic studies have shown that after pneumonectomy, no thickening of the alveolar septa occurred (Cowan and Crystal, 1975). However in rats, initial transient septal thickening which later on returned to normal has been demonstrated by a scanning electron microscopic study (Burri et al., 1982). It is assumed to be due to increased collagen synthesis (Burri et al.. 1982). Other studies (Burri and Sehovic, 1979: Thet and Law. 1984) found no change in volume proportion of interstitial matrix by light and electron microscopy.

\subsubsection{Alveolar multiplication}

Old as well as modern morphometric techniques have not solved the riddle of the most debated area of compensatory lung growth, whether postpneumonectomy compensatory growth is accompanied by formation of new alveoli (Addis, 1928; Bremer. 1936: Longacre and Johansmann. 1940: Cohn. 1940: Romanova. 1960; Gnavi et al., 1970; Nattie et al., 1974: Langston et al.. 1977: Thurlbeck et al., 1981) or by an increase in the size of already existing structures by dilatation (Reinhoff et al.. 1935: Sery et al., 1969; Buhain and Brody, 1973; Boatman, 1977; Boatman et al., 1983).

Before modern morphometric techniques, dimensional studies were done by counting and measuring surface features of alveoli and evaluation of alveolar multiplication by comparing histological sections. Reinhoff et al. (1935) made histological comparisons of the excised lung with the remaining lung 6 months following pneumonectomy. He deduced that compensatory changes were accompanied by dilatation of already existing respiratory units, without an increase in number of conducting airways and blood vessels.

Cohn (1940) studied the effect of pneumonectomy in rats after 30 days and reported a prior increase in alveolar septal thickening and then alveolar multiplication. Kaszler (1955) observed alveolar dilatation and increased vascularization in dogs 3 weeks after pneumonectomy.

Modern morphometric techniques are more comprehensive and precise. By using these techniques, mean linear intercept (the average interalveolar wall distance), mean chord length of alveoli, alveolar surface area, number of alveoli per unit volume, and total number of alveoli can be estimated. In the case of an increase in lung volume due 
to overinflation. mean linear intercept and mean chord length of alveoli will increase to the cube root of the increase in the lung volume. The number of alveoli per unit volume will decrease inversely to the increase in the lung volume. Surface area will increase to the two-thirds power of the increase in the lung volume. In the case of increased complexity due to complete alveolar multiplication, mean linear intercept, mean chord length of alveoli and number of alveoli per unit volume will remain constant, whereas alveolar surface area will increase directly with the increase in the lung volume.

The relative ratio of volume proportion (density) of alveolar duct air $\left(\mathrm{V}_{v d}\right)$ to volume proportion (density) of alveolar air $\left(V_{v a}\right)$ is a useful variable to assess alveolar multiplication. If multiplication of airspaces occurs maintaining the normal architecture of the lung, then the relative proportion of $\mathrm{V}_{v a}$ and $\mathrm{V}_{v d}$ should remain unchanged. Depending upon isotropic or anisotropic expansion by simple expansion of existing airspaces $V_{v d} / V_{v a}$ might change or remain unaltered. A decrease in $V_{v d} / V_{v a}$ due to relative increase in $V_{v a}$ should occur with lengthening of alveolar wall and could result in an increase of alveolar surface area without alveolar multiplication (Burri et al. 1982).

Langston et al. (1977) considered alveolar multiplication to occur in rabbits pneumonectomized at the age of 10 weeks, and be complete since the total alveolar number was equal to that of the controls. There was an insignificant increase in $V_{v d}$ but the number of alveoli per unit volume and mean linear intercept did not differ. The surface to volume ratio of airspaces remained unchanged (an indicator of alveolar multiplication). Similarly in 20 week old puppies, 10 weeks following pneumonectomy, alveolar number was found to be equal to that of the controls. The number of alveoli. average interalveolar wall distance and surface to volume ratio was not different. Hence, it was concluded that alveolar multiplication took place in dogs (Thurlbeck et al., 1981).

The opposite point of view has been expressed by Boatman (1977) who found that 4 weeks postpneumonectomy in rabbits. mean airspace diameter increased by $25 \%$. $V_{v d}$ by $22-33 \%, V_{v w}$ (volume proportion of alveolar wall) by $30 \%$ and lung volume equal to that of the controls. There was a decrease in alveoli per unit volume and thickness of air-blood barrier. He concluded that compensatory growth was associated with dilatation of alveoli and alveolar ducts. 


\subsubsection{Effect of age}

It is often assumed that compensatory growth after extirpation of a lung or part of a lung is a modification of normal growth (Cagle and Thurlbeck. 1988). Normal somatic growth appears to be accompanied by lung growth. Most strains of rats grow throughout their life and probably their lungs do so too (Donaldson. 1924). In humans and animals alveolar multiplication is greatest in early life (Thurlbeck, 1975). Hence, it is probable that compensatory growth of lung is also age dependant.

In earlier studies, Bremer (1936) and Longacre and Johansmann (1940) concluded from their studies on cats and dogs respectively that alveolar multiplication occured in younger animals after resection of lung, but not in older ones. Cohn (1940) observed an increase in the alveolar number after pneumonectomy in young as well as older rats and observed a greater increase in young ones compared to the older animals.

For the past 2 decades using modern morphometric and biochemical techniques. conflicting results have been reported concerning the effect of age at the time of surgery. Sery et al.. (1969) have indicated that, in comparison to controls, both young (6-10 week old) and adult rabbits achieved complete lung volume restitution without a marked increase in alveolar surface area after pneumonectomy. They concluded that in young and adult rabbits, adaptation was due to hypertrophy of already existing respiratory elements and not due to hyperplastic regeneration. Similar findings were reported by Buhain and Brody (1973). They used 3 and 10 week old rats. They concluded that in younger animals. enlargement of alveoli and alveolar ducts took place. whereas in older ones enlargement of alveolar ducts occurred. Wandel et al. (1983) lobectomized adult female rats which achieved complete lung volume response. They hypothesized that older animals with limited growth capacity adapt as completely as younger animals.

In another experiment. rats with body weights 85,193 and 330 gram underwent left pneumonectomy. After 14 days. young as well as older rats restored lung weight completely. but the response in older rats was delayed by 5-12 days. The net protein accumulation was doubled in young animals but was less efficient in older ones (Rannels et al., 1984).

In contrast to the above observations, some investigators have noticed significant 
quantitative and/or qualitative differences between young and old age group of animals. Nattie et al. (1974) observed that young (30 day old) and old ( 80 day old) rats achieved complete lung volume and weight response. They noticed that the surface alveoli multiplied whereas the internal alveoli enlarged in size in younger animals. while the surface. as well as, the internal alveoli dilatated in older animals. Holmes and Thurlbeck (1979) observed that after left pneumonectomy, 4 week old rats restored lung tissue by alveolar multiplication, but 8 and 12 week old rats did not show significant increase in alveolar number. The overall response in terms of lung weight. volume, protein, and DNA was significantly less in 12 week old rats. In guinea pigs. the response after resection of a lung or part of a lung in younger animals (15 days- 2 months) was multiplication of alveoli and bronchi. whereas in older animals (1-2 years of age) enlargement of the remaining lung structures occurred (Gnavi et al.,1970).

After experimental collapse of the left lung, a $58 \%$ increase in right lung DNA content was found in 3 week old rats in comparison to $28 \%$ increase in 10 week old rats (Inselman et al, 1977). Cagle and Thurlbeck (1988) performed pneumonectomy on 10, 18, and 26 week old rabbits. Four weeks postpneumonectomy, 14 and 22 week old rabbits showed a significant increase in lung weight, volume, DNA. RNA. protein content and surface area but equivocal alveolar multiplication. The 30 week old rabbits showed an increase in lung weight, lung volume. RNA, protein content but not in DNA content and alveolar surface area. From their studies, they suggested that compensatory lung growth does not follow normal lung growth but a some different mechanism is involved since normal lung growth in rabbits was accompanied by alveolar multiplication.

\subsubsection{Duration of response}

In most studies postpneumonectomy response has been assessed within a short period following resection of the lung. Davies et al. (1982) performed pneumonectomy on 6 to 10 week old and 1 year old beagle dogs and studied the response five years later. They found that the difference in lung volume and total alveolar number in the right lungs of controls and both experimental groups were insignificant. However, they noticed enlargement of the distal airways in experimentals. The investigators 
concluded that alveolar multiplication occurred in the initial stage but was temporary. After a longer duration, increase in alveolar number did not continue.

\subsubsection{Effect of sex}

Somatic growth pattern is different in male and female rats. Fischer males after the age of approximately one year stop gaining weight, whereas females continue to grow until the end of their life (Cupovic and Milovic, 1975). Investigations done of the postpneumonectomy adaptive response have used male animals (Nattie et al.. 1974: Das and Thurlbeck, 1979; Holmes and Thurlbeck, 1979: Burri et al.. 1982; Watkins et al., 1985: Bennett et al., 1985: Cagle and Thurlbeck, 1988). female animals (Fisher and Simnett, 1973; Brody and Buhain, 1973: Tartter et al.. 1973) or mixed sexes (Sery et al.. 1969; Langston et al., 1977; Thurlbeck et al,.. 1981; Boatman et al., 1983; Arnup et al., 1984). Some studies have utilized both sexes without matching sex for control and experimentals (Sery et al. 1969; Thurlbeck et al., 1981; Boatman et al., 1983). To date, only one study (Boatman et al., 1983) has compared the postpneumonectomy compensatory response in the right lungs following left pneumonectomy of male and female rabbits of the same age and body weight. They used 7 male and 2 female rabbits. They did not find any significant difference in the morphometric parameters (wet lung weight, lung volume, mean linear intercept, volume density of alveolar tissue. volume density of alveolar duct space, arithmetic mean thickness of air blood barrier) of the right lung between both the sexes. Thus, they concluded that postpneumonectomy adaptive response is similar in male and female animals.

\subsubsection{Lobar response}

Left pneumonectomy, which represents resection of $35 \%$ of lung tissue, is the most commonly used surgical procedure to study postpneumonectomy compensatory lung growth. However, right bilobectomy resulting in removal of $25 \%$ of lung mass (Burri and Sehovic. 1979, Burri et al., 1982), and right pneumonectomy, ablating approximately $65 \%$ of total lung weight (Sery et al.. 1969), have also been performed. Thus. the discrepancy of the results reported, to some extent, may be the result of the above mentioned techniques. Morphometric studies, after pneumonectomy or lobectomy are 
often done on one lobe only (Cohn. 1940; Romenova, 1960; Buhain and Brody, 1973; Burri and Sehovic, 1979), therefore, misinterpretations of the postpneumonectomy response of the lung is possible from a limited sample. If lobar responses are different, extrapolation to the whole lung would lead to conflicting results.

Rannels et al. (1979) found that following pneumonectomy, the right middle and lower lobes formed the same proportion of total lung weight as in unoperated rats, but that the upper lobe formed a lower and the post-caval lobe formed a higher proportion of the total lung weight. Protein synthesis was not different among the lobes and it was concluded that the growth of all the lobes was proportional (Rannels et al.. 1979).

Langston et al. (1977) noticed fewer alveoli per unit volume in the right middle lobe than the lower lobe of left pneumonectomized rabbits, but on the other hand. no difference in inter-alveolar wall distance and surface to volume ratio was observed. Thus, it was concluded that no difference in the response of lobes occurred, and the observation was regarded as a random statistical association.

In 20 week old puppies, after an 11 week recovery from left pneumonectomy. the lower lobe appeared to respond most in the three lobes studied for morphometric analysis. In the lower lobe, average inter-alveolar wall distance was less and alveoli per unit volume were more than in the cardiac and the middle lobe. The cardiac lobe had the fewest alveoli per unit volume. An assumption was made that the lower lobe herniated through the incomplete mediastinum and responded to mechanical stretch. It was concluded that compensatory response of the right lung after pneumonectomy was greater in lower lobe than in middle and cardiac lobe (Thurlbeck et al., 1981). Boatman (1977) observed slightly larger alveoli and lower surface density in the upper lobe than in the lower lobe following pneumonectomy but no conclusion was drawn.

In rats at the age of 6,10 . and 14 weeks 2 weeks postpneumonectomy. difference in lobar response was evident. It was found that the middle and upper lobe in 6 week old, and the upper lobe in 10 week old rats, had larger alveoli than the lower lobe. The post-caval lobe was used for biochemical analysis. In 14 week old rats, no significant difference among the lobes was found after pneumonectomy. However, the middle lobe had larger alveoli in the control animals (Holmes and Thurlbeck. 1979).

Arnup et al. (1984) observed that after left pneumonectomy in 10 week old mongrel 
puppies, all the lobes increased in weight, but the cardiac lobe gained more than double the weight of the controls. The cardiac lobe crossed the incomplete mediastinum to occupy the lower left hemithorax in pneumonectomy dogs. Arnup et al. (1984) concluded that the cardiac lobe was subjected to more effective growth stimulus than the other lobes.

Davies et al. (1982) pneumonectomized dogs of 6-10 weeks and 1 year of age and observed that the cardiac lobe underwent the most significant increase in young and adult animals and displayed significantly reduced alveolar density. They deduced that cardiac lobe was effected mostly by stretch.

\subsubsection{Location of response}

Internal or central airspaces are arranged in a more complex three-dimensional geometrical pattern. whereas the surface or subpleural alveoli are arranged in one plane (Nattie et al., 1974). They noticed that after surgery in young rats, the surface alveoli showed multiplication and the internal alveoli, on the other hand, dilatation. However. Burri et al. (1982) did not find any difference in size of peripheral and central alveoli in their studies of post-bilobectomy of rats.

Brody et al. (1978) reported that the labelling of the alveolar wall of subpleural alveoli with ${ }^{3} \mathrm{H}$-thymidine increased by the third day, but it did not increase until sixth day after pneumonectomy in other alveoli. After plombage, the reaction was blunted in subpleural alveoli but not in central ones.

\subsubsection{Physiological studies}

Assessment of postpneumonectomy response has also been done by studying physiological changes. The physiological alterations are related to the changes in chest wall recoil. difference in shape between the lung and chest wall or dysanaptic growth of the airways (failure of the airways to grow to the same extent as the lung parenchyma). and changes in recoil of lung parenchyma. Lung recoil depends principally upon collagen and elastin fibres, and surface tension at the air-surface interface of airspaces. Functional studies are informative about the extent and nature of compensatory growth. As pressure-volume behavior is the basic mechanical property and can be measured 
directly, it is most commonly used to study the physiological changes in vivo or in vitro in combination with morphometric studies.

Carter et al. (1938) concluded from their study based on arterial oxygen saturation, that 3 and 6 month old puppies after pneumonectomy show complete restoration in comparison to adults. Based on total lung capacity (TLC), similar findings were reported by Wilcox et al. (1979). Other studies based on TLC in dogs (Ford et al., 1981: Arnup et al. 1984: Greville et al., 1986) and in rabbits (Yee and Hyatt, 1983) have also documented complete volume response after pneumonectomy. Massion and Schilling (1964) performed pulmonary function studies on puppies and adult dogs 18 months after lobectomy. They found an increase in function after lower lobectomy and decrease in function after upper lobectomy.

Four weeks after pneumonectomy in rabbits, no difference in lung weight. TLC, and static pressure-volume curve was noticed between experimentals and controls. Forced vital capacity (FVC) was smaller in experimentals and it was suggested that alveolar multiplication occurred as a result of adaptation (Yee and Hyatt. 1983). Similar findings were observed in rats (Buhain and Brody. 1973) and in dogs (Arnup et al.. 1984).

Based on in vivo and in vitro studies performed on 20 week old puppies 11 weeks postpneumonectomy. Ford et al. (1981) observed a small increase in elastic recoil in the remaining lung. They also found an increase in residual volume (RV) or RV/TLC with associated increase in functional residual capacity (FRC). They found a difference in regional distribution of volume which was present at RV and FRC. After pneumonectomy, the regions at the left base were more expanded than those on the right at FRC and RV. The regional RV/TLC and FRC/TLC were greater in the pneumonectomy group than in the controls. They (Ford et al., 1981) considered this to result from an increased outward chest wall recoil, perhaps related to the differences in shape of chest wall and remaining lung.

The physiological studies done so far suggest that during compensatory lung growth, lung recoil changes little, chest wall recoil increases more, and that the properties of the central airways are altered probably due to dysanaptic growth between the airways and parenchyma (Cagle and Thurlbeck, 1988). 


\subsubsection{Control of compensatory lung growth}

Several hypotheses have been put forth to explain the mechanisms of postpneumonectomy compensatory growth by which the residual lung tissue senses the need to compensate for the resected lung. Mechanical stretch, hypoxia or hypoxemia, increased blood flow through the rest of the lung, growth hormone activity, steroids, functional load and organ specific chalone dilution have been suggested to play direct or indirect role in the restoration of the lung tissue. Since the lungs are the gas exchanging units and are in direct contact with the ambient air, air pollutants like ozone have also been considered as a possible cause of altered compensatory lung response.

\section{a. Mechanical stretch}

The oldest hypothesis (Cohn. 1940) is that the degree of the mechanical stretch or tension on the remaining lung after pneumonectomy generated to fill the empty space in the thoracic cavity, triggers the proliferative response. Experimentally, Cohn (1940) altered this stretch or tension after pneumonectomy by inert wax plombage, thoracoplasty. and phrenic nerve avulsion and found that reduction in the compensatory lung response was proportional to the cavity created by the resected lung tissue. A similar conclusion was made by Fisher and Simnett (1973) after studying the effect of postpneumonectomy plastic sponge plombage in the thoracic cavity of rats. Mead (1973) suggested that lung growth is due to a gravity-dependant stress gradient, subjecting upper lobe to greater transpulmonary pressure. Burri (1974) speculated that during normal lung growth and development. increase in tension of the developing elastic network, because of increase in the size of the thorax, may be responsible for the outgrowth of the alveolar septa.

Nattie et al. (1974) noticed an increase in surface alveolar multiplication after pneumonectomy and attributed this to a greater stretch in this region. Davies et al. (1982) also suggested that this increase could be due to a greater ventilatory stretch in the subpleural region. Following pneumonectomy in adult mice after plombage, an early burst of DNA synthesis was found to be delayed in subpleural alveoli but central alveoli were not affected (Brody et al.. 1978). Thus, a limited role of the mechanical stretch as a stimulus to the adaptive response was considered evident. Cowan and 
Crystal (1975) did not notice any significant increase in the lung collagen content or rate of lung collagen synthesis per cell (measured as ${ }^{14} \mathrm{C}$-proline incorporation) in 12 week old rabbits with plombage after pneumonectomy, whereas pneumonectomized animals without plombage did show an increase.

Compensatory lung growth after creating an enlarged intrathoracic space by collapsing one lung has also been studied in rats. The increase in cellular proliferation in the contralateral lung was considered an effect of mechanical stretch (Inselman et al.. 1977; Tartter and Goss, 1973). After collapse of the left lung, the mitotic index doubled. Simnett (1974) blunted this increase by implanting cotton wool in the cavity created by the collapsed lung. On the other hand. sustained mechanical stretch by hyperventilation did not influence alveolar development in the growing lungs of rats (Bartlett Jr., 1972).

\section{b. Hypoxia and hypoxemia}

Hypoxia is known to stimulate postnatal lung growth (Pepelko, 1970: Bartlett and Remmers, 1971; Burri and Weibel, 1971) as well as growth of salamander gills (Bond. 1960) and the tracheal system in the insects (Wiggleworth. 1954).

In humans (Jerek. 1970) as well as in dogs (Longacre and Johansmann. 1940). normal arterial blood gases have been demonstrated at rest within a few days of pneumonectomy. In young as well as older pneumonectomized rats pulmonary arterial oxygen, carbon dioxide and $\mathrm{pH}$, after 2 hours of surgery were found, to be in the range of controls (Nattie et al..1974). Severe hypoxemia was not noticed in any of the animals. They (Nattie et al..1974) concluded that early hypoxemic stress is unlikely to be the sole determinant of lung growth after pneumonectomy. However, Brody (1975) showed that difference in the inspired oxygen concentration had a significant effect on the early postpneumonectomy response. He demonstrated that total lung volume increased $33 \%$ more than controls after pneumonectomy in the second postoperative week. Decreased inspired oxygen tension (17\% or $14 \%$ ) accentuated that increase in total lung volume. An increased inspired oxygen tension abolished the increase in total lung volume in the first week but not the second week. without affecting the increase in lung weight. He also observed changes in lung pressure-volume curves and 
suggested that oxygen might have influenced synthesis or cross-linking of lung elastin.

\section{c. Oxygen consumption}

Oxygen consumption and energy metabolism are fundamental processes at the cellular level. Since lungs function as gas exchangers, any alteration in oxygen consumption could effect the structure of the lungs. According to Burri and Weibel (1971). as long as the organism does not receive appropriate quantity of oxygen to cover its needs. lung growth may be stimulated.

Weibel et al. (1979) showed that oxygen consumption is closely related to the morphologic pulmonary diffusing capacity. which is the conductance of the lung for oxygen. Weibel (1979) observed that animals with higher physical activity have larger alveolar surface area and larger pulmonary diffusing capacity. and an increase in pulmonary diffusing capacity was proportional to the increase in oxygen consumption. Weibel et al. (1979) observed that the Etruscan shrew, which weighs only $2 \mathrm{~g}$, had oxygen consumption per gram body weight as high as five times than that of man. It had small alveoli and larger alveolar surface area per unit lung volume. They suggested that lung growth may largely be regulated by oxygen consumption.

Gehr et al (1978) raised 4 week old rats for 3 weeks at $11^{\circ} \mathrm{C}$ ambient temperature and it resulted in an oxygen consumption increase of $64 \%$, a $13 \%$ increase in capillary blood volume, a $19 \%$ increase in tissue volume and an $18 \%$ increase in specific alveolar surface area. Lechner and Banchero (1980) exposed 2 to 4 week old guinea pigs to a temperature of $5^{\circ} \mathrm{C}$, and observed an increase in lung volume, alveolar surface area and capillary surface area. However, such changes were not observed in adult guinea pigs on exposure to cold. Japanese waltzing mice, which exhibit excessive motor activity because of a congenital defect in their vestibular apparatus, had a body weight half that of normal mice but four-fifths of lung volume and an even greater change in alveolar surface area (Geelhaar and Weibel, 1971).

However,there are discrepancies regarding the role of oxygen consumption as a determinant of lung growth. Bartlett (1970) showed that altered oxygen consumption after administration of thyroxine did not effect lung structure. Thompson (1980) showed that administration of antithyriod drugs did not effect lung growth. Bartlett 
and Areson (1978) compared lung dimensions of Japanese waltzing mice with their phenotypically normal litter-mates in order to eliminate the variable of evolutionary adaptation. There was no difference between the two groups when compared for specific lung volume, alveolar surface area and total alveolar number.

The oxygen consumption hypothesis can be used to explain compensatory lung growth following pneumonectomy. While absolute oxygen consumption does not increase, oxygen consumption per lung does and an increase in morphologic diffusing capacity would thus be desirable. However, it should be pointed out that the right lung has sufficient capacity to handle oxygen transfer.

\section{d. Specific growth factors}

Following pneumonectomy, a role of specific lung growth factors has been demonstrated. Romanova et al. (1967) performed pneumonectomy on pregnant rats on days 15 to 20 of gestation. After 5 days, the lungs of fetuses of pneumonectomy mothers were heavier, and their mitotic indices were higher compared to controls. It was speculated that a humoral factor was responsible for the stimulation of lung growth in the fetuses which crossed through the placenta in the mothers subjected to pneumonectomy. As no increase in the division of liver cells was observed in the same fetuses. the factor was considered organ specific.

A substance possessing physical properties similar to somatomedin- $C$ was detected in rabbit serum 9 days after pneumonectomy. This substance was capable of stimulating incorporation of ${ }^{3} \mathrm{H}$-thymidine into DNA of cultured human type II pneumocytes (Smith et al., 1980). However, somatomedin-C level was not found to be increased in pneumonectomized or in controls (Thurlbeck et al.. 1984).

Humoral inhibitors of compensatory response after resection of a part of the lung or other organs have been documented. Saetren (1956) observed an increase in mitotic figures after partial ablation of liver or kidney. After injection of the macerates of the removed organ, the mitotic response was inhibited. This observation led to an assumption of organ specific, not species specific, humoral mitotic inhibitors called chalones which were produced by the tissue and which were proportional to the tissue mass (Bullough, 1965). Simnett et al. (1969) observed inhibition of mitosis of mouse 
alveolar cells in organ cultures of rats and mice lung when treated with lung extracts. and they suggested the existence of an alveolar cell chalone. It was suggested that high proportion of blood following pneumonectomy would diminish the amount of locally produced chalone. This would diminish the restraining effect on cell proliferation and result in compensatory lung growth (Fisher and Simnett, 1973).

\section{e. Hormones}

There is evidence that hormones may be involved in regulation of the postpneumonectomy response. Brody and Buhain (1973) implanted MtTF4 tumor (which secretes large amount of growth hormone, prolactin and ACTH) by injecting saline homogenate of MtTF4 tumor subcutaneously in female rats. Pneumonectomy was performed on these rats. Another set of rats underwent hypophysectomy followed by pneumonectomy to study the effect of hormone deficit. They (Brody and Buhain. 1973) found that pneumonectomy resulted in an increase in absolute and specific lung weight. lung volume, and DNA content. The MtTF4 implantation resulted in bigger animals, larger lungs, and similar amount of DNA compared to the controls, but specific lung weight and volume was decreased. Hypophysectomy resulted in small lungs but increased specific lung weight. The rats with the combination of pneumonectomy and MtTF4 showed an additive effect and they had bigger lungs but less DNA content compared to pneumonectomy alone. On the other hand. hypophysectomized pneumonectomy rats had smaller lungs than pneumonectomy alone but specific lung weight and volume were increased. The investigators concluded that growth hormone may play an important role in controlling lung size during compensatory lung growth.

Pneumonectomy performed 5 days after bilateral adrenalectomy resulted in nearly doubling lung weight. DNA. RNA, and protein content compared to pneumonectomy alone (Bennett et al.. 1985). This increase in compensatory response was blunted by giving daily dose of hydrocortisone $5 \mathrm{mg} / \mathrm{kg}$ of body weight. The authors suggested that glucocorticoids may play some role in compensatory lung growth. 


\section{f. Ozone $\left(\mathrm{O}_{3}\right)$}

$\mathrm{O}_{3}$ is a common urban air pollutant. Boatman et al. (1983) studied the effect of ozone on compensatory lung growth. They compared controls, $\mathrm{O}_{3}$ exposed controls, pneumonectomized and $O_{3}$ exposed pneumonectomized 10 week old rabbits. On exposure to $\mathrm{O}_{3}$ an increase of $15 \%$ in lung volume was observed. Pneumonectomy caused a $40 \%$ increase in lung volume and a $29 \%$ increase in alveolar surface area. There was a further increase of $15 \%$ in lung volume of pneumonectomized animals upon exposure to $\mathrm{O}_{3}$. They. however, concluded that exposure to ozone does not effect the compensatory lung response following pneumonectomy.

\section{g. Endotoxins}

Administration of endotoxins has been shown to accentuate the compensatory lung growth in adult rats, but the mechanism by which it takes place is not known (Sosenko and Frank. 1985).

\subsection{Rationale}

In conclusion. studies done to date have shown conflicting results, in terms of completeness of response and alveolar multiplication. Generally, either males or females or mixed sexes have been used to study compensatory lung response. Thus, one reason for conflicting results might be a difference in compensatory response in males and females. This has not been studied systematically. Often an assumption has been made that all lobes behave similarly after pneumonectomy, and only one lobe has been studied as a representative sample of the whole lung. This might also account for the interlaboratory result variations. 


\section{Chapter 2}

\section{MATERIALS AND METHODS}

\subsection{Materials}

\subsubsection{Animals}

All animals were purchased from Charles River Breeding Laboratories (Guelph. Ontario. Canada). They arrived at the age of three weeks in four batches and were housed in the departmental animal care unit. They were given food (standard purina rat chow) and water ad libitum.

\subsubsection{Chemicals}

The reagents used in this study were either purchased from Fisher Scientific (Fairlawn, New Jersey. U.S.A.) or from J.T. Baker Chemical Company (New Jersey. U.S.A.). unless otherwise mentioned.

\subsection{Methodology}

\subsubsection{General experimental design}

At the age of four weeks, both male and female litters matched for body weight were randomly segregated to four groups as follows:

Group 1: Male pneumonectomy group

Group 2: Male sham-operated group

Group 3: Female pneumonectomy group 
Group 4: Female sham-operated group

Right lungs were either used for biochemical analysis (to assess the biochemical changes in protein and DNA content) or morphometric analysis (quantitative assessment of the structural changes in individual lobes).

Table 2.1: Number of animals used per group per analysis (morphometric and biochemical.)

\begin{tabular}{||l|l|l|l|l||}
\hline \hline Analysis & Group 1 & Group 2 & Group 3 & Group 4 \\
\hline \hline Biochemical & $n=10$ & $n=12$ & $n=12$ & $n=11$ \\
Morphometric & $n=10$ & $n=9$ & $n=11$ & $n=10$ \\
\hline
\end{tabular}

\subsubsection{Experimental protocol}

\section{a. Surgery}

The animals at four weeks of age were premedicated approximately 30 minutes before surgery with an intramuscular atropine sulphate injection (Rafter 8 Products. Calgary. Canada) $0.4 \mathrm{mg} / 100 \mathrm{~g}$ body weight, to lessen bronchial secretions. Animals were then placed in a halothane (Halocarbon Laboratories Inc., New Jersey. U.S.A.) vapour saturated chamber until anaesthetized. During the surgery, the rats were continuously anasthetized with halothane inhalation. Initial body weight was measured (Delta range Mettler PE 360). The left side of chest was shaved and painted with povidine ${ }^{R}$ and alcohol. A skin incision, approximately an inch long, was made. The skin was separated from the muscular layer by blunt dissection. The muscular layer was incised and the thoracic cavity was opened by cutting through the fifth intercostal space. The hilum of the left lung was clamped and the left lung was removed. The hilum was ligated with 2-0 silk thread. The right lung was gently inflated with oxygen $\left(\right.$ Medigas $^{R}$ ). The ribs were approximated and thoracic cavity was closed with 4-0 polypropylene sutures. The muscular layer and skin were closed in two layers with continous sutures. An intramuscular injection of penicillin-streptomycin was given ( 0.1 $\mathrm{ml} / 100 \mathrm{~g}$ body weight) to minimize the chances of postoperative infection. Injection of Demerol ${ }^{R}$ (Winthrop Laboratories. Aurora. Ontario) was given $(0.15 \mathrm{mg} / 100$ 
g body weight) intramuscularly to relieve postoperative pain. Sham operations were similarly performed except that the thoracic cavity was not opened.

The animals regained consciousness soon after the surgical procedure. Postoperative mortality rate was less than $2 \%$. Animals were allowed liberal access to food and water.

\section{b. Termination}

Three weeks post-operatively, at the age of seven weeks, the animals were injected with sodium pentobarbital ( $5 \mathrm{mg} / 100 \mathrm{~g}$ body weight) intraperitoneally. In order to degas their lungs, they were given $100 \%$ oxygen. The animals were exsanguinated by cutting the abdominal aorta to lessen the amount of pulmonary blood volume and the diaphragm was incised to cause pneumothorax to collapse the lungs. The trachea was cannulated and the lungs were removed from the thoracic cavity along with the heart and the extrapulmonary tissue.

\subsubsection{Pressure-volume curve manuever}

The cannulated trachea was attached to a connector in lung chamber designed for excised lungs, connected to a precalibrated pressure-volume curve plotting equipment (Validyne. Model MC; Hewitt Packard. Model 7041 A X-Y recorder). After 10 minutes. the lungs were inflated with a step-wise motor-driven air syringe to a transpulmonary pressure of $25 \mathrm{~cm}$ water and then deflated to a transpulmonary pressure of $0 \mathrm{~cm}$ water. During this procedure. if the pressure did not remain constant at $25 \mathrm{~cm}$ of water after inflation, this was considered as an indication of leakage and the lungs were discarded. For each animal, two pressure-volume curves were plotted and the second deflation limb was used for analysis. Total lung capacity (TLC) was defined as the amount of air in the lung at a transpulmonary pressure of $25 \mathrm{~cm}$ of water at the end of the second inflation. Recoil pressures were recorded at 10 percentiles of TLC. According to the method of Colebatch et al. (1979), all the data points over $30 \%$ of TLC were analysed by fitting a single exponential to the pressure-volume curve, using a digital computer. The single exponential expression was:

$\mathrm{V}=\mathrm{V}_{\max }-b e^{-K p}$ 
where $V$ is the volume at pressure $p, V_{\max }$ is the theoretical volume of air at infinite transpulmonary pressure, $b$ the difference between $V_{\max }$ and the intercept on the volume axis and $K$ is a constant that describes the shape of the curve.

\subsubsection{Biochemistry}

Extrapulmonary tissue was removed and the wet lung weight of right and left lungs were measured. Right lungs were frozen in liquid nitrogen and stored at $-70^{\circ} \mathrm{C}$. The frozen lung samples were lyophylized (VirTis Preservator model 10-PR. Freezermobile 12 Freezedryer) until constant weight was achieved. Samples were thinly sliced and dry lung weight was measured (Sartorius 2000MP).

\section{a. DNA and protein extraction}

The procedure of Schimdt-Thannhauser (1945) as modified by Wannemacher (1965) was used for extraction of DNA and protein. Thinly sliced lung samples were soaked in $2 \mathrm{ml}$ phosphate buffer saline (PBS) and stored in a refrigerator overnight. Samples were homogenized with a homogenizer (Caframo. Wiarton. Ontario). Fifty percent trichloroacetic acid (TCA) was added to the homogenate $(4 \mathrm{ml})$ to get a final concentration $15 \%$ of TCA, in order to precipitate macromolecules (acid insoluble proteins, ribonucleic acid and deoxyribonucleic acid). Samples were centrifuged (Beckman. model J-68) at $2000 \times \mathrm{g}$ for 10 minutes. Precipitates were washed with sodium acetate saturated ethanol and the supernatants were discarded. Two $\mathrm{ml}$ of $1 \mathrm{M}$ sodium hydroxide $(\mathrm{NaOH})$ was added to each of the residues and were placed in a prewarmed water bath at $37^{\circ} \mathrm{C}$ (Shaker bath. Forma Scientific) for one hour. After centrifuging at $2000 \times \mathrm{g}$ for 10 minutes, the supernatants were decanted into clean tubes and digestion of the residues was repeated with $2 \mathrm{ml}$ of $\mathrm{NaOH}$. The supernatants were pooled. Cold $6 \mathrm{M}$ perchloric acid (PCA) was added to the supernatants to get a final concentration of $0.3 \mathrm{M} \mathrm{PCA}$ and vortexed. Aliquots of the supernatants were used for alkali soluble protein estimation. After one-half hour. PCA treated samples were centrifuged at $2000 \times \mathrm{g}$ for 10 minutes and supernatants were discarded. One $\mathrm{ml}$ of 1M PCA was added to all residues and incubated at $90^{\circ} \mathrm{C}$ in a water bath (Blue M. Illinois) for 20 minutes. After centrifuging. the supernatants were poured into clean 
tubes and incubation of the residues was repeated as above with $1 \mathrm{ml}$ of $1 \mathrm{MPCA}$. The supernatants were pooled and fractions of those were used for DNA estimation.

\section{b. Alkali soluble protein estimation}

Alkali soluble protein content was estimated by method of Lowry et al. (1951). Bovine serum albumin (BSA. Sigma A-4378) dissolved in $0.1 \mathrm{M} \mathrm{NaOH}$ was used as standard stock solution $(500 \mu \mathrm{gBA} / \mathrm{ml})$. The stock solution was divided into aliquots and stored at $-20^{\circ} \mathrm{C}$ until required for an assay. One aliquot was thawed and pipetted out to prepare a standard curve with duplicate standards containing $0,10,25,50,100$. 150. $200 \mu \mathrm{g}$ of BSA. Samples were diluted 1:10 with distilled water. $150 \mu l$ of diluted samples were taken and the total volumes of samples and standards were made up to $500 \mu l .5 \mathrm{ml}$ of freshly prepared Lowry's solution (2\% sodium carbonate solution in $0.1 \mathrm{M} \mathrm{NaOH}, 1 \%$ copper sulphate solution, $2 \%$ sodium tartrate solution and all mixed in 100:1:1 ratio) was added, vortexed and allowed to sit at room temperature for 15-20 minutes. To each standard and sample, $500 \mathrm{ul}$ of $1 \mathrm{M}$ of freshly prepared Folin's Reagent (2N Folin-Coicalteau phenol reagent solution diluted with distilled water and $1 \mathrm{M} \mathrm{NaOH}$ to final $\mathrm{pH}$ of 1.8) was added. The absorbance was read at $660 \mathrm{~nm}$ in a spectrophotometer (Philips Pye Unicam SP6-550 UV/Vis). Absorbance readings of the lung samples were all within the linear range of the standard curve. By approximating the absorbance on the standard curve, protein contents per sample were calculated.

$$
\begin{gathered}
\text { Protein/lung }(\mathrm{mg})=\frac{\text { protein } \mu g \text { from the standard curve } \times \mathrm{DF}}{1000} \\
\text { Dilution factor }(\mathrm{DF})=\frac{\text { Total volume of the aliquot after dilution }}{\text { Fraction of sample taken }} \times \\
\frac{\text { Total volume of } \mathrm{NaOH} \text { soluble supernatant }}{\ddots \text { Volume of aliquot taken }}
\end{gathered}
$$

c. Deoxyribonucleic acid (DNA) estimation

DNA content was measured according to Burton's method (1956) using calf thymus DNA (Sigma D-1501) as standard. The standard stock solution $(0.4 \mathrm{mg} / \mathrm{ml})$ was 


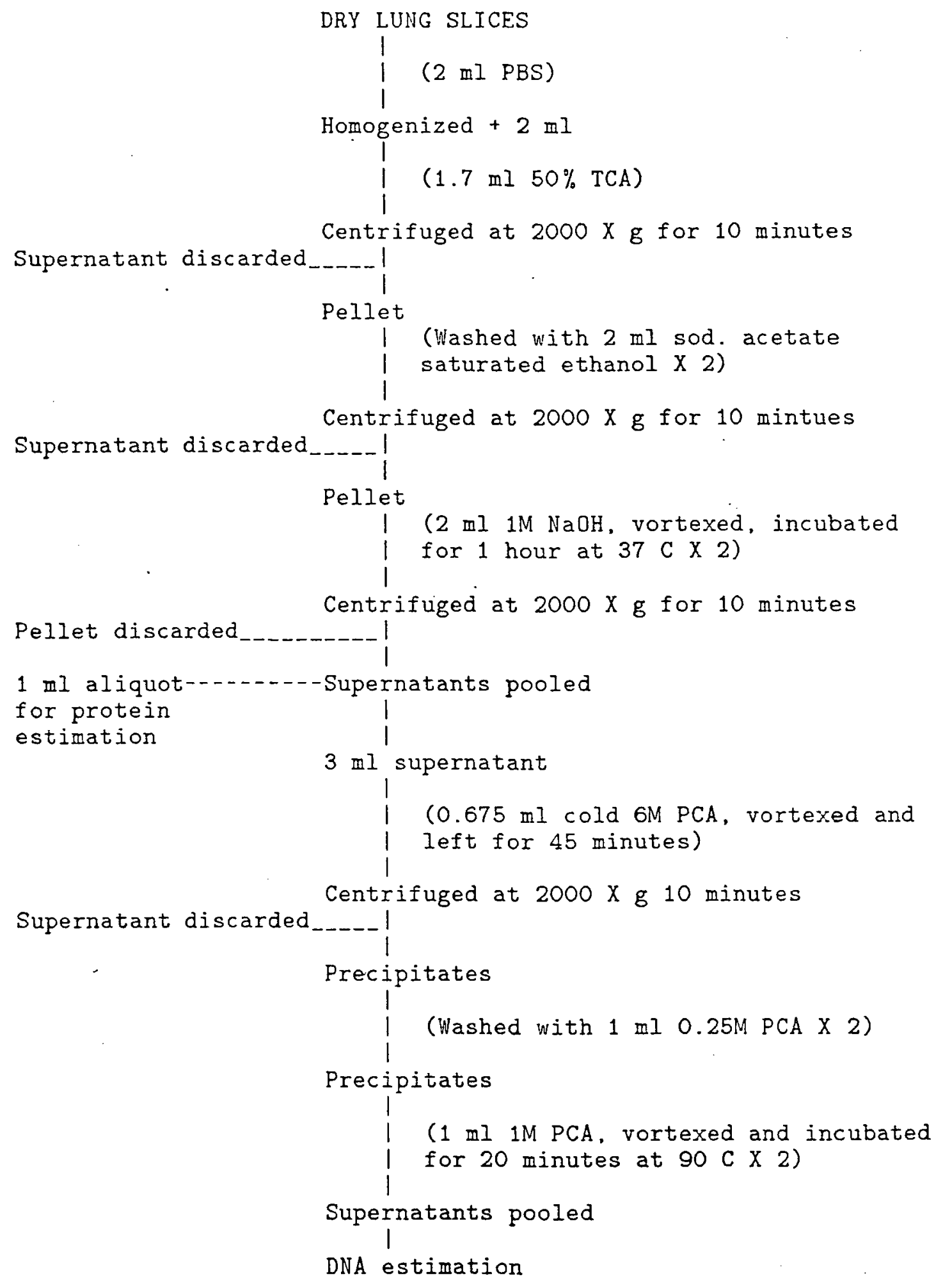

Figure 2.1: DNA and protein extraction 
prepared and stored at $-20^{\circ} \mathrm{C}$. An aliquot was thawed, diluted 1:2 with 1.7M PCA and incubated at $90^{\circ} \mathrm{C}$ for 20 minutes. After cooling, aliquots were pipetted out in duplicate to obtain standards containing $0,16,32,48,64,80,100,120 \mu g$ of DNA. All standard and sample volumes were made up to $1 \mathrm{ml}$ with $1.7 \mathrm{M} \mathrm{PCA}$. Two $\mathrm{ml}$ of diphenylamine reagent $(1 \mathrm{~g}$ diphenylamine. $100 \mathrm{ml}$ of glacial acetic acid, $2.75 \mathrm{ml}$ concentrated sulphuric acid) prepared immediately before use. was added and vortexed. incubated in a pre-heated water bath at $90^{\circ} \mathrm{C}$ for 10 minutes. After cooling. the absorbance of the mixture was read at $600 \mathrm{~nm}$ in a spectrophotometer. The standard curve used for DNA estimation was linear and all the samples fell within the limits of the standard curve. The DNA content per lung was calculated as follows:

$$
\begin{aligned}
\text { DNA/lung }(\mathrm{mg})= & \frac{\mu \mathrm{g} \text { DNA calculated from standard curve } \times \text { DF }}{.1000} \\
\text { Dilution factor }(\mathrm{DF})= & \frac{\text { Total volume of supernatant after PCA incubation }}{\text { Volume of fraction taken for DNA assay }} \times \\
& \frac{\text { Total volume of } \mathrm{NaOH} \text { supernatant }}{\text { Volume taken for DNA precipitation }}
\end{aligned}
$$

\subsubsection{Morphometry}

\section{a. Lung fixation and lung volume determination}

The lungs with cannulated trachea were taken out of the pressure-volume curve chamber and extrapulmonary tissue was removed. The left lung in sham-operated rats was ligated at the hilum, and was removed and weighed. The right lung after weighing was submerged and distended with a $5 \mathrm{cc}$ syringe using $10 \%$ buffed formaldehyde. The cannula was attached to the perfusion system for 72 hours at a constant transpulmonary pressure of $25 \mathrm{~cm}$ of water.

After fixation, the trachea was clamped to prevent fixative leakage and detached from the perfusion system. The hilum was ligated and the trachea was removed. A beaker full of water was placed on a balance (Delta range Mettler PE 360) and tared. The lung was suspended from a laboratory stand and completely submerged under water without touching the sides or the bottom of the beaker. Lung volume $\left(\mathrm{cm}^{3}\right)$ due to water displacement was estimated as equal to the weight in grams depicted on the balance (Scherle 1970). 
According to Archimedes principle which states:

"A body partially or totally submerged in a body of fluid experiences a bouyant force (FB) equal to the weight of the fluid displaced by the volume of that body."

$$
\begin{aligned}
\text { Weight of fluid displaced } & =\text { bouyant force (FB) } \\
\text { Volume of lung }(\mathrm{VI}) & =\frac{\mathrm{FB}}{\text { specific gravity of fluid }}
\end{aligned}
$$

The bronchi of individual lobes were then ligated and the lobes were separated. The volumes of individual lobes were determined by using the procedure mentioned above.

\section{b. Lung sampling and tissue processing}

A mid-saggital block of each lobe was made and its edges trimmed. As the configuration of the post-caval lobe was irregular, its sides were not trimmed. Blocks were photographed and contact prints were made from the negatives. Blocks were embedded in paraffin. Two $5 \mu$ thick sections were cut and stained with hematoxylin and eosin for light microscopic studies.

\section{c. Tissue shrinkage factor}

The area of the block was measured by a computer assisted digitizer (Apple lle. Bioquant II. R. \& M. Biometrics) from the contact prints of the blocks before tissue processing and embedding (pre-processed). After tissue processing and embedding (post-processed). the area of the stained section was also measured by similar technique as described above. The shrinkage factor was determined by dividing the area of the tissue sections by the area of the pre-processed lung tissue. Area shrinkage and linear shrinkage factors calculated as follows:

$$
\begin{aligned}
\text { Area shrinkage factor (asf) } & =\frac{\text { Area of post-processed tissue }}{\text { Area of pre-processed tissue }} \\
\text { Linear shrinkage factor }(\mathrm{Isf}) & =\sqrt{\frac{\text { Area of post-processed tissue }}{\text { Area of post-processed tissue }}}
\end{aligned}
$$

No corrections were made for the thickness of the section. 


\section{d. Light microscopic morphometric measurements}

All the slides used were coded to abolish the chances of bias in morphometric measurements (Holmes and Thurlbeck. 1979: Aherne and Dunhill, 1982: Kawakami. 1984). A microscope with manual stage (Leitz. Telepromar) was used for morphometry. Each slide was projected onto a screen with a square grid with 42 equidistant test points and two diagonal cross hair test lines.

Using a $40 \times$ objective, the predetermined area of the grid was $0.0625 \mathrm{~mm}^{2}$ and total length of the two diagonal cross test lines was $0.64 \mathrm{~mm}$. After leaving $1 \mathrm{~mm}$ margin. the rest of the area was used to choose 20 predetermined equidistant fields using a $4 \times 5$ matrix. A field with more than $25 \%$ of non-parenchymatous tissue (blood vessels, wall of the conducting airways, connective tissue septi) was discarded and next adjacent field was used for measurements.

Each of the 42 test points were counted according to their placement on histological structures, i.e., alveolar air, duct air, alveolar wall, bronchial air, and nonparenchymatous tissue. The smallest discrete structures surrounded by alveolar walls were considered as alveoli. The alveolar duct was considered as the cylindrical core of air within the alveolar duct and sacs internal to the mouth of alveoli. Conducting airway air was referred as bronchial air.

The counting principle used in measuring random sections was based on Delesse principle which states:

"Area proportions are equivalent to volumetric proportions" and "the planimetric fractions of a section occupied by sections of a given component correspond to the fraction of the tissue volume occupied by this component".

Thus, number of test points for each of the tissue components were expressed as a proportion of the number of test points. This represents volume proportion of the tissue structure.

$$
\mathrm{V}_{v x}=\frac{\text { Number of test points falling on a structure } \mathrm{X}}{42 \text { or Total number of test points }}
$$

Intercepts were counted either as wall intercepts (Iw) or duct intercepts (Id) and the sum of the two $(I w+I d)$ represented total number of intercepts $(l a)$. If the wall of the alveoli fell across the test line, two intercepts were counted (2 air exchanging 


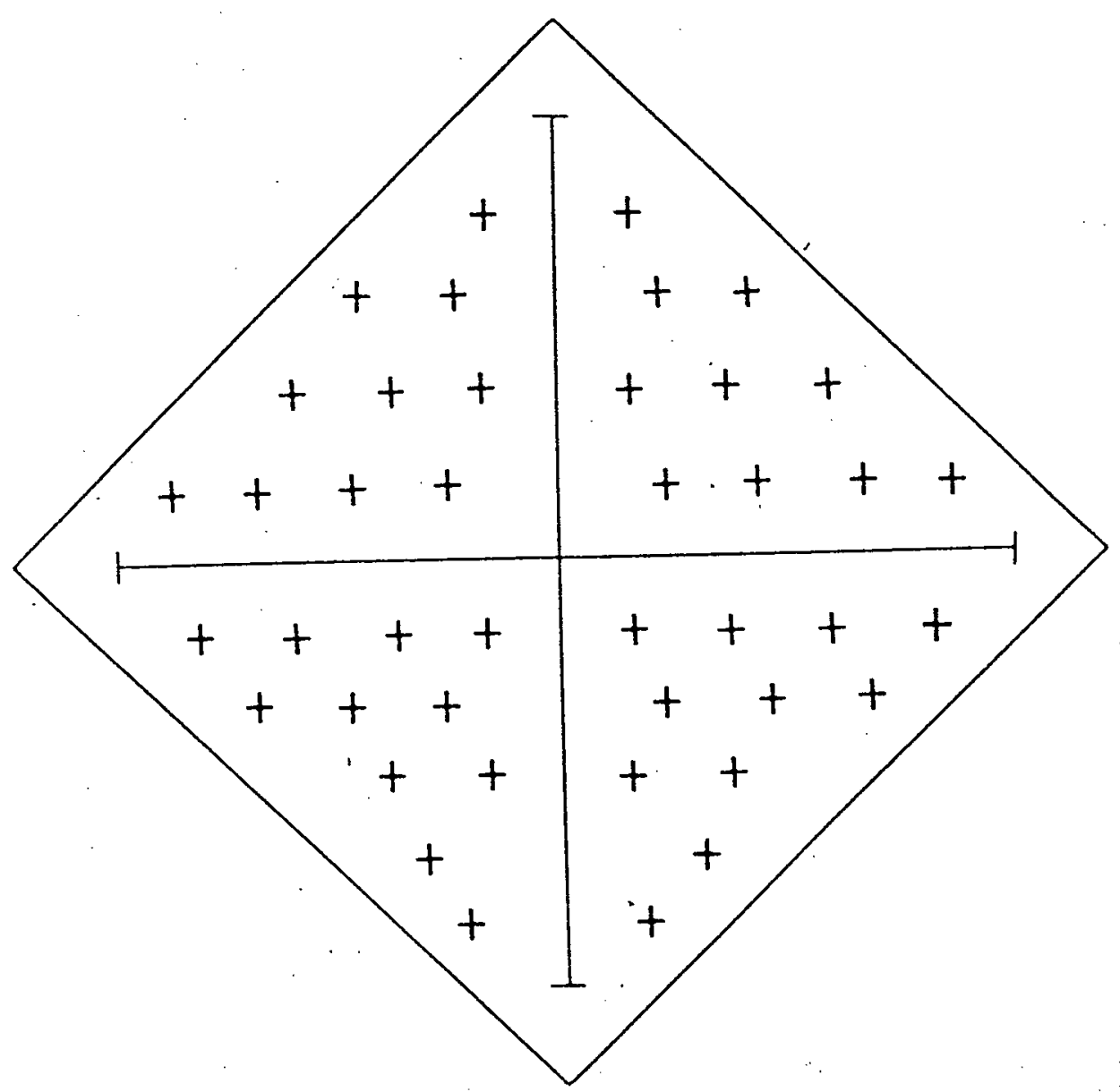

Figure 2.2: Test grid used for light microscopic morphometry. 
surfaces), but if the alveolar wall touched the upper or right side of the test lines or the end of the test line lodged in the wall of the alveolus or in any other tissue structure. it was counted as one intercept. For the duct intercepts (ld). an interception of the test line by an imaginary line across the mouth of the alveolus was counted as two intercepts.

From these morphometric values, mean linear intercept or average interalveolar wall distance $\left(L_{m}\right)$, mean chord length of alveoli $\left(\bar{I}_{a l v}\right)$. and alveolar surface area $\left(\mathrm{Sw}_{T}\right)$ were calculated. The total length of the test line on the grid was corrected for tissue shrinkage in order to project on to fixed tissue. The mean linear intercepts were calculated by dividing the total projected length of test lines by the number of wall intercepts (see Table 2.2).

The number of the alveoli that lay within the grid and on the upper left and right sides of the grid were counted.

The known area $(A)$ of the grid was corrected for tissue shrinkage during processing. The counted number of alveoli were used to calculate the number of alveoli per unit area (NA), number of alveoli per unit volume (Nv), total number of alveoli $\left(\mathrm{Na}_{T}\right)$. and average volume of an alveolus $\left(\overline{\mathrm{V}}_{\text {alv }}\right)$. The distribution constant of the characteristic linear dimension of alveoli $(J)$ was considered as one and shape constant $(\beta)$ of alveolus was taken as 1.55 (Weibel, 1963).

\subsection{Statistical analysis of data}

Group means \pm the standard errors of the means (SEM) were calculated for all variables. Statistical evaluation of the results between the groups was performed by using Student's t-test. The significant level was set at $P<0.05$ to compare the groups. A single factor analysis of variance (ANOVA) was used to test the hypothesis that the means of all lobes were equal. If the hypothesis was rejected at $P<0.01$ than Student Neuman Keuls (SNK) multiple range test was used in order to locate a significant difference at $P<0.05$ level. 


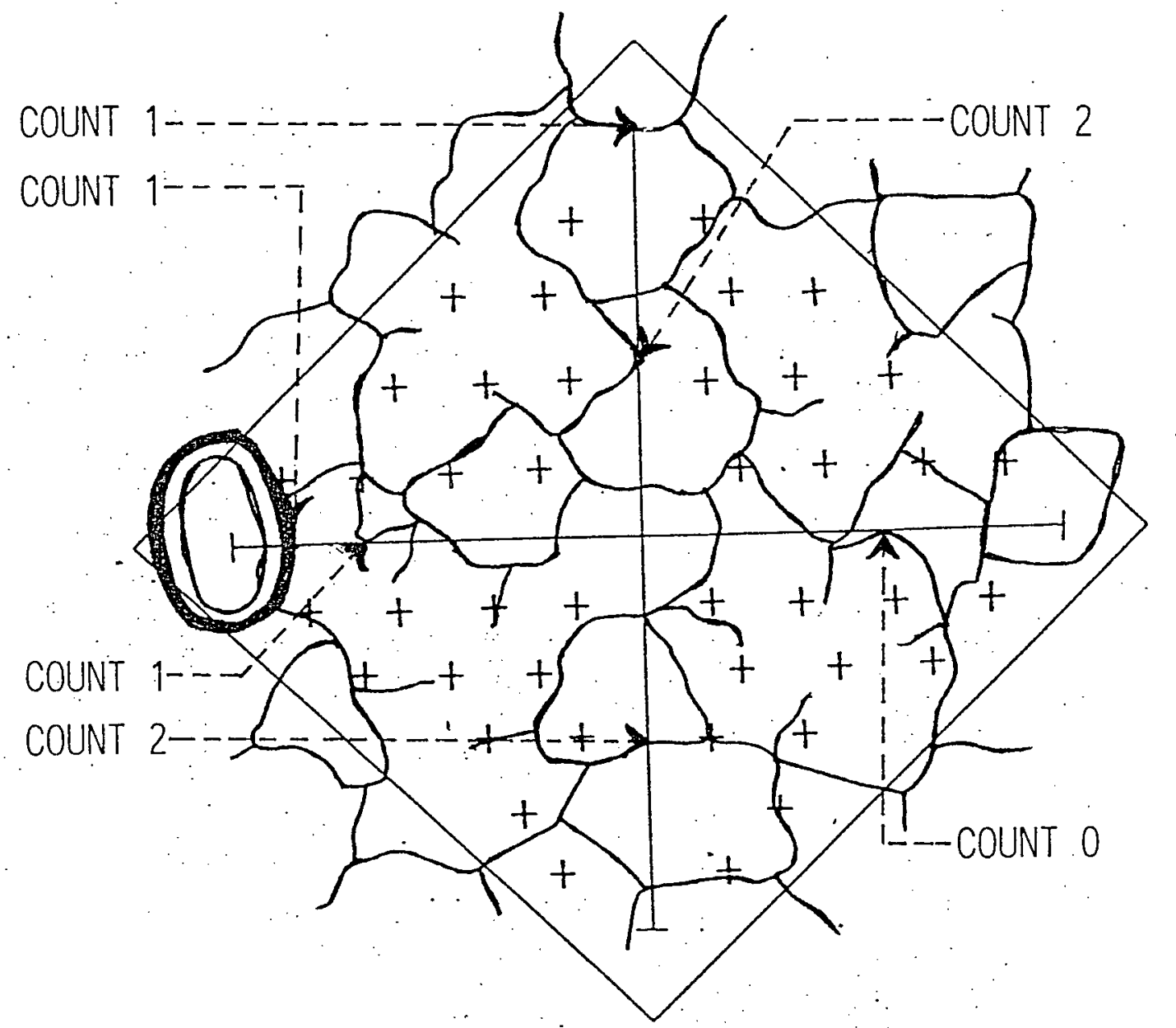

Figure 2.3: Illustration of intercept counting. 


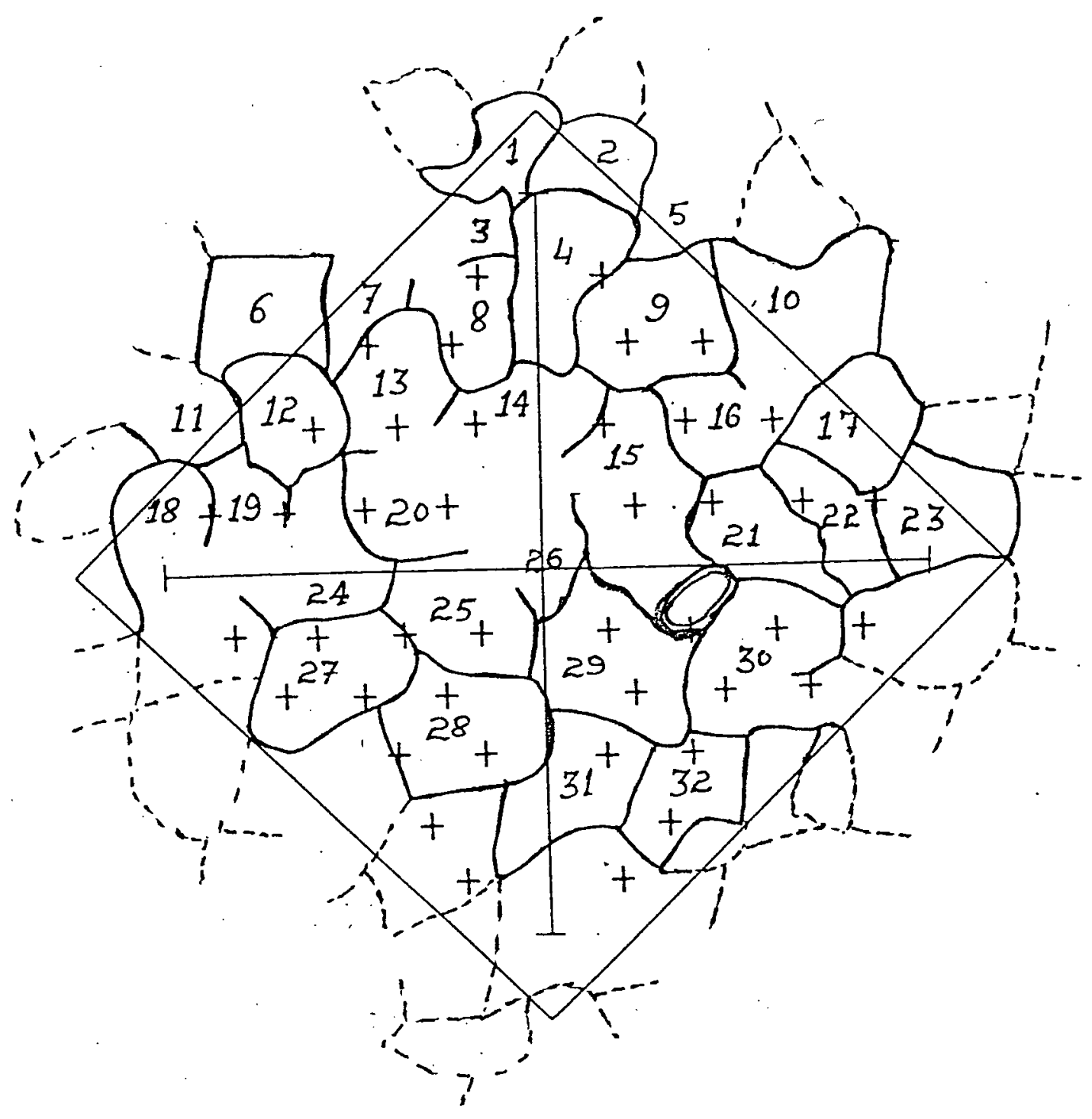

Figure 2.4: Illustration of alveolar counting. 
Table 2.2: Morphometric calculations

\begin{tabular}{|c|c|}
\hline Parameter & Calculation \\
\hline Wall intercepts & $=\mathrm{I} w$ \\
\hline Duct intercepts & $=I d$ \\
\hline Total intercepts (la) & $=I w+I d$ \\
\hline Volume proportion of: & \\
\hline Alveolar air & $=\mathrm{V}_{v a}$ \\
\hline Duct air & $=\mathrm{V}_{v d}$ \\
\hline Alveolar wall & $=V_{v w}$ \\
\hline Bronchial air & $=\mathrm{V}_{v b}$ \\
\hline Non-parenchymatous & $=\mathrm{V}_{v n p}$ \\
\hline Number of alveoli in a field & $=\mathrm{N}$ \\
\hline $\begin{array}{l}\text { Total length of the test line } \\
\text { (corrected for linear shrinkage (Isf)) }\end{array}$ & $=\mathrm{L}_{T}$ \\
\hline $\begin{array}{l}\text { Area of the grid } \\
\text { (corrected for shrinkage (asf)) }\end{array}$ & $=A$ \\
\hline Mean linear intercept $\left(\mathrm{L}_{m}\right)$ & $=\frac{2 L_{T}}{I w}$ \\
\hline Mean chord length of alveoli $\left(\mathbb{T}_{a l v}\right)$ & $=\frac{2 \mathrm{~L}_{T} \times \mathrm{V}_{v a}}{\mathrm{la}}$ \\
\hline Alveolar surface area $\left(S w_{T}\right)$ & $=\frac{4 \times \mathrm{VI}}{\mathrm{MLI}}$ \\
\hline Alveoli per unit area (NA) & $=\frac{N}{A}$ \\
\hline Number of alveoli per unit volume & $=\frac{J \times \sqrt{N A^{3}}}{\beta \times \sqrt{V_{v a}}}$ \\
\hline Distribution constant $(\mathrm{J})$ & $=1$ \\
\hline Shape constant $(\beta)$ & $=1.55$ \\
\hline Total number of alveoli $\left(\mathrm{Na}_{T}\right)$ & $=\mathrm{N} \mathbf{v} \times \mathrm{VI}$ \\
\hline Average alveolar volume $\left(\overline{\mathrm{V}}_{a l v}\right)$ & $=\frac{\mathrm{Vl} \times \mathrm{V}_{v a}}{\mathrm{Na}_{T}}$ \\
\hline
\end{tabular}




\section{Chapter 3}

\section{RESULTS}

Post-operatively, none of the animals showed any sign of stress or infection. All animals were sacrificed 3 weeks after surgery and no evidence of pneumonia was noticed in the lungs grossly or microscopically. Abbreviations are shown in Table 3.1. As each is used for the first time in the text, it will be preceded by the full term.

\subsection{Expression of results}

Results are expressed under three general groupings: somatic growth. lung growth. and lung mechanics. Lung growth parameters are expressed in absolute terms, specific terms (per 100 gram body weight), and relative terms (per gram dry lung weight). Compensatory lung growth following pneumonectomy is compared to the right lung of controls and both lungs of controls. The latter was estimated from right and left lung weight i.e.

$$
\text { Variables of both lungs }=\frac{\left(W l_{R}+W l_{L}\right) \times \text { Variable in right lung }}{W l_{R}}
$$

The right lung of the rat has four lobes (upper, middle, post-caval, and lower), while the left lung has only one lobe. Therefore, in the text, if comparisons were done. either among the four lobes or between the same lobes of postpneumonectomy and sham- operated groups, reference is made to the right lung. Global quantitative morphometric measurements $(G)$ of a variable were corrected for individual lobar volumes by calculating the sum of upper $(U)$. middle $(M)$, post-caval $(P c)$, and lower $(L)$ lobes 
Table 3.1: Abbreviations

\begin{tabular}{|c|c|}
\hline Parameter & Abbreviation \\
\hline Body weight & Wb \\
\hline Nose-tail length & NTL \\
\hline Right lung weight & $\mathrm{W} l_{R}$ \\
\hline Left lung weight & $\mathrm{W} l_{L}$ \\
\hline Total lung weight & $\mathrm{W} l_{T}$ \\
\hline Right lung volume & $\mathrm{V} l_{R}$ \\
\hline Left lung volume & $\mathrm{V} l_{L}$ \\
\hline Total lung volume & $\mathrm{V} l_{T}$ \\
\hline Lobe volume & $\mathrm{V} l_{L O B E}$ \\
\hline Right dry lung weight & $W_{d r y} l_{R}$ \\
\hline Total dry lung weight & $\mathrm{W}_{d r y} l_{T}$ \\
\hline Right lung deoxyribonucleic acid content & $\mathrm{DNA} l_{R}$ \\
\hline Total lung deoxyribonucleic acid content & $\mathrm{DNA} l_{T}$ \\
\hline Deoxyribonucleic acid per gram dry lung weight & $\mathrm{DNA} / \mathrm{g} W_{d r y} l$ \\
\hline Right lung protein content & $\operatorname{Prol}_{R}$ \\
\hline Total lung protein content & $\operatorname{Prol}_{T}$ \\
\hline Protein to DNA ratio & Protein/DNA \\
\hline Mean linear intercept & $\mathrm{L}_{m}$ \\
\hline Mean chord length of alveoli & $\overline{\mathrm{I}}_{a l v}$ \\
\hline Alveolar surface area per right lung & $\mathrm{Sw}_{R}$ \\
\hline Total alveolar surface area & $\mathrm{Sw}_{T}$ \\
\hline Lobar alveolar surface area & $S W_{L O B E}$ \\
\hline Number of alveoli per unit volume & $\mathrm{Nv}$ \\
\hline Average volume of alveoli & $\overline{\mathrm{V}}_{\text {alv }}$ \\
\hline Number of alveoli per right lung & $\mathrm{Na}_{R}$ \\
\hline Total number of alveoli & $\mathrm{Na}_{T}$ \\
\hline Total lung capacity & TLC \\
\hline TLC per gram lung weight & $\mathrm{TLC} / \mathrm{g} \mathrm{Wl}$ \\
\hline
\end{tabular}


proportional to their volumes.

$$
\begin{aligned}
\mathrm{A}(\mathrm{G}) & =\frac{\mathrm{A}(\mathrm{U}) \times \mathrm{VI}_{\text {lobe }}(U)+\mathrm{A}(\mathrm{M}) \times \mathrm{VI}_{\text {lobe }}(M)}{\mathrm{V} l_{R}} \\
& +\frac{\mathrm{A}(\mathrm{Pc}) \times \mathrm{VI}_{\text {lobe }}(P c)+\mathrm{A}(\mathrm{L}) \times \mathrm{VI} \mathrm{I}_{\text {lobe }}(L)}{\mathrm{V} l_{R}}
\end{aligned}
$$

where $A=$ value of morphometric variable.

Some global measurements e. g. total number of alveoli, alveolar surface area, are simply the sum of lobar values.

\subsection{Somatic growth}

As shown in Table 3.2 and Table A.1 (see Appendix A), at the beginning of the experiment, 4 week old females weighed slightly but significantly $(P<0.02)$ less than males in both sham-operated (control) and pneumonectomy (experimental) groups. During the three week postoperative period, females gained $110 \%$ in body weight (Wb). whereas males gained $180 \%$. At the time of sacrifice, male experimentals were $48 \%$ and shams $41 \%$ heavier $(P<0.0001)$ than the comparative female groups. However.

Table 3.2: Somatic growth results for male sham-operated vs female sham-operated group, and male pneumonectomy vs female pnuemonectomy group.

\begin{tabular}{||l|c|c||c|c||}
\hline \hline Variable & $\begin{array}{c}\text { Male } \\
\text { sham }\end{array}$ & $\begin{array}{c}\text { Female } \\
\text { sham }\end{array}$ & $\begin{array}{c}\text { Male } \\
\text { pneumo }\end{array}$ & $\begin{array}{c}\text { Female } \\
\text { pneumo }\end{array}$ \\
\hline $\begin{array}{l}\text { Wb }(\mathrm{g}) \\
(4 \text { weeks) }\end{array}$ & $86 \pm 1.6$ & $80 \pm 1.9^{* *}$ & $90 \pm 1.8$ & $80 \pm 1.1^{* *}$ \\
$\begin{array}{l}\text { Wb }(\mathrm{g}) \\
(7 \text { weeks })\end{array}$ & $250 \pm 4.9$ & $177 \pm 3.1^{*}$ & $252 \pm 3.4$ & $170 \pm 2.4^{*}$ \\
NTL (cm) & $37 \pm 0.3$ & $34 \pm 0.2^{*}$ & $38 \pm 0.2$ & $35 \pm 0.1^{*}$ \\
\hline
\end{tabular}

Values are means \pm SEM's.

$* \mathrm{P}<0.0001, * * \mathrm{P}<0.02$.

pneumonectomy did not effect body weight gain in either males or females. Nose-tail length was also significantly $(P<0.0001)$ less in females than males. Nose-tail length was also not effected by pneumonectomy in females as well as in males. 


\subsection{Compensatory response}

\subsubsection{Extent of response}

\section{a. Males}

Means \pm SEM of absolute and specific values of right lung weight $\left(W l_{R}\right)$. left lung weight $\left(\mathrm{W} l_{L}\right)$, total lung weight $\left(\mathrm{W} l_{T}\right)$, right lung volume $\left(\mathrm{V} l_{R}\right)$, total lung volume $\left(\mathrm{V} l_{T}\right)$, and content of deoxyribonucleic acid (DNAl $l_{R}, \mathrm{DNAl}_{T}$ ) and protein ( Prol $_{R}$. $\mathrm{Prol}_{T}$ ) are shown in Table 3.3. After pneumonectomy absolute $W l_{R}$ and $\mathrm{V} l_{R}$ increased and were $150 \%$ and $162 \%$ of the right lung of sham-operated rats $(P<0.0001)$. The dry lung weight of right lung $\left(\mathrm{W}_{d r y} l_{R}\right)$ increased $144 \%$ compared to the shams $(\mathrm{P}<0.0001)$. No difference in $\mathrm{W}_{d r y} l_{R}: \mathrm{W} l_{R}$ ratio was found between sham and pneumo groups. Lyophilized lungs were used for DNA and protein measurements. Postpneumonectomy, $\mathrm{DNA} l_{R}$ and $\mathrm{Prol}_{R}$ were significantly $(\mathrm{P}<0.007)$ increased and were $126 \%$ and $138 \%$ of the sham-operated rats.

The $W l_{R}, W{ }_{d r y} l_{R}$ and $V l_{R}$ in the pneumonectomy group was increased and was equal to $\mathrm{W} l_{T}, \mathrm{~W}_{\text {dry }} l_{T}$ and $\mathrm{V} l_{T}$ of sham-operated rats. However, DNAl $l_{R}$ and $\operatorname{Prol}_{R}$ of the pneumonectomy group, while increased, were significantly $(P<0.007)$ less than $\mathrm{DNAl}_{T}$ and $\mathrm{Prol}_{T}$ in the sham males $(\mathrm{P}<0.007)$. Since body weight of both groups were the same, specific changes followed the absolute values.

\section{b. Females}

The extent of compensatory response in females was similar to that of males as shown in Table 3.4. The $\mathrm{W} l_{R}, \mathrm{~W}_{d r y} l_{R}, \mathrm{~V} l_{R}, \mathrm{DNA} l_{R}$ and $\operatorname{Pro} l_{R}$ were all significantly $(P<0.0001)$ increased in pneumonectomy females compared to those of right lung of sham-operated females. The $W l_{R}, W_{d r y} l_{R}$ and $V l_{R}$ of postpneumonectomy animals were equivalent to those of both lungs of sham-operated animals. However. DNA $l_{R}$ and $\mathrm{Prol}_{R}$ of pneumonectomy group were significantly $(\mathrm{P}<0.0001)$ less than those of both lungs of sham-operated group. As body weights of both, sham-operated and pneumonectomy were similar, specific values comparatively did not differ from absolute values. 
Table 3.3: Extent of compensatory lung growth results for male pneumonectomy group compared to male sham-operated group.

\begin{tabular}{|c|c|c|c|}
\hline Variables & Male pneumo & Male sham & $\%$ change \\
\hline $\bar{W} l_{R}(\mathrm{~g})$ & $1.094 \pm 0.03$ & $0.728 \pm 0.02^{*}$ & 50 \\
\hline$W l_{T}(\mathrm{~g})$ & $1.094 \pm 0.03$ & $1.068 \pm 0.02$ & 2 \\
\hline$W_{d r y} l_{R}(\mathrm{~g})$ & $0.207 \pm 0.006$ & $0.144 \pm 0.003^{* *}$ & 44 \\
\hline$W_{d r y} l_{T}(\mathrm{~g})$ & $0.207 \pm 0.006$ & $0.220 \pm 0.004$ & -9 \\
\hline $\mathrm{V} l_{R}(\mathrm{ml})$ & $10.49 \pm 0.34$ & $6.57 \pm 0.32^{*}$ & 60 \\
\hline $\mathrm{V} l_{T}(\mathrm{ml})$ & $10.49 \pm 0.34$ & $9.34 \pm 0.46$ & 12 \\
\hline $\mathrm{DNA} l_{R}(\mathrm{mg})$ & $5.25 \pm 0.14$ & $4.15 \pm 0.09^{*}$ & 26 \\
\hline $\mathrm{DNAl}_{T}(\mathrm{mg})$ & $5.25 \pm 0.14$ & $6.32 \pm 0.12^{* *}$ & -17 \\
\hline $\operatorname{Prol}_{R}(\mathrm{mg})$ & $87.36 \pm 2.77$ & $63.19 \pm 1.0^{* *}$ & 38 \\
\hline $\operatorname{Prol}_{T}(\mathrm{mg})$ & $87.36 \pm 2.77$ & $96.29 \pm 1.43^{* * *}$ & -9 \\
\hline $\mathrm{W} l_{T} / 100 \mathrm{~g} \mathrm{~Wb}(\mathrm{~g})$ & $0.433 \pm 0.011$ & $0.430 \pm 0.01$ & 0 \\
\hline$W_{d r y} l_{T} / 100 \mathrm{~g} W b(\mathrm{~g})$ & $0.082 \pm 0.001$ & $0.084 \pm 0.001$ & -2 \\
\hline $\mathrm{V} l_{T} / 100 \mathrm{~g} \mathrm{~Wb}(\mathrm{ml})$ & $4.17 \pm 0.14$ & $4.01 \pm 0.11$ & 4 \\
\hline $\mathrm{DNA}_{T} / 100 \mathrm{~g} \mathrm{~Wb}(\mathrm{mg})$ & $2.07 \pm 0.03$ & $2.41 \pm 0.05^{*}$ & -14 \\
\hline $\operatorname{Prol}_{T} / 100 \mathrm{~g}$ Wb (mg) & $34.47 \pm 0.82$ & $36.79 \pm 0.66^{* x *}$ & -6 \\
\hline
\end{tabular}

Values are means \pm SEM's.

$* \mathrm{P}<0.0001, * * \mathrm{P}<0.005, * * * \mathrm{P}<0.05$.

$\%$ change is an increase in a parameter following pneumonectomy. 
Table 3.4: Extent of compensatory lung growth results for female pneumonectomy group compared to female sham-operated group.

\begin{tabular}{||l||c|c|r||}
\hline Variables & Female pneumo & Female sham & \% change \\
\hline$W l_{R}(\mathrm{~g})$ & $0.893 \pm 0.020$ & $0.590 \pm 0.010^{*}$ & 51 \\
$W l_{T}(\mathrm{~g})$ & $0.893 \pm 0.020$ & $0.877 \pm 0.020$ & 2 \\
$W W_{d r y} l_{R}(\mathrm{~g})$ & $0.167 \pm 0.005$ & $0.118 \pm 0.003^{*}$ & 41 \\
$W_{d r y} l_{T}(\mathrm{~g})$ & $0.167 \pm 0.005$ & $0.181 \pm 0.004$ & -8 \\
$V l_{R}(\mathrm{ml})$ & $8.57 \pm 0.40$ & $5.83 \pm 0.19^{*}$ & 47 \\
$V l_{T}(\mathrm{ml})$ & $8.57 \pm 0.40$ & $8.42 \pm 0.31$ & 2 \\
$\mathrm{DNA} l_{R}(\mathrm{mg})$ & $4.31 \pm 0.14$ & $3.44 \pm 0.10^{*}$ & 25 \\
$\mathrm{DNA} l_{T}(\mathrm{mg})$ & $4.31 \pm 0.14$ & $5.27 \pm 0.13^{*}$ & -19 \\
$\operatorname{Pro} l_{R}(\mathrm{mg})$ & $80.19 \pm 1.90$ & $59.69 \pm 1.60^{*}$ & 34 \\
$\operatorname{Pro} l_{T}(\mathrm{mg})$ & $80.19 \pm 1.90$ & $91.48 \pm 2.22^{*}$ & -13 \\
$W l_{T} / 100 \mathrm{~g} \mathrm{~Wb}(\mathrm{~g})$ & $0.525 \pm 0.015$ & $0.496 \pm 0.008$ & 6 \\
$W_{\text {dry }} l_{T} / 100 \mathrm{~g} \mathrm{~Wb}(\mathrm{~g})$ & $0.098 \pm 0.002$ & $0.101 \pm 0.001$ & -3 \\
$\mathrm{Vl} l_{T} / 100 \mathrm{~g} \mathrm{~Wb}(\mathrm{ml})$ & $5.13 \pm 0.16$ & $4.83 \pm 0.18$ & 6 \\
$\mathrm{DNA} l_{T} / 100 \mathrm{~g} \mathrm{~Wb}(\mathrm{mg})$ & $2.54 \pm 0.05$ & $2.95 \pm 0.04^{*}$ & -14 \\
$\operatorname{Pro} l_{T} / 100 \mathrm{~g} \mathrm{~W} b(\mathrm{mg})$ & $47.31 \pm 0.81$ & $51.18 \pm 0.87^{*}$ & -8 \\
\hline \hline
\end{tabular}

Values are means \pm SEM's.

$* \mathrm{P}<0.0005$.

$\%$ change is an increase in a parameter following pneumonectomy. 


\section{c. Difference in males and females}

Data used for comparing males and females are shown in Tables 3.3 and 3.4. However. direct comparison between males and females are also shown in Appendix, mainly for use of statistical expression and are shown in Tables A.2-A.3.

Absolute $W l_{R} . W l_{L}, W l_{T}, W W_{d r y} l_{T}$, and $D N A l_{T}$ of sham-operated females were significantly $(\mathrm{P}<0.0001)$ less than those of the sham-operated males. The $\mathrm{Prol}_{T}$ and $\mathrm{V} l_{T}$ in female shams was also less but not significantly $(\mathrm{P}<0.08$ and $\mathrm{P}<0.07)$ than those of male shams. Female shams weighed significantly less than male shams and specific $W l_{T}, V l_{T}$. DNAl $l_{T}$, and $\mathrm{Prol}_{T}$ were higher $(\mathrm{P}<0.002)$ in females by $14 \% .21 \%$. $22 \%$, and $39 \%$ respectively than those of males (see Table A.2).

After pneumonectomy, the $W l_{R}, W_{d r y} l_{R}$ and $D N A l_{R}$ content were significantly $(P<0.0001)$ higher in males than that of the females. Unlike sham-operated groups. the $V l_{R}$ and $\mathrm{Prol}_{R}$ was also significantly $(\mathrm{P}<0.05)$ larger in male pneumos than that of female pneumos. Once again the body weight of female pneumonectomy group was less, and specific $W l_{R}, V l_{R}, D N A l_{R}$. Prol $l_{R}$ were greater in the female pneumonectomy group compared to male pneumonectomy group.

Thus, it is evident by the findings that male lungs after pneumonectomy are bigger since $\mathrm{W} l_{R}, \mathrm{~V} l_{R}, \mathrm{DNA} l_{R}$, and $\mathrm{Prol}_{R}$ content are higher in absolute terms. After normalizing for body weight. female lungs have a larger $W l_{R}, V l_{R}$. DNA $l_{R}$ and $\operatorname{Prol}_{R}$ content than those of males and this is similar to sham-operated animals.

\subsubsection{Nature of response (Lobar response)}

The qualitative and quantitative morphometric data of lobar changes after pneumonectomy in males and females are shown in Table 3.5-3.7.

\section{a. Males}

Absolute volumes of upper, middle, post-caval, and lower lobe were $76 \%, 52 \%, 70 \%$. and $52 \%$ larger $(P<0.01-P<0.0005)$ respectively following pneumonectomy compared to the sham-operated rats. Morphometric evidence of dilation was present in all lobes: these include an increase in mean linear intercept $\left(L_{m}\right)$, mean chord length $\left(T_{\text {alv }}\right)$ and 
Table 3.5: Lobe volumes $(\mathrm{ml})$ : Male pneumonectomy group compared to male sham-operated group and female pneumonectomy group compared to female sham-operated group.

\begin{tabular}{||l|c|c|c||}
\hline Lobes & Pneumonectomy group & sham-operated group & \% change \\
\hline \hline Males & & & \\
Upper lobe & $1.85 \pm 0.06$ & $1.05 \pm 0.05^{*}$ & 76 \\
Middle lobe & $2.07 \pm 0.07$ & $1.36 \pm 0.07^{*}$ & 52 \\
Post-caval lobe & $2.18 \pm 0.12$ & $1.28 \pm 0.05^{*}$ & 70 \\
Lower lobe & $4.38 \pm 0.21$ & $2.87 \pm 0.17^{*}$ & 53 \\
Females & & & \\
Upper lobe & $1.32 \pm 0.08$ & $0.88 \pm 0.03^{*}$ & 52 \\
Middle lobe & $1.83 \pm 0.07$ & $1.23 \pm 0.05^{*}$ & 49 \\
Post-caval lobe & $1.92 \pm 0.10$ & $1.11 \pm 0.03^{*}$ & 73 \\
Lower lobe & $3.48 \pm 0.19$ & $2.61 \pm 0.10^{* *}$ & 33 \\
\hline \hline
\end{tabular}

Values are means \pm SEM's.

$\mathrm{P}<0.0005, * * \mathrm{P}<0.005$.

$\%$ change is an increase in a parameter following pneumonectomy.

a decrease in number of alveoli per unit volume $(\mathrm{Nv})$. Following pneumonectomy. $\mathrm{Nv}$ was significantly decreased in all lobes, in addition $\mathrm{L}_{m}$ was increased in the upper lobe and $\bar{T}_{\text {alv }}$ was increased in the middle and post-caval lobes (table 3.6). The upper lobe increased most in volume, but the increase in $L_{m}$ and $T_{a l v}$ following pneumonectomy was not significant. The fall in number of alveoli per unit volume was, however, significant but was least of the four lobes.

\section{b. Females}

The compensatory lung response in females was in general similar to that of males. After pneumonectomy lobar volumes were increased by $52 \%, 49 \%, 73 \%$ and $33 \%$ in upper, middle. post-caval, and lower lobes respectively. compared to the shamoperated females (see Table 3.5). Following pneumonectomy $L_{m}$ in all lobes expect the upper lobe was significantly $(P<0.03-P<0.0005)$ increased. $\bar{I}_{a l v}$ of all lobes increased significantly $(P<0.008)$ after pneumonectomy. A significant $(P<0.0001)$ decrease in $\mathrm{Nv}$ in the middle and post-caval lobes of $30 \%$ and $59 \%$ respectively. was noticed in pneumonectomy group. In the upper and lower lobes, the decrease in Nv was $14 \%$ and $10 \%$ respectively but this did not reach conventional levels of significant 
Table 3.6: Lobar morphometric response results for male pneumonectomy group compared to male sham-operated group.

\begin{tabular}{|c|c|c|c|}
\hline Variables & Male pneumo & Male sham & $\%$ change \\
\hline \multicolumn{4}{|l|}{$\overline{\mathrm{L}_{m}(\mu)}$} \\
\hline Upper lobe & $74.3 \pm 2.0$ & $74.6 \pm 2.6$ & - \\
\hline Middle lobe & $83.1 \pm 2.2$ & $77.0 \pm 3.0$ & 8 \\
\hline Post-caval lobe & $88.8 \pm 2.2$ & $82.9 \pm 2.1$ & 7 \\
\hline Lower lobe & $81.0 \pm 1.6$ & $74.4 \pm 2.2^{* *}$ & 9 \\
\hline \multicolumn{4}{|l|}{$\bar{T}_{a l \underline{v}}(\mu)$} \\
\hline Upper lobe & $41.0 \pm 1.1$ & $38.4 \pm 0.9$ & 6 \\
\hline Middle lobe & $44.8 \pm 0.8$ & $40.4 \pm 0.9^{* *}$ & 11 \\
\hline Post-caval lobe & $46.2 \pm 1.2$ & $41.4 \pm 1.0^{* *}$ & 11 \\
\hline Lower lobe & $42.7 \pm 0.7$ & $40.2 \pm 1.2$ & 4 \\
\hline \multicolumn{4}{|l|}{$\operatorname{Sw}_{L O B E}\left(m^{2}\right)$} \\
\hline Upper lobe & $0.100 \pm 0.004$ & $0.057 \pm 0.002^{*}$ & 75 \\
\hline Middle lobe & $0.100 \pm 0.004$ & $0.071 \pm 0.003^{*}$ & 41 \\
\hline Post-caval lobe & $0.098 \pm 0.005$ & $0.061 \pm 0.002^{*}$ & 60 \\
\hline $\begin{array}{l}\text { Lower lobe } \\
\text { Nv }\left(\times 10^{6}\right)\end{array}$ & $0.216 \pm 0.009$ & $0.155 \pm 0.008^{*}$ & 39 \\
\hline Upper lobe & $2.84 \pm 0.12$ & $3.39 \pm 0.20^{*}$ & -20 \\
\hline Middle lobe & $2.51 \pm 0.09$ & $3.31 \pm 0.18$ & -32 \\
\hline Post-caval lobe & $2.03 \pm 0.09$ & $3.17 \pm 0.12^{*}$ & -56 \\
\hline Lower lobe & $2.83 \pm 0.14$ & $3.90 \pm 0.18^{\circ}$ & -38 \\
\hline
\end{tabular}

Values are means \pm SEM's.

$* \mathrm{P}<0.0005, * * \mathrm{P}<0.01, * * * \mathrm{P}<0.05$.

$\%$ change is an increase in a parameter following pneumonectomy. 
Táble 3.7: Lobar morphometric response results for female pneumonectomy group compared to female sham-operated group.

\begin{tabular}{||l|c|c|r||}
\hline \hline Variables & Female pneumo & Female sham & \% change \\
\hline \hline $\mathrm{L}_{m}(\mu)$ & & & \\
Upper lobe & $80.0 \pm 2.6$ & $72.1 \pm 2.9$ & 11 \\
Middle lobe & $81.8 \pm 2.0$ & $72.8 \pm 2.1^{* *}$ & 12 \\
Post-caval lobe & $86.2 \pm 2.1$ & $75.4 \pm 1.1^{*}$ & 14 \\
Lower lobe & $78.8 \pm 2.2$ & $71.3 \pm 1.8^{* * *}$ & 10 \\
$\bar{I}_{\text {alv }}(\mu)$ & & & \\
Upper lobe & $41.9 \pm 1.2$ & $37.3 \pm 0.7^{* *}$ & 12 \\
Middle lobe & $43.9 \pm 0.8$ & $36.6 \pm 0.7^{*}$ & 20 \\
Post-caval lobe & $46.1 \pm 1.1$ & $38.9 \pm 0.9^{*}$ & 18 \\
Lower lobe & $42.7 \pm 1.3$ & $37.5 \pm 1.0^{* *}$ & 14 \\
Sw LOBE $\left.^{*} m^{2}\right)$ & & & \\
Upper lobe & $0.067 \pm 0.002$ & $0.049 \pm 0.001^{*}$ & 37 \\
Middle lobe & $0.089 \pm 0.003$ & $0.068 \pm 0.003^{*}$ & 31 \\
Post-caval lobe & $0.088 \pm 0.004$ & $0.059 \pm 0.001^{*}$ & 49 \\
Lower lobe & $0.176 \pm 0.008$ & $0.147 \pm 0.006^{* *}$ & 20 \\
Nv $\left(\times 10^{6}\right)$ & & & \\
Upper lobe & $2.95 \pm 0.15$ & $3.38 \pm 0.16$ & -14 \\
Middle lobe & $2.62 \pm 0.11$ & $3.41 \pm 0.11^{*}$ & -30 \\
Post-caval lobe & $2.04 \pm 0.07$ & $3.24 \pm 0.13^{*}$ & -59 \\
Lower lobe & $3.25 \pm 0.13$ & $3.57 \pm 0.14$ & -10 \\
\hline \hline
\end{tabular}

Values are means \pm SEM's.

$* \mathrm{P}<0.0005, * * \mathrm{P}<0.01, * * * \mathrm{P}<0.05$.

$\%$ change is an increase in a parameter following pneumonectomy.

(see Table 3.7). Thus it appears that female following pneumonectomy, the middle and post-caval lobes increase more in lung volume than other two lobes. An increase in the size of alveoli and decrease in number of alveoli per unit volume are considerably more in the middle and post-caval lobes than the upper and lower lobes. Evidence of simple overinflation is thus greater in females than males.

\subsubsection{Differences between males and females}

In males the upper lobe expanded most, with post-caval lobe expanding the almost as much, and the middle and the lower lobes the least. In contrast the upper lobe expanded relatively little ( $52 \%$ compared to $76 \%$ ), and the lower lobe expanded to a relatively small extent ( $33 \%$ compared to $53 \%$ ) in the females. The post-caval lobe 
( $73 \%$ compared to $70 \%)$ and the lower lobe $(49 \%$ compared to $52 \%)$ increased about the same in both sexes. The proportion that the various lobes contributed to total lung volume was very similar:- upper lobe (16\% in males, $15 \%$ in females). middle lobe ( $21 \%$ in both sexes), post-caval lobe $(19.5 \%$ in males. $19 \%$ in females), and lower lobe ( $44 \%$ in males, $45 \%$ in females) in sham-operated groups.

\subsubsection{Nature of response (Global response).}

The quantitative and qualitative morphometric analysis of data obatained by point, intercept and alveolar counts of tissue sections, in males and females is shown in Table 3.8 and 3.9. The global change for alveolar surface area of right lung $\left(S w_{R}\right)$ and total number of alveoli in right lung $\left(\mathrm{Na}_{R}\right)$ is the total of all lobe values. The mean linear intercepts $\left(L_{m}\right)$, mean chord length of alveoli $\left(\bar{I}_{a l v}\right)$, number of alveoli (Nv). and average volume of alveoli $\left(\bar{V}_{a l v}\right)$ has been calculated as described in "Expression of Results" section.

\section{a. Males.}

A significant $(\mathrm{P}<0.05)$ increase in $\mathrm{L}_{m}$ and $T_{\text {alv }}$, and a reduction $(\mathrm{P}<0.0008)$ in $\mathrm{Nv}$ was observed following pneumonectomy compared to shams. The $\mathrm{Sw}_{R}$ and $\mathrm{Na}_{R}$. after pneumonectomy, increased significantly $(P<0.002)$ compared to the right lung of shams, but $\mathrm{Na}_{R}$ were less than that of both lungs of the controls $(\mathrm{P}<0.0001) . \mathrm{Sw}_{R}$ was not only not significantly different that $\mathrm{Sw}_{T}$ in the shams, but actually slightly larger. Specific values followed absolute values due to the lack of difference of $\mathrm{Wb}$ between pneumonectomy and sham-operated group.

\section{b. Females.}

$\bar{T}_{\text {alv }}$ and $L_{m}$ increased significantly after pneumonectomy and $N v$ declined by $22 \%$ $(\mathrm{P}<0.0001)$. The $\mathrm{Sw}_{R}$ and $\mathrm{Na}_{R}$ showed a significant (P.0.0005) increase compared to right lung of sham-operated females, but $\mathrm{Na}_{R}$ was signifcantly less $(\mathrm{P}<0.0001)$ than $\mathrm{Na}_{T}$ of both lungs of controls. $\mathrm{Sw}_{R}$ was less than $\mathrm{Sw}_{T}$ of the controls, but not significantly so. Since, there was no difference in body weight of the pneumonectomy 
Table 3.8: Global morphometric response results for male pneumonectomy group compared to male sham-operated group.

\begin{tabular}{||l|c|c|r||}
\hline \hline Variable & Male pneumo & Male sham & \% change \\
\hline \hline $\mathrm{L}_{m}(\mu)$ & $82.0 \pm 1.2$ & $76.6 \pm 2.0^{* *}$ & 7 \\
$\mathrm{I}_{a l v}(\mu)$ & $43.6 \pm 0.5$ & $39.9 \pm 0.6^{*}$ & 9 \\
$\mathrm{Nv}\left(\times 10^{6}\right)$ & $2.59 \pm 0.09$ & $3.64 \pm 0.15^{*}$ & -40 \\
$\mathrm{~S} \mathrm{w}_{R}\left(\mathrm{~m}^{2}\right)$ & $0.514 \pm 0.018$ & $0.340 \pm 0.013^{*}$ & 51 \\
$\mathrm{Sw}_{T}\left(m^{2}\right)$ & $0.514 \pm 0.018$ & $0.485 \pm 0.020$ & 6 \\
$\mathrm{Na}_{R}\left(\times 10^{6}\right)$ & $26.6 \pm 0.7$ & $23.2 \pm 0.4^{*}$ & 15 \\
$\mathrm{Na}_{T}\left(\times 10^{6}\right)$ & $26.6 \pm 0.7$ & $33.0 \pm 0.7^{*}$ & -24 \\
$\mathrm{Sw}_{R} / 100 \mathrm{~g} \mathrm{~Wb}\left(m^{2}\right)$ & $0.204 \pm 0.008$ & $0.146 \pm 0.003^{*}$ & 40 \\
$\mathrm{SW}_{T} / 100 \mathrm{~g} \mathrm{~Wb}\left(m^{2}\right)$ & $0.204 \pm 0.008$ & $0.208 \pm 0.006$ & 0 \\
$\mathrm{Na}_{R} / 100 g \mathrm{~Wb}\left(\times 10^{6}\right)$ & $10.66 \pm 0.47$ & $10.07 \pm 0.31$ & 6 \\
$\mathrm{Na}_{T} / 100 g \mathrm{~Wb}\left(\times 10^{6}\right)$ & $10.66 \pm 0.47$ & $14.33 \pm 0.52^{*}$ & -35 \\
\hline \hline
\end{tabular}

Values are means \pm SEM's.

$* \mathrm{P}<0.002, * * \mathrm{P}<0.05$.

$\%$ change is an increase in a parameter following pneumonectomy.

and the sham-operated group. specific values followed absolute values.

c. Difference in males and females.

\section{i. Sham-operated}

$T_{\text {alv }}$ was significantly $(P<0.03)$ smaller in female shams compared to male shams, as shown in Table A.6 (see Appendix A). The $L_{m}$ was also smaller in females but was not significant. The $\mathrm{Sw}_{R}$ and $\mathrm{Sw}_{T}$ were slightly higher in male shams but not significantly so. $\mathrm{Na}_{R}$ and $\mathrm{Na}_{T}$ were significantly $(\mathrm{P}<0.002)$ lower in female shams than that male shams. Since there was a significant difference in $\mathrm{W} b$ between males and females. the specific values of $\mathrm{Sw}_{R}, \mathrm{Sw}_{T} . \mathrm{Na}_{R}$, and $\mathrm{Na}_{T}$ of female sham-operated group were significantly higher than those of male sham-operated group.

\section{ii. Pneumonectomy}

As shown in Table A.7 (see Appendix A), no difference in the $\bar{I}_{\text {alv }}$ and $L_{m}$ were observed between male and female pneumonectomy groups. The $\mathrm{Nv}$ in male pneumonectomy group was found to be less than female pneumonectomy group but was insignificant 
Table 3.9: Global morphometric response results for female pneumonectomy group compared to female sham-operated group.

\begin{tabular}{||l|c|c|r||}
\hline \hline Variables & Female pneumo & Female sham & \% change \\
\hline \hline $\mathrm{L}_{m}(\mu)$ & $81.6 \pm 1.7$ & $72.6 \pm 1.5^{* *}$ & 12 \\
$\overline{\mathrm{I}}_{\text {alv }}(\mu)$ & $43.6 \pm 0.9$ & $37.6 \pm 0.6^{*}$ & 16 \\
$\mathrm{Nv}\left(\times 10^{6}\right)$ & $2.82 \pm 0.08$ & $3.44 \pm 0.07^{*}$ & -22 \\
$\mathrm{~S} \mathrm{w}_{R}\left(m^{2}\right)$ & $0.418 \pm 0.014$ & $0.320 \pm 0.010^{*}$ & 31 \\
$\mathrm{~S} \mathrm{w}_{T}\left(m^{2}\right)$ & $0.418 \pm 0.014$ & $0.462 \pm 0.017$ & -10 \\
$\mathrm{Na}_{R}\left(\times 10^{6}\right)$ & $23.3 \pm 0.5$ & $19.8 \pm 0.5$ & 18 \\
$\mathrm{Na}_{T}\left(\times 10^{6}\right)$ & $23.3 \pm 0.5$ & $28.6 \pm 0.9^{*}$ & -23 \\
$\mathrm{SW}_{R} / 100 g \mathrm{~Wb}\left(m^{2}\right)$ & $0.251 \pm 0.007$ & $0.184 \pm 0.008^{*}$ & 36 \\
$\mathrm{Sw}_{T} / 100 g \mathrm{~Wb}\left(m^{2}\right)$ & $0.251 \pm 0.007$ & $0.266 \pm 0.013$ & -6 \\
$\mathrm{Na}_{R} / 100 g \mathrm{~Wb}\left(\times 10^{6}\right)$ & $14.06 \pm 0.38$ & $11.42 \pm 0.48^{*}$ & 23 \\
$\mathrm{Na}_{T} / 100 g \mathrm{~Wb}\left(\times 10^{6}\right)$ & $14.06 \pm 0.38$ & $16.47 \pm 0.73^{* *}$ & -17 \\
\hline \hline
\end{tabular}

Values are means \pm SEM's.

$* \mathrm{P}<0.0005, * * \mathrm{P}<0.01$.

$\%$ change is an increase in parameter following pneumonectomy.

$(\mathrm{P}<0.08)$. The $\mathrm{Sw}_{R}$ was significantly $(\mathrm{P}<0.0007)$ less in female pneumonectomy group. The total number of alveoli in postpneumonectomy females was significantly $(\mathrm{P}<0.002)$ less than that of postpneumonectomy males. Similarly. $\mathrm{Sw}_{T}$ and $\mathrm{Na}_{T}$. corrected for body weight, were greater in female pneumonectomy group compared to male pneumonectomy group.

\subsubsection{Biochemical changes.}

DNA per gram dry lung weight (DNA/g $\mathrm{W}_{d r y} l$ ) and protein to DNA ratio (Protein/DNA) are shown in Table 3.10. After pneumonectomy. DNA/g $W_{d r y} l$ decreased significantly $(\mathrm{P}<0.0001)$ in males and females compared to their respective sham-operated group. However, DNA/g $W_{d r y} l$ in males and females did not differ in both pneumonectomy and sham-operated groups. The Protein/DNA ratio was significantly $(P<0.0006$ : $P<0.003)$ increased in male and female pneumonectomy groups compared to male and female sham-operated groups respectively. A significantly $(P<0.0001)$ higher Protein/DNA ratio was found in females compared to males both in sham-operated and pneumonectomy groups.

This indicates that following pneumonectomy. DNA content does not increase as 
Table 3.10: Nature of lung growth, a biochemical aspect: Male sham-operated vs male pneumonectomy group, and female sham-operated vs female pneumonectomy group.

\begin{tabular}{||l|c|c||c|c||}
\hline \hline Variables & $\begin{array}{c}\text { Male } \\
\text { sham }\end{array}$ & $\begin{array}{c}\text { Male } \\
\text { pneumo }\end{array}$ & $\begin{array}{c}\text { Female } \\
\text { sham }\end{array}$ & $\begin{array}{c}\text { Female } \\
\text { pneumo }\end{array}$ \\
\hline \hline${\text { DNA/g W } \text { dry }^{l}(\mathrm{mg})}^{28.68}$ & $25.33^{*}$ & 29.12 & $25.82^{*}$ \\
& \pm 0.36 & \pm 0.37 & \pm 0.36 & \pm 0.33 \\
Protein/DNA (mg/mg) & 15.2 & $16.6^{*}$ & 17.3 & $18.6^{*}$ \\
& \pm 0.25 & \pm 0.17 & \pm 0.22 & \pm 0.29 \\
\hline \hline
\end{tabular}

Values are means \pm SEM's.

$* \mathrm{P}<0.005$.

much as dry lung weight. The Protein/DNA ratio. which is an indicator of cell size. also shows an enlargement of cells after pneumonectomy in males as well as in females.

\subsection{Lung mechanics.}

As shown in Table 3.11 and Table A.9 (see Appendix A), total lung capacity (TLC) and specific TLC increased in both male and female pneumonectomy groups, to match the lungs of the sham-operated groups. TLC was significantly $(P<0.04)$ greater in male pneumonectomy and sham-operated groups compared to female pneumonectomy and sham-operated groups. However, after correction for body weight, specific TLC increased significantly $(P<0.01)$ in the female pneumonectomy group compared to the male pneumonectomy group (see Table A.9). The specific TLC was also higher in female shams compared to male shams, but not significantly. The relative TLC:lung weight (air/g W $l_{T}$ ) was not different between any two groups. As shown in Figure 3.1, a significant $(P<0.004-P<0.05)$ loss of elastic recoil was recorded at $90 \%$ $50 \%$ of TLC in post- pneumonectomy females compared to sham-operated females. An insignificant loss of elastic lung recoil was also observed in male pneumonectomy group compared to sham-operated group in the mid volume of the curve (see figure 3.2). No pressure-volume curve differences were observed between male and female shams (see figure 3.3) as well as male and female pneumonectomy groups. Following pneumonectomy in females, the shape constant $\mathrm{K}$ of the pressure-volume curve was significantly higher. Hence, it shows that sham-operated males and females exhibit 


\section{P-V Curve}

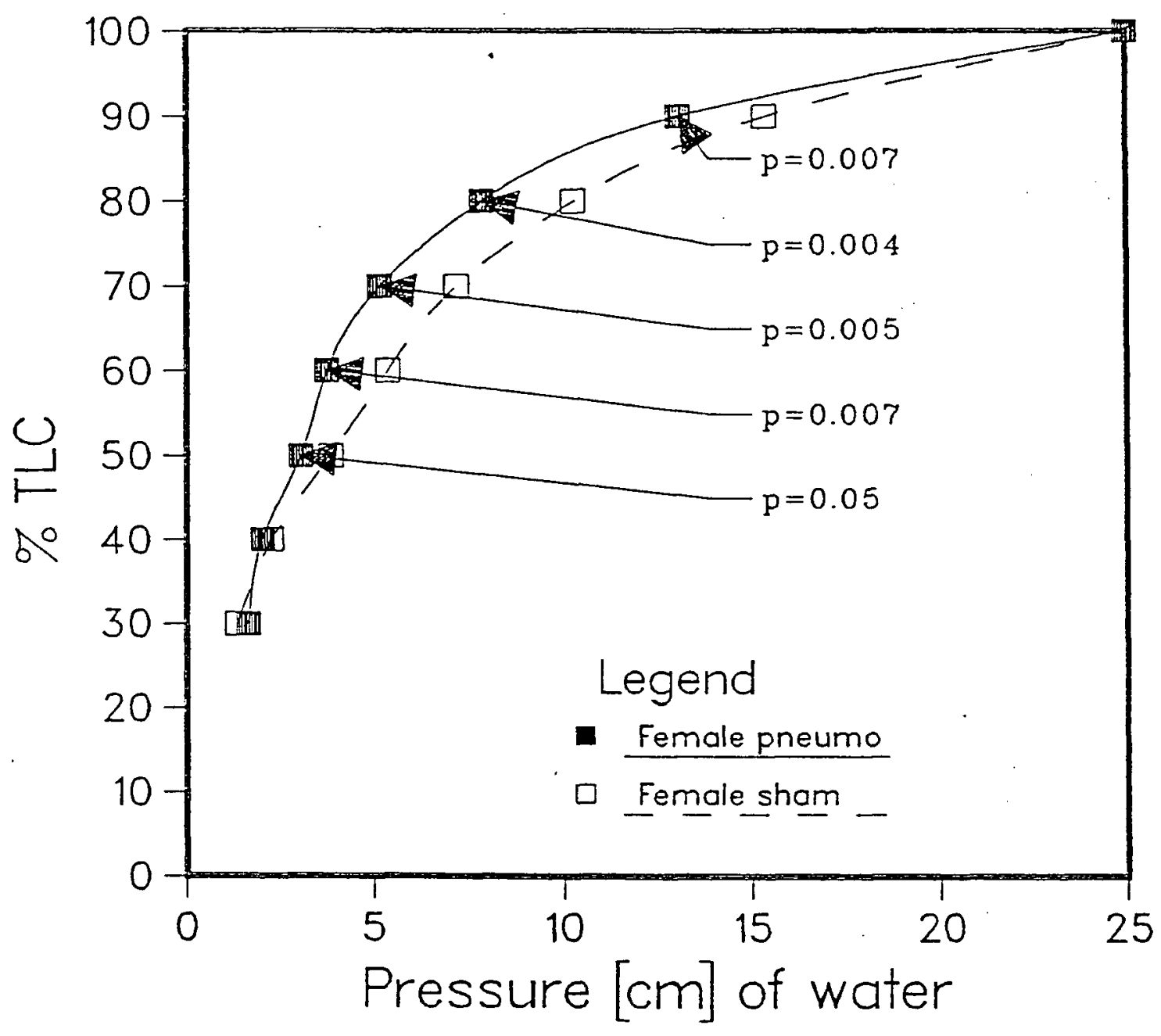

Figure 3.1: Static pressure-volume curve of female pneumonectomy group plotted against female sham-operated group. 


\section{P-V Curve}

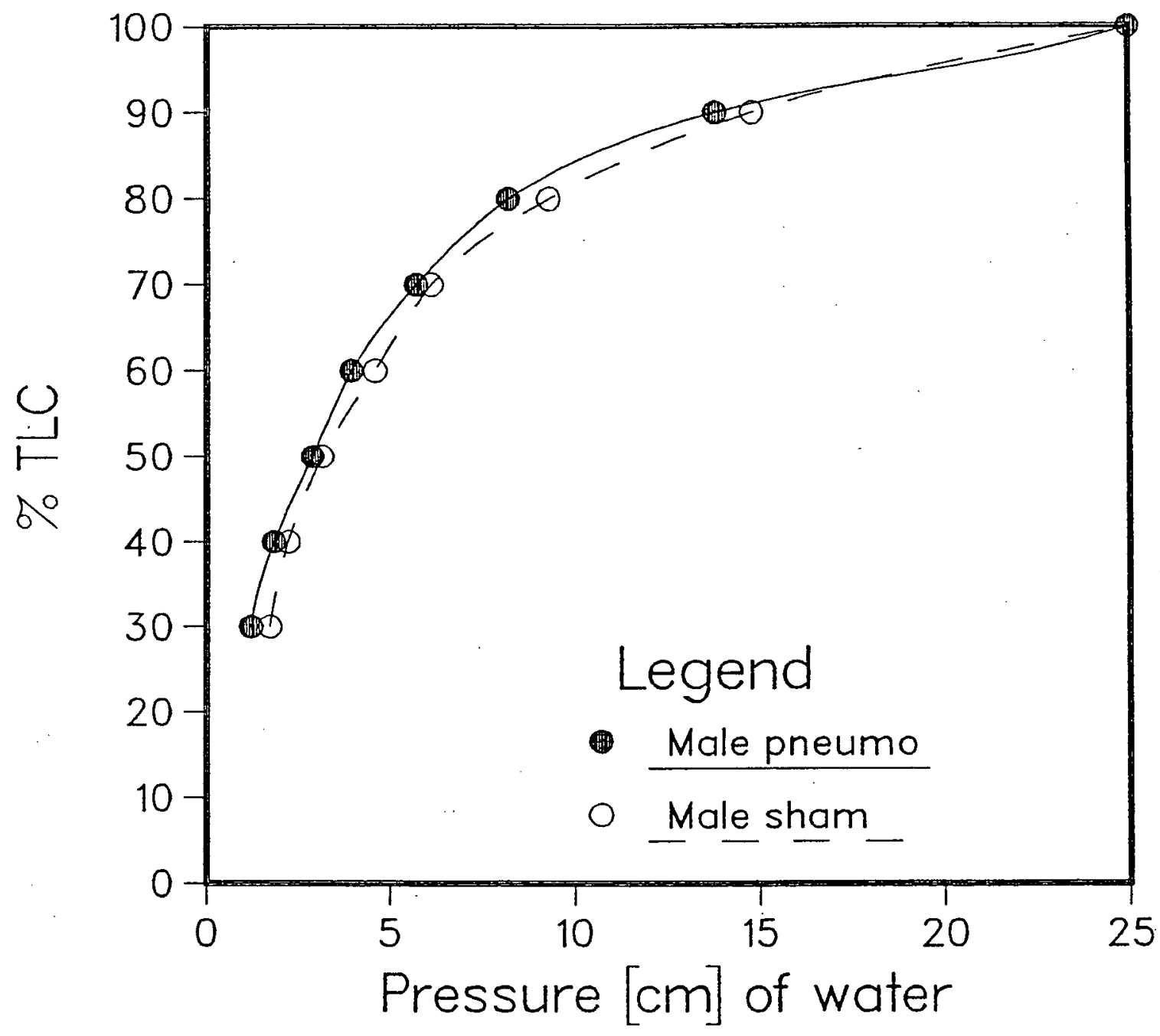

Figure 3.2: Static pressure-volume curve of male pneumonectomy group vs. male sham-operated group. 
Table 3.11: Static pressure-volume curve results for male sham-operated vs male pneumonectomy group, and female sham-operated vs female pneumonectomy group.

\begin{tabular}{||l|c|c||c|c||}
\hline Variables & $\begin{array}{c}\text { male } \\
\text { sham }\end{array}$ & $\begin{array}{c}\text { male } \\
\text { pneumo }\end{array}$ & $\begin{array}{c}\text { female } \\
\text { sham }\end{array}$ & $\begin{array}{c}\text { female } \\
\text { pneumo }\end{array}$ \\
\hline \hline TLC $(\mathrm{ml})$ & 8.1 & 8.1 & 6.6 & 6.8 \\
& \pm 0.63 & \pm 0.49 & \pm 0.18 & \pm 0.3 \\
TLC $/ 100 \mathrm{~g} \mathrm{~Wb}(\mathrm{ml})$ & 3.45 & 3.23 & 3.83 & 4.0 \\
& \pm 0.25 & \pm 0.17 & \pm 0.12 & \pm 0.19 \\
TLC $/ \mathrm{g} W_{l}(\mathrm{ml})$ & 7.31 & 6.79 & 7.3 & 7.14 \\
& \pm 0.47 & \pm 0.38 & \pm 0.3 & \pm 0.34 \\
Constant $\mathrm{K}$ & 0.125 & 0.139 & 0.114 & 0.139 \\
& \pm 0.005 & \pm 0.006 & \pm 0.006 & \pm 0.004 \\
\hline \hline
\end{tabular}

Values are means \pm SEM's.

$* \mathrm{P}<0.002$.

similar pressure-volume characteristics, but after pneumonectomy changes are more evident in females.

\subsection{Morphometric interlobar differences in shams}

\subsubsection{Males.}

Data of mean $\pm S E M L_{m}, \bar{l}_{a l v}$. Nv. and $\bar{V}_{\text {alv }}$ in all lobes of the right lung in all groups are shown in Table 3.12. $L_{m}$ and $\bar{I}_{a l v}$ were smaller in the upper lobe compared to the post-caval lobe in male sham-operated rats. The lower lobe also had smaller $L_{m}$ and $\overline{\mathrm{V}}_{a l v}$, and larger Nv than those in the post-caval lobe. $\bar{I}_{a l v}$ in the lower lobe was also smaller compared to the post-caval lobe but not significantly so.

\subsubsection{Females.}

The lower lobe in female sham-operated rats had slightly smaller $L_{m}, \bar{I}_{\text {alv }}$ and $\bar{V}_{\text {alv }}$. and slightly larger $\mathrm{Nv}$ than those in the post-caval lobe, but these differences were insignificant.

Hence, it appears that the post-caval lobe in males has larger but fewer alveoli compared to the lower and upper lobes. However, there is no difference in the lobes 
P-V Curve

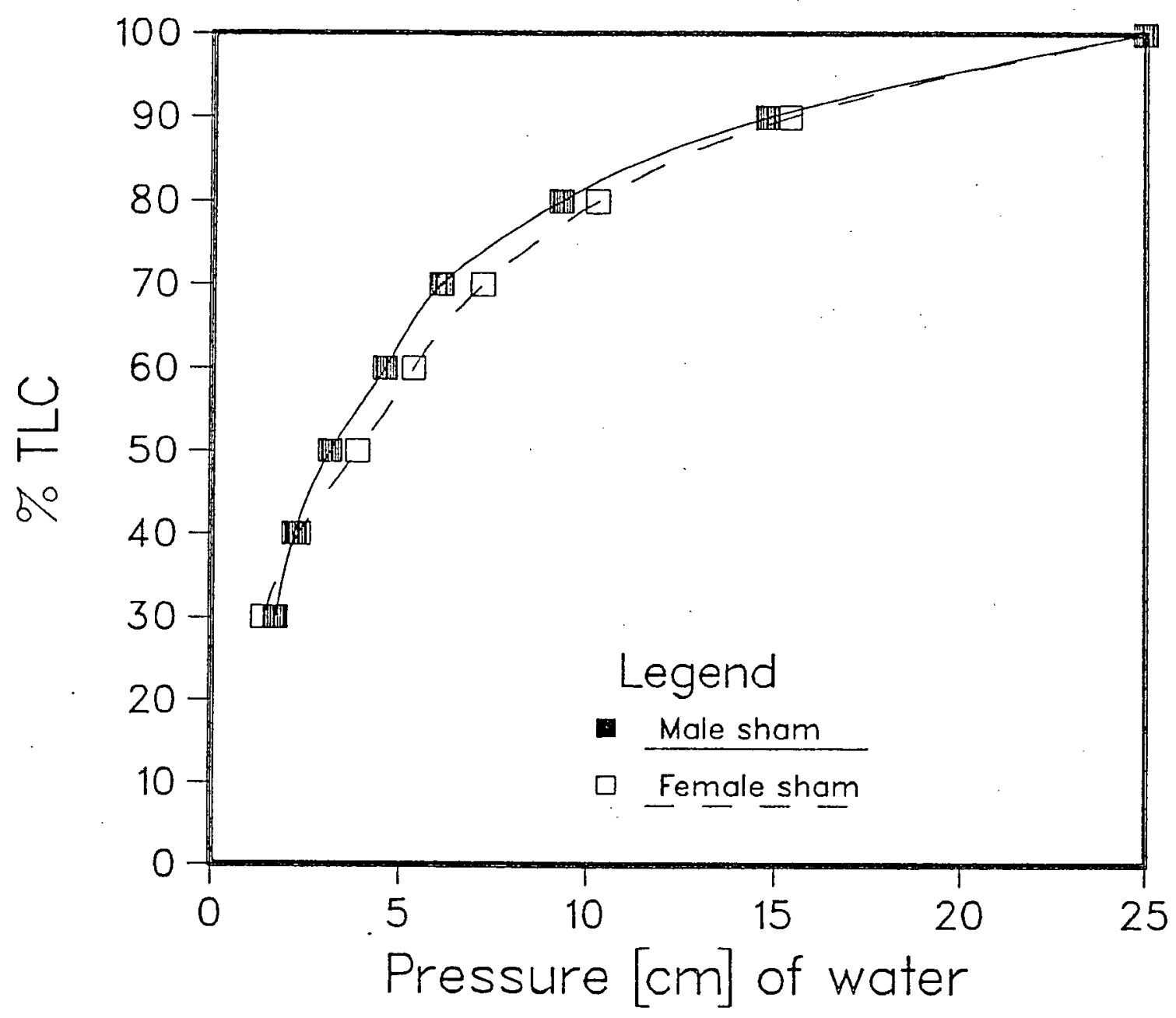

Figure 3.3: Static pressure-volume curve of male sham-operated group vs. female sham-operated group. 
Table 3.12: Morphometric results for interlobar difference

\begin{tabular}{|c|c|c|c|c|}
\hline $\begin{array}{l}\text { Variables } \\
\text { and groups }\end{array}$ & $\begin{array}{l}\text { Upper } \\
\text { lobe }\end{array}$ & $\begin{array}{c}\text { Middle } \\
\text { lobe }\end{array}$ & $\begin{array}{l}\text { Post-caval } \\
\text { lobe }\end{array}$ & $\begin{array}{l}\text { Lower } \\
\text { lobe }\end{array}$ \\
\hline$L_{m}(\mu)$ & & & & \\
\hline Male pneumo & $74.3 \pm 2.0^{\circ}$ & $83.1 \pm 2.2^{6}$ & $88.8 \pm 2.2^{c}$ & $81.0 \pm 1.6^{b}$ \\
\hline Male sham & $74.6 \pm 2.6^{\alpha}$ & $77.0 \pm 3.0^{a, b}$ & $82.9 \pm 2.1^{\delta}$ & $74.4 \pm 2.2^{a}$ \\
\hline Female pneumo & $80.0 \pm 2.6^{a, b}$ & $81.8 \pm 2.0^{a, b}$ & $86.2 \pm 2.1^{b}$ & $78.8 \pm 2.2^{a}$ \\
\hline $\begin{array}{l}\text { Female sham } \\
T_{\text {alu }}(\mu)\end{array}$ & $72.1 \pm 2.9^{\circ}$ & $72.8 \pm 2.1^{a}$ & $75.4 \pm 1.1^{a}$ & $71.3 \pm 1.8^{\circ}$ \\
\hline Male pneumo & $41.0 \pm 1.1^{\circ}$ & $44.8 \pm 0.8^{b, \epsilon}$ & $46.2 \pm 1.2^{\epsilon}$ & $42.7 \pm 0.7^{\dot{a}, b}$ \\
\hline Male sham & $38.4 \pm 0.9^{a}$ & $40.4 \pm 0.9^{a, b}$ & $41.4 \pm 1.0^{b}$ & $40.2 \pm 1.2^{a, b}$ \\
\hline Female pneumo & $41.9 \pm 1.2^{a}$ & $43.9 \pm 0.8^{a, 8}$ & $46.1 \pm 1.1^{b}$ & $42.7 \pm 0.7^{a, b}$ \\
\hline $\begin{array}{l}\text { Female sham } \\
N \vee\left(\times 10^{6}\right)\end{array}$ & $37.3 \pm 0.7^{a}$ & $36.6 \pm 0.7^{a}$ & $38.9 \pm 0.9^{a}$ & $37.5 \pm 1.0^{\alpha}$ \\
\hline Male pneumo & $2.84 \pm 0.12^{\circ}$ & $2.51 \pm 0.08^{b}$ & $2.03 \pm 0.09^{c}$ & $2.83 \pm 0.14^{a, b}$ \\
\hline Male sham & $3.39 \pm 0.20^{a, b}$ & $3.31 \pm 0.18^{a}$ & $3.17 \pm 0.12^{a}$ & $3.90 \pm 0.18^{b}$ \\
\hline Female pneumo & $2.95 \pm 0.15^{a, c}$ & $2.62 \pm 0.11^{a}$ & $2.04 \pm 0.07^{b}$ & $3.25 \pm 0.13^{e}$ \\
\hline $\begin{array}{l}\text { Female sham } \\
\bar{V}_{\text {alv }}\left(\times 10^{-6}\right)\end{array}$ & $3.38 \pm 0.16^{a}$ & $3.41 \pm 0.11^{a}$ & $3.24 \pm 0.13^{a}$ & $3.57 \pm 0.14^{a}$ \\
\hline Male pneumo & $0.218 \pm 0.013^{\circ}$ & $0.267 \pm 0.013^{6}$ & $0.314 \pm 0.014^{c}$ & $0.237 \pm 0.019^{a, b}$ \\
\hline Male sham & $0.191 \pm 0.018^{a, b}$ & $0.191 \pm 0.012^{a, b}$ & $0.194 \pm 0.007^{\circ}$ & $0.166 \pm 0.010^{b}$ \\
\hline Fernale pneumo & $0.229 \pm 0.016^{\circ}$ & $0.245 \pm 0.008^{\circ}$ & $0.307 \pm 0.012^{b}$ & $0.197 \pm 0.006^{c}$ \\
\hline Fernale sham & $0.191 \pm 0.007^{\circ}$ & $0.181 \pm 0.007^{a}$ & $0.196 \pm 0.009^{\circ}$ & $0.180 \pm 0.006^{a}$ \\
\hline
\end{tabular}

Values are means \pm SEM's.

a. b. c. $d$ in each horizontal row. means without a common superscript are significantly different $(P<0.05)$. 
of females. 


\section{Chapter 4}

\section{DISCUSSION}

The main purpose of this research was to compare the response of pneumonectomy in males to that of females. There are two main reasons for doing this experiment. Firstly, systematic comparison has not been made previously, and secondly. a difference between the two may account for the inconsistent pneumonectomy responses observed in different laboratories as reported in the literature. The experiment also provided an opportunity to consider variations between lobes of the right lung in normal animals, difference in lobar response between male and female lungs, and normal lung and somatic growth. Strictly speaking normal animals were not available in this study but Buhain and Brody (1973), Langston et al. (1977), and Rannels et al. (1984) found no difference in lung and somatic growth between sham-operated and unoperated animals. Hence, in the present study, sham-operated rats will be used to assess normal growth.

As indicated, one hypothesis in the present work is that the postpneumonectomy response would be different in males and females. This might be expected if hormones are involved in the postpneumonectomy response and there is evidence that this is the case (Brody and Buhain, 1973). The discussion will cover, in order, somatic growth. extent of response. nature of response, lung mechanics, lung growth characteristics. interlobar differences and assessment of male and female lung differences, both in pneumonectomy and sham-operated. Finally, the data will be analyzed to see if this can shed light on inter-laboratory discrepancies. 


\subsection{Somatic growth}

Somatic growth was assessed by measuring body weight at the beginning of the experiment when the animals were 4 weeks of age, and at the time of sacrifice at 7 weeks of age. Females weighed slightly, but significantly, less compared to males at 4 weeks of age (79 g vs $86 \mathrm{~g}$ : see Table 3.2). During the following 3 weeks, males gained more weight than females. Females were thus considerably smaller than males at the end of the experiment (177 g vs $250 \mathrm{~g}$; see Table 3.2). Nose-tail length was also measured at the time of termination. Females had smaller NTL measurements (see Table 3.2). Pneumonectomy did not affect Wb or NTL measurements. This was consistent with the findings of Nattie et al. (1974). Cowan and Crystal (1975). Boatman (1977), and Brody and Buhain (1973).

\subsection{Extent of response}

Completeness of response after pneumonectomy has often been assumed if lung weight and lung volume of the remaining lung matches both lungs of the controls (Nattie et al.. 1974; Langston et al., 1977: Thurlbeck et al., 1981). As discussed earlier in the introduction. most studies have reported complete compensatory lung growth response as early as 1 week in rats after pneumonectomy (Romanova et al., 1967; Buhain and Brody, 1973; Rannels et al., 1979). Normal lung growth is usually estimated by measuring lung weight and lung volume. which appear to be also influenced by body size (Bartlett Jr.. 1970; Cunningham et al., 1974: Thurlbeck, 1975). As age increases. lung weight and lung volume increase less compared to body size (Cohn. 1939: Burri et al., 1974). There is also a disassociation between lung weight and lung volume. As age increases. lung weight increases less than lung volume. It is also true that lungs have a unique expansile property, thus lung volume could increase without an increase in lung weight. In humans, lungs at full expansion contain approximately $6 \mathrm{ml}$ air per gram at 6 years of age compared to $3 \mathrm{ml}$ air per gram at birth (Thurlbeck, 1975).

The results of this experiment showed that absolute lung weights increase $50 \%$ in males and females following pneumonectomy compared to those of the right lung of sham-operated groups, and they also matched the absolute WI of both lungs of shams 
(see Tables 3.3 and 3.4). Similarly, VI of the right lung after pneumonectomy increased by $60 \%$ and $47 \%$ in males and females respectively, and was equivalent to the $\mathrm{VI}$ of both lungs of the shams in both sexes. Hence, it is evident that irrespective of sex. the remaining lung three weeks after pneumonectomy showed a complete response using the criteria of $\mathrm{WI}$ and $\mathrm{VI}$. These observations are consistent with Sery et al. (1969), Romanova (1971), Nattie et al. (1974), Langston et al. (1977). Burri and Sehovic (1979). Thurlbeck et al. (1981), but were in contrast to Buhain and Brody (1973), and Holmes and Thurlbeck (1979).

An increase in lung weight can be accomplished by an increase in cell number (hyperplasia), cell size (hypertrophy). and in the intercellular connective tissue matrix (Thurlbeck 1975). The DNA content in all cells in body is constant (Enesco and Leblond, 1962), and thus an increase in DNA indicates hyperplasia (Enesco and Leblond. 1962; Winick and Noble, 1965). On the other hand, protein measurements in the lung include intracellular and extracellular proteins, particularly blood and connective tissue proteins. Alkali soluble protein excludes connective tissue protein and an increase in the Protein/DNA ratio and RNA/DNA ratio has been used to indicate hypertrophy (Winick and Noble, 1965).

In the present study, the dry to wet lung weight ratio in males and females following pneumonectomy did not differ from the shams, and these findings were similar to those of Rannels et al. (1979). DNA and protein content of the right lung after pneumonectomy was significantly increased in males and females compared to the right lung of sham-operated groups (Table 3.3 and 3.4). However, the amount of DNA and protein was significantly less than the amount present in both lungs of sham-operated rats in both males and females. Thus, these measurements indicate that the response after pneumonectomy in both sexes is accompanied by cellular multiplication and is incomplete. These findings are compatible with the results reported previously by Thet and Law (1984) and Buhain and Brody (1973), but are in conflict to those of Watkins et al. (1985). Rannels et al. (1979), and Bennett et al. (1985). The last two authors used adult rats weighing 200 and 330 grams and studied the postpneumonectomy response after 7 and 14 days. Rannels et al. (1979) showed that at 7 days the increase in DNA, RNA and protein content was half that those noted at 14 days. Watkins et al. (1985), using 82 gram rats, showed that 2 weeks postpneumonectomy. 
DNA, RNA, and protein were equivalent to those of both lungs of sham-operated rats. As lung size is influenced by body size (Bartlett Jr. 1970; Thurlbeck, 1975), results of the present study have also been expressed after correction for body weight (specific values). Specific $W l_{T}, \mathrm{~W}_{d r y} l_{T}, \mathrm{~V} l_{T}, \mathrm{DNA} l_{T}$ and $\mathrm{Prol}_{T}$ content were significantly greater in the female pneumonectomy group and the female sham-operated group compared to those of male pneumonectomy group and male sham-operated group respectively (Tables 3.3 and 3.4). Hence, it was evident that normally, as well as after pneumonectomy, female rats have relatively bigger lungs than males rats at the age of seven weeks. In contrast, absolute changes were greater in males. It was also apparent that compensatory lung growth expressed as a percentage change of baseline was not different in males and females.

\subsection{Nature of response}

As mentioned earlier, compensatory growth may be brought about by an increase in number of cells. and increase in size of cells or both. Lung weight is also dependent upon an increase in connective tissue and other substances. Connective tissue comprises $10 \%-25 \%$ of dry lung weight and of which collagen comprises $60 \%-65 \%$ and elastin $20 \%-25 \%$ and the rest are proteoglycans and glycoproteins (Rennard and Crystal, 1981).

In this experiment. cellular multiplication was evident, as an increase in total DNA of the lung occurred. However, when DNA was compared to dry lung weight, the relative amount of DNA was decreased (see Table 3.10). This is not easy to explain, but may indicate that the unit structure of the lung is altered in postpneumonectomy. It may be that other components of lung have increased more than DNA and these may include collagen, elastin, proteoglycans, and other substances. The ratio of protein to DNA increased after pneumonectomy (see Table 3.10), and this might be attributed to an increase in cell size. The observed increase in the ratio of protein to DNA does not agree with the findings reported by some investigators (Buhain and Brody. 1973: Cowan and Crystal, 1975), but does so with Rannels et al. (1979). They (Rannels et al., 1979) found a slight increase in Protein/DNA ratio and a significant increase in RNA/DNA ratio in flushed lungs of rats two weeks after pneumonectomy. They con- 
cluded an increase in RNA/DNA ratio was due to shift of proteins towards connective tissue synthesis. Morphometrically. Thet and Law (1984) noticed an increase in the volume of type I pneumocytes and interstitial cells.

A major issue which has not been addressed in detail before, and which had not been investigated here, is the contribution of blood to lung weight. Following pneumonectomy, the remaining lung must accept the entire cardiac output and this results in approximately $54 \%$ more blood flow through it (the left. lung comprises of about 35\% of total lung weight in rats). Inselman et al. (1977) estimated that in normal rats. blood proteins contributed $14 \%$ of lung protein content. Even after flushing the pulmonary arteries with saline a $13 \%$ contribution of blood proteins in lung protein content has been reported (Rannels et al.. 1979). The animals used in the present study were exsanguinated, and thus the lungs in the present study probably had more blood than the flushed lungs.

Accepting the estimate of Inselman et al. (1977), then $14 \%$ of the $87.36 \mathrm{mg}$ of lung protein $(12.23 \mathrm{mg})$ in males following pneumonectomy was blood protein. Because the right lung comprises $65 \%$ of total lung weight. $4.28 \mathrm{mg}$ of the $12.23 \mathrm{mg}$ of blood protein were due to left pneumonectomy. Thus, after deducting the estimate of blood proteins of the left lung from the values of the right lung of male pneumonectomy rats. Protein/DNA ratio is $15.8 \mathrm{mg} / \mathrm{mg}$ which is very close to the value of $15.2 \mathrm{mg} / \mathrm{mg}$ of sham-operated rats. Similar calculations in females after pneumonectomy shows that Protein/DNA ratio was $17.6 \mathrm{mg} / \mathrm{mg}$ which is also nearly equal to the value of shamoperated females $(17.3 \mathrm{mg} / \mathrm{mg})$. Hence, it is likely that increase in protein to DNA ratio following pneumonectomy was due to increase in blood proteins rather than cellular hypertrophy.

Another approach to the nature of response is to examine the morphology of the lung. Morphometry is a term referring to a body of quantitative methods of measuring the anatomical structures of an organ. These methods can be used to calculate various parameters of lung structure (see Table 2.2) and it is possible to examine changes in these to assess the nature of the postpneumonectomy response. $L_{m}$. which is an indirect measure of the dimensions of airspaces and $\bar{I}_{\text {alv }}$ which is a measurement of alveolar size would be expected to increase if airspaces dilate as a result of pneumonectomy. If airspaces enlarge isotropically by overinflation. the 
increase in $L_{m}$ and $T_{a l v}$ would be proportional to the cube root of the increase in lung volume. The increase in alveolar surface area would be proportional to the increase in lung volume to the two-thirds power. The change in Nv would be inversely proportional to the increase in lung volume. In the case of an increase in the complexity of the lung by complete alveolar multiplication, $L_{m}, \bar{l}_{a l v}$, and $\mathrm{Nv}$ would remain constant, and surface area would increase directly proportional to the change in lung volume. Burri and his colleagues (1982) have suggested that increased alveolar complexity can also result from lengthening of alveolar walls. This change would produce similar results in $L_{m}, \bar{I}_{a l v}$, and $S w$, but not $\mathrm{Nv}$.

\subsection{Global response}

\subsubsection{Males}

In males after pneumonectomy, $L_{m}$ and $\bar{T}_{a l v}$ increased significantly but were less than the expected values by simple expansion (see Table 4.1). Nv was decreased less and alveolar surface area increased more than the predicted increase in overinflation. The number of alveoli was significantly increased compared to the right lung of controls. All these values changed less than predicted from increased surface complexity due to alveolar multiplication. Thus, it is evident that in males following pneumonectomy. dilatation as well as alveolar multiplication of alveoli took place, and dilatation appears to be a major change. These findings were similar to the observations made by Holmes and Thurlbeck (1979) and Nattie et al. (1974), but different from the findings of Buhain and Brody (1973) where they concluded that pneumonectomy only resulted in dilatation of already existing airspaces. They (Buhain and Brody, 1973) used Long-Evan rats and sacrificed them 4 and 8 weeks after surgery. Therefore, the discrepancy could be due to a different strain of animals and longer duration following pneumonectomy. These findings, of course, also differ from those in which complete compensatory alveolar multiplication has been observed (Langston et al., 1977) in rabbits, and (Thurlbeck et al., 1981) in puppies. 
Table 4.1: Global morphometric response in males following pneumonectomy.

\begin{tabular}{|c|c|c|c|}
\hline $\begin{array}{l}\text { Variables } \\
\text { and } \\
\text { Lobes }\end{array}$ & $\begin{array}{c}\text { Observed } \\
\text { [1] }\end{array}$ & $\begin{array}{c}\text { Expected by } \\
\text { simple expansion } \\
{[2]}\end{array}$ & $\begin{array}{c}\text { Expected by } \\
\text { increased complexity } \\
{[3]}\end{array}$ \\
\hline $\mathrm{L}_{m}(\mu)$ & $82.0 \pm 1.2$ & $89.5 \pm 2.4$ & $76.6 \pm 2.0$ \\
\hline$\overline{\mathrm{T}}_{\text {alv }}(\mu)$ & $43.6 \pm 0.6$ & $46.7 \pm 0.7$ & $39.9 \pm 0.6$ \\
\hline $\mathrm{Sw}_{R}\left(m^{2}\right)$ & $0.514 \pm 0.018$ & $0.465 \pm 0.019$ & $0.544 \pm 0.022$ \\
\hline Nv $\left(\times 10^{6}\right)$ & $2.59 \pm 0.09$ & $2.28 \pm 0.09$ & $3.64 \pm 0.15$ \\
\hline
\end{tabular}

Values are means \pm SEM's

1 . is the observed value following pneumonectomy.

2. is the predicted value if the lung volume increases by overinflation and isotropic expansion.

3 . is the predicted value if the lung volume increases by an increase in surface complexity due to complete alveolar multiplication.

\subsubsection{Females}

In females, $L_{m}, \bar{I}_{a l v}$, and $S_{w_{R}}$ increased close to values predicted by simple expansion of the lungs (see Table 4.2). On the other hand, $N v$ decreased less than predicted from isotropic expansion. Observed values were considerably different from those predicted from complete increased complexity. Thus, it is apparent that in females. pneumonectomy resulted mainly in dilatation of the existing airspaces, although direct alveolar counting showed a significant increase in the right lung.

Since the females were smaller in body weight. $\mathrm{Sw}_{R}$ and $\mathrm{Na}_{R}$. were significantly higher in postpneumonectomy and sham-operated females after correction for body weight compared to postpneumonectomy and sham-operated males respectively. These findings are consistant with the earlier observations that females, relative to their body weight, have bigger lungs. 
Table 4.2: Global morphometric response in females following pneumonectomy.

\begin{tabular}{||l|c|c|c||}
\hline \hline $\begin{array}{l}\text { Variables } \\
\text { and } \\
\text { Lobes }\end{array}$ & Observed & $\begin{array}{c}\text { Expected by } \\
\text { simple expansion } \\
{[1]}\end{array}$ & $\begin{array}{c}\text { Expected by } \\
\text { increased complexity }\end{array}$ \\
\hline $\mathrm{L}_{m}(\mu)$ & $82.6 \pm 1.7$ & $82.6 \pm 1.7$ & {$[3]$} \\
$\bar{I}_{a l v}(\mu)$ & $43.6 \pm 0.9$ & $42.7 \pm 0.7$ & $72.6 \pm 1.5$ \\
$\mathrm{Sw}_{R}\left(m^{2}\right)$ & $0.418 \pm 0.014$ & $0.414 \pm 0.013$ & $37.6 \pm 0.6$ \\
$\mathrm{Nv}\left(\times 10^{6}\right)$ & $2.82 \pm 0.08$ & $2.34 \pm 0.05$ & $0.471 \pm 0.015$ \\
\hline \hline
\end{tabular}

Values are means \pm SEM's.

1. is the observed value following pneumonectomy.

2. is the predicted value if the lung volume increases by overinflation and isotropic expansion.

3. is the predicted value if the lung volume increases by an increase in surface complexity due to complete alveolar multiplication.

\subsection{Lobar response}

\subsubsection{Males}

All lobes increased in volume (upper lobe $76 \%$, middle lobe $52 \%$, post-caval lobe 70\%. lower lobe 52\%; see Table 3.5). Three morphometric variables $\left(L_{m}, \bar{I}_{\text {alv }}\right.$. Nv) are affected by overexpansion. Nv was decreased in all lobes, and in the others except the upper lobe, an additional variable indicated overinflation (see table 3.6). Table 4.3 shows the results of 4 variables that were found and in which comparison can be made to theoretic values that would be obtained. In all but 2 of the 16 instances ( $L_{m}$ and $\mathrm{SW}_{L O B E}$ of the upper lobe) the morphometric variables showed alterations which indicated overinflation. These findings are, of course, in keeping with the global values. Similarly, all values indicated an increase in surface complexity i.e. all of the values were different from those pridicted from dilatation alone. This again is in keeping with the global values. The finding that $L_{m}$ and $S_{w_{L O B E}}$ of the upper lobe were equal to those predicted from increased complexity due to alveolar multiplication suggests that alveolar multiplication may be more complete in this lobe compared to others, but that the changes in the other lobes were similar i.e. overexpansion plus increase in surface complexity. 
Table 4.3: Lobar morphometric response in males following pneumonectomy.

\begin{tabular}{||l|c|c|c||}
\hline \hline $\begin{array}{l}\text { Variables } \\
\text { and } \\
\text { Lobes }\end{array}$ & Observed & $\begin{array}{c}\text { Expected by } \\
\text { simple expansion } \\
{[2]}\end{array}$ & $\begin{array}{c}\text { Expected by } \\
\text { increased complexity } \\
{[3]}\end{array}$ \\
\hline $\begin{array}{l}\mathrm{L}_{m}(\mu) \\
\text { Upper lobe }\end{array}$ & $74.3 \pm 2.0$ & $80.1 \pm 3.2$ & $74.6 \pm 2.6$ \\
Middle lobe & $83.1 \pm 2.2$ & $88.6 \pm 3.5$ & $77.0 \pm 3.0$ \\
$\begin{array}{l}\text { Post-caval lobe } \\
\text { Lower lobe }\end{array}$ & $88.8 \pm 2.2$ & $99.0 \pm 2.5$ & $82.9 \pm 2.1$ \\
\hline $\begin{array}{l}\text { Ialv }(\mu) \\
\text { Upper lobe }\end{array}$ & $41.0 \pm 1.6$ & $85.7 \pm 2.5$ & $74.4 \pm 2.2$ \\
Middle lobe & $44.8 \pm 0.8$ & $46.4 \pm 1.0$ & $38.4 \pm 0.9$ \\
Post-caval lobe & $46.2 \pm 1.2$ & $49.4 \pm 1.1$ & $40.4 \pm 0.9$ \\
Lower lobe & $42.7 \pm 0.7$ & $46.3 \pm 1.4$ & $41.4 \pm 1.0$ \\
Sw $w_{L O B E}\left(m^{2}\right)$ & & & $40.2 \pm 1.2$ \\
Upper lobe & $.100 \pm .004$ & $.083 \pm .004$ & $.100 \pm .004$ \\
Middle lobe & $.100 \pm .004$ & $.094 \pm .004$ & $.108 \pm .005$ \\
Post-caval lobe & $.098 \pm .005$ & $.088 \pm .002$ & $.105 \pm .003$ \\
Lower lobe & $.216 \pm .009$ & $.206 \pm .011$ & $.237 \pm .013$ \\
Nv $\left(\times 10^{6}\right)$ & & & \\
\hline Upper lobe & $2.84 \pm .12$ & $1.92 \pm .11$ & $3.39 \pm .20$ \\
Middle lobe & $2.51 \pm .09$ & $2.18 \pm .12$ & $3.31 \pm .18$ \\
Post-caval lobe & $2.03 \pm .09$ & $1.86 \pm .07$ & $3.17 \pm .12$ \\
Lower lobe & $2.83 \pm .14$ & $2.55 \pm .12$ & $3.90 \pm .18$ \\
\hline \hline
\end{tabular}

Values are means \pm SEM's.

1. is the observed value following pneumonectomy.

2. is the predicted value if the lung volume increases by overinflation and isotropic expansion.

3. is the predicted value if the lung volume increases by an increase in surface complexity due to complete alveolar multiplication. 


\subsubsection{Females}

All lobes increased in volumes in females as well (upper lobe $52 \%$, middle lobe $49 \%$. post-caval lobe $73 \%$, and lower lobe $33 \%$; see Table 3.5 ). When morphometric changes were estimated. $L_{m}$ (upper lobe $P=0.06$ ) and $T_{a l v}$ in all lobes were increased significantly. Nv was decreased in the upper $(P=0.06)$ and the lower lobe (Table 3.7). When the observed changes were compared to those predicted from either expansion or alveolar multiplication all but 3 ( $T_{\text {alv }}$ of the middle and lower lobes and $S w_{L O B E}$ the lower lobe) of the 16 measurements lay between those predicted from alveolar multiplication and those predicted from overexpansion. The three exceptions were in keeping with the simple overinflation. Once again this is in contrast with the global response which indicate both overinflation and alveolar multiplication. Alveolar multiplication may be least in the lower lobe followed by the middle lobe.

Hence, it is clear that all lobes in both sexes increase in volume and there is no striking difference between the lobes although the upper and the post-caval lobe in males and the post-caval lobe in the females expanded the most. The lower lobe increased in volume the least in both sexes. The most obvious change is overinflation. However, there is evidence of increased surface complexity in all lobes of males and is statistically significant in the upper and the lower lobes. In females. simple expansion is the main feature in all the lobes.

\subsection{Lung mechanics}

In this experiment, absolute TLC, specific TLC and air/g WI after pneumonectomy did not differ from the controls in either males or females (see Table 3.11). These findings were consistent with those of Ford et al. (1981) and Arnup et al. (1984). Absolute TLC was significantly less (23\%) in females but no difference was found after normalizing for $\mathrm{W} b$. No difference in air/g WI was found between males and females, with the exception that the specific TLC was higher in females following pneumonectomy. In males after pneumonectomy. the static pressure-volume curve was similar to controls (see Figure 3.2). These results are compatible to those of Buhain and Brody (1973). Ford et al. (1981), and Arnup et al. (1984). However. 
Table 4.4: Lobar morphometric response in females following pneumonectomy.

\begin{tabular}{|c|c|c|c|}
\hline $\begin{array}{l}\text { Variables } \\
\text { and } \\
\text { Lobes }\end{array}$ & $\begin{array}{c}\text { Observed } \\
{[1]}\end{array}$ & $\begin{array}{c}\text { Expected by } \\
\text { simple expansion } \\
{[2]}\end{array}$ & $\begin{array}{c}\text { Expected by } \\
\text { increased complexity } \\
{[3]}\end{array}$ \\
\hline $\mathrm{L}_{m}(\mu)$ & & & \\
\hline Upper lobe & $80.0 \pm 2.6$ & $82.9 \pm 3.4$ & $72.1 \pm 2.9$ \\
\hline Middle lobe & $81.8 \pm 2.0$ & $83.1 \pm 2.4$ & $72.8 \pm 2.1$ \\
\hline Post-caval lobe & $86.2 \pm 2.1$ & $90.6 \pm 1.4$ & $75.4 \pm 1.1$ \\
\hline $\begin{array}{l}\text { Lower lobe } \\
\bar{I}_{\text {alv }}(\mu)\end{array}$ & $78.8 \pm 2.2$ & $78.5 \pm 2.0$ & $71.3 \pm 1.8$ \\
\hline$\overline{\text { Upper lobe }}$ & $41.9 \pm 1.2$ & $42.9 \pm 0.8$ & $37.3 \pm 0.7$ \\
\hline Middle lobe & $43.9 \pm 0.8$ & $41.7 \pm 0.8$ & $36.6 \pm 0.7$ \\
\hline Post-caval lobe & $46.1 \pm 1.1$ & $46.7 \pm 1.1$ & $38.9 \pm 0.9$ \\
\hline $\begin{array}{l}\text { Lower lobe } \\
\text { Sw } w_{L O B E}\left(m^{2}\right)\end{array}$ & $42.7 \pm 1.3$ & $41.3 \pm 1.1$ & $37.5 \pm 1.0$ \\
\hline Upper lobe & $.067 \pm .002$ & $.064 \pm .002$ & $.074 \pm .002$ \\
\hline Middle lobe & $.089 \pm .003$ & $.088 \pm .004$ & $.101 \pm .004$ \\
\hline Post-caval lobe & $.088 \pm .004$ & $.085 \pm .002$ & $.102 \pm .003$ \\
\hline $\begin{array}{l}\text { Lower lobe } \\
\text { Nv }\left(\times 10^{6}\right)\end{array}$ & $.176 \pm .008$ & $.178 \pm .007$ & $.196 \pm .008$ \\
\hline Upper lobe & $2.95 \pm .15$ & $2.33 \pm .10$ & $3.38 \pm .16$ \\
\hline Middle lobe & $2.62 \pm .11$ & $2.29 \pm .07$ & $3.41 \pm .11$ \\
\hline Post-caval lobe & $2.04 \pm .07$ & $1.87 \pm .07$ & $3.24 \pm .13$ \\
\hline Lower lobe & $3.25 \pm .13$ & $2.68 \pm .10$ & $3.57 \pm .14$ \\
\hline
\end{tabular}

Values are means \pm SEM's.

1. is the observed value following pneumonectomy.

2. is the predicted value if the lung volume increases by overinflation and isotropic expansion.

3 . is the predicted value if the lung volume increases by an increase in surface complexity due to complete alveolar multiplication. 
loss of elastic lung recoil was evident in mid-volumes of the static pressure-volume curve in the female pneumonectomy group (see Figure 3.1). In this experiment, lungs were removed from the thoracic cavity, and therefore the effect of the chest cage was eliminated. Collagen and elastin are principally responsible for lung recoil. The initial $50 \%$ of elastic lung recoil depends upon elastin and afterwards collagen acts at higher pressures. It may be possible that connective tissue formation after pneumonectomy is different in females compared to males. However, elastin and collagen were not measured in this experiment.

\section{7 $\quad$ Lung structure at age 7 weeks}

Normal lung growth differences between 7 week old males and females were observed in sham-operated animals. Absolute parameters of lung growth $\left(\mathrm{W} l_{T}, \mathrm{~W}_{d r y} l_{T}, \mathrm{~V} l_{T}\right.$. $\mathrm{DNAl}_{T}, \mathrm{Prol}_{T}$ ) were greater in males than in females (Table A.1 Appendix A). These differences were consistent in the right lung as well as in both lungs. When all these values were expressed as specific values, these were higher in females compared to those of males. These differences appear to be due to differences in somatic growth. Figure 4.1 and 4.2 show the regression lines of the increase in lung weight and lung volume to body weight in male rats. Sprague-Dawley litter males between 4 and 7 weeks of age were obtained from another experiment (Controls in a study of the effect of hypobaric hypoxia). If the body weight of females (177 g) at the end of the present study is projected to these data, then the predicted lung weight in males is $0.88 \mathrm{~g}$ and lung volume $8.2 \mathrm{ml}$ (see Figure 4.1 and 4.2). These values are very close to those observed in the females in the present study $(0.877 \mathrm{~g}$ and $8.4 \mathrm{ml})$. Therefore, it appears that greater absolute values in males, and greater specific values in females at 7 weeks of age, is because lung weight and lung volume increase less relative to body weight (Cohn, 1940; Burri et al., 1974; Thurlbeck, 1975).

When dimensions were considered in individual lobes, there was some indication of a difference in size of airspaces in shams. In males, $L_{m}$ and $T_{a l v}$ were significantly greater in the post-caval lobe compared to the upper lobe. When the post-caval lobe was compared to the lower lobe, all estimates of airspaces $\left(L_{m}, \bar{l}_{a l v}, N v, \bar{V}_{a l v}\right)$ indicated that airspaces in general and alveoli in particular, were bigger in the post-caval lobe. 


\section{Lung Weight}

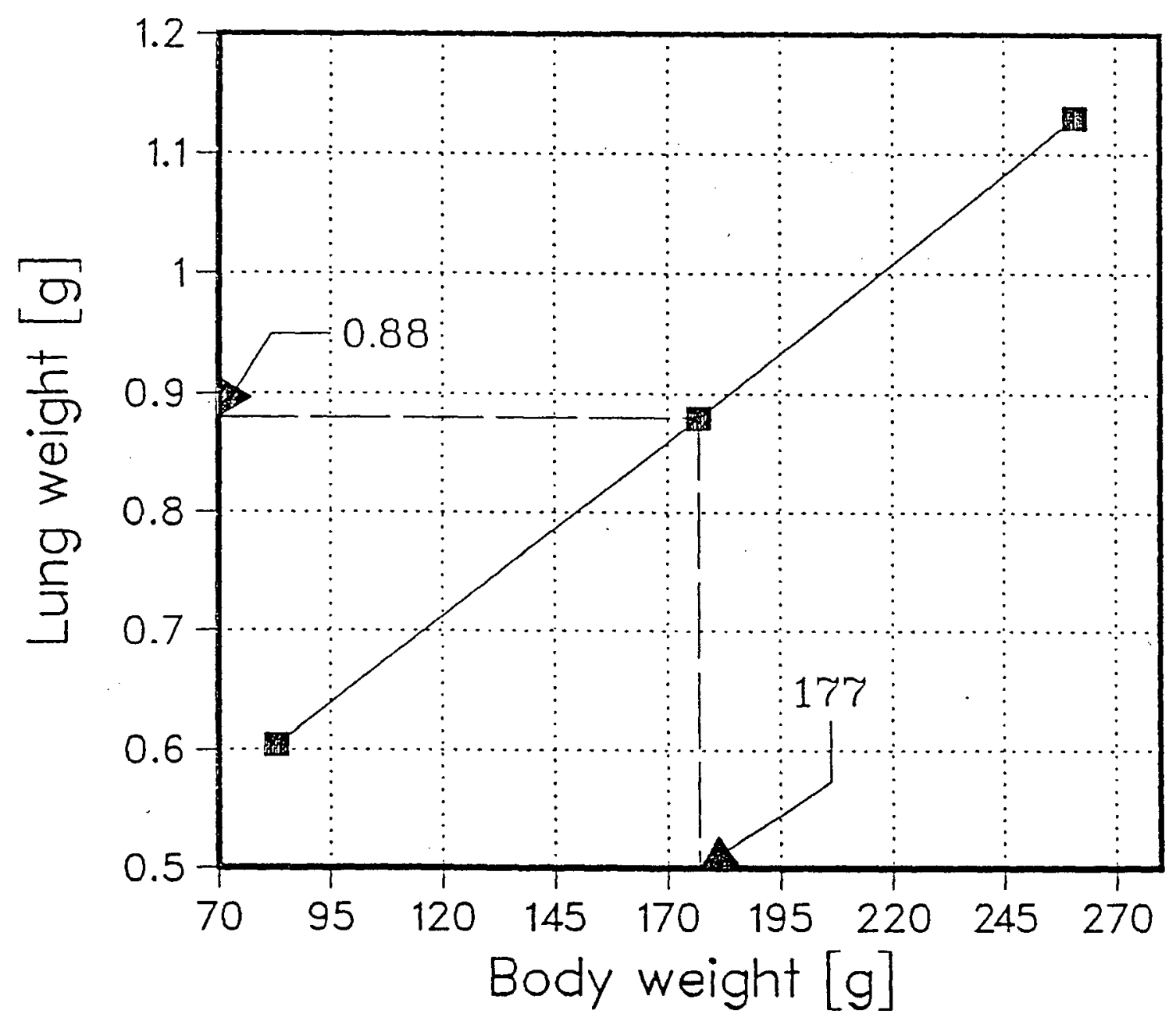

Figure 4.1: Lung weight in males at the time of $177 \mathrm{~g}$ body weight. 


\section{Lung Volume}

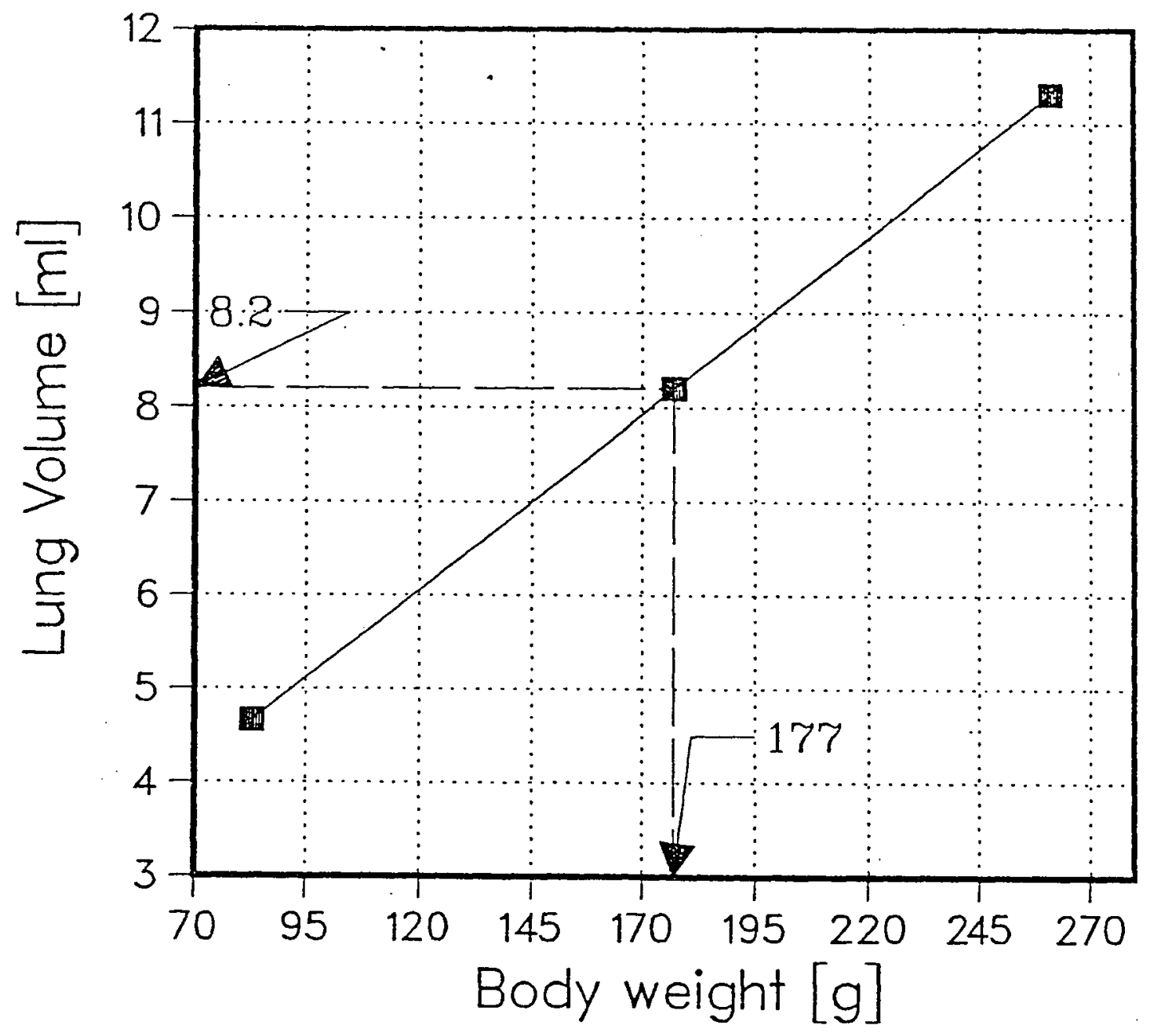

Figure 4.2: Lung volume in males at the time of $177 \mathrm{~g}$ body weight. 
However, no differences were observed in airspace dimensions in females. Holmes and Thurlbeck (1979) studied lobe differences in sham-operated rats, but they did not compare the post-caval lobe. They found that at the age of 14 weeks, the middle lobe had bigger alveoli than the lower and upper lobes.

\subsection{Difference between males and females follow- ing pneumonectomy}

Before considering the difference in postpneumonectomy compensatory lung growth between males and females, it is appropriate to consider difference between shamoperated male and female animals. Assessment of somatic growth showed an evident difference between males and females, with males being much larger. Accordingly. assessment of lung size was much larger in males. However, when lung dimensions were corrected for body size, specific dimensions were greater in females. This is attributed to the well recognized decrease in specific dimensions with increased somatic growth (Cohn, 1940; Burri et al, 1974: Thurlbeck, 1975). It has been shown above. that males of similar body size as that of females at 7 weeks of age, have similar specific lung dimensions. Morphometrically, absolute measurements $\left(\mathrm{Na}_{T} . \mathrm{SW}_{T}\right)$ were greater in sham-operated males reflecting greater lung volumes, but global values of the unit structure of the lung $\left(\mathrm{L}_{m}, \overline{\mathrm{T}}_{a l v}\right.$, Nv) were not different (see Table A.6 Appendix A). In terms of pressure-volume characteristics. TLC was larger in males reflecting their larger size, but when pressure-volume curves expressed as a percentage of TLC. the curves were not different (Figure 3.3).

In response to pneumonectomy, differences were apparent between males and females. As males are bigger, so were the changes in absolute lung measurements, but due to the smaller size of females, they had greater specific changes. However, the percentage changes following pneumonectomy were identical in both sexes. The compensatory response after pneumonectomy was complete in terms of lung weight and lung volume but incomplete for DNA and protein content in both sexes. Primarily, the compensatory response was hyperplastic in both males and females. The decrease in DNA/g W $\mathrm{g}_{d r y} l$ and increase in Protein/DNA ratio was probably due to excess blood proteins following pneumonectomy. 
Following pneumonectomy. morphometric analysis show that overinflation was a major feature of compensatory response. Some morphometric measurements are indicative of increased surface complexity in males, but it is evident that alveolar multiplication was incomplete. On the other hand, in females it is apparent that simple expansion was more important and increased alveolar surface compexity was less important.

Pressure-volume characteristics were different following pneumonectomy in males and females. In females, loss of elastic lung recoil was observed in mid lung volumes as the pressure-volume curve was shifted upward and to the left. This observation remained unexplained. Lung distensibility depends on alveolar surface forces and connective tissue forces. In rats as well as in other species, the shape constant, $\mathrm{K}$. of the pressure-volume curve has been shown to be directly related to the mean size of the airspaces as assessed by the mean linear intercept (Haber et al.. 1983). Following pneumonectomy in females, the mean linear intercept increased significantly (see Table 3.9) and the shape constant $K$ of pressure- volume curve was significantly $(\mathrm{P}=0.002)$ higher $(K=0.139 \pm 0.004)$ compared to shams $(K=0.114 \pm 0.006)$. These findings are consistant with the hypothesis of Haber et al. (1983) that the shape of the pressure-volume curve is determined by airspace size. However, in males. $L_{m}$ also increased significantly after pneumonectomy (see Table 3.8), but there was no change in $\mathrm{K}$. This suggests that besides increase in the size of airspaces, connective tissue changes (which were not measured in this study) might be responsible for loss of elastic lung recoil in females.

\subsection{Intersex response and differences in the lit- erature}

Considering the general similarities in compensatory response in males and females in this study, it is very unlikely that the results of an experiment would be noticeably affected, in which animals of different sexes were used. However, an experiment in which sham-operated animals are of one sex and pneumonectimized animals the other, could possibly show conflicting results. Using the data from the present study, if comparison was made between a male sham-operated group and a female pneumonectomy 
Table 4.5: Results for hypothetical experiment $[\mathrm{A}]$ using data from the present study.

\begin{tabular}{||l|c|c||}
\hline \hline Variables & $\begin{array}{c}\text { Sham-operated } \\
\text { males and } 3 \text { females }\end{array}$ & $\begin{array}{c}\text { Pneumonectomy } \\
\text { males and } 6 \text { females }\end{array}$ \\
\hline $\mathrm{W} l_{R}(\mathrm{~g})$ & $0.655 \pm 0.016$ & $0.975 \pm 0.046^{*}$ \\
$\mathrm{~W} l_{T}(\mathrm{~g})$ & $0.971 \pm 0.022$ & $0.975 \pm 0.046$ \\
$\mathrm{~V} l_{R}(\mathrm{ml})$ & $5.99 \pm 0.16$ & $9.36 \pm 0.63^{*}$ \\
$\mathrm{~V} l_{T}(\mathrm{ml})$ & $8.64 \pm 0.26$ & $9.36 \pm 0.63$ \\
$\mathrm{~W}_{d r y} l_{R}(\mathrm{~g})$ & $0.136 \pm 0.005$ & $0.181 \pm 0.010^{* *}$ \\
$\mathrm{~W}_{d r y} l_{T}(\mathrm{~g})$ & $0.207 \pm 0.007$ & $0.181 \pm 0.010$ \\
$\mathrm{DNA} l_{R}(\mathrm{mg})$ & $3.88 \pm 0.14$ & $4.69 \pm 0.29^{* *}$ \\
$\mathrm{DNA} l_{T}(\mathrm{mg})$ & $5.92 \pm 0.19$ & $4.69 \pm 0.29^{* *}$ \\
$\mathrm{Prol}_{R}(\mathrm{mg})$ & $61.19 \pm 1.23$ & $84.24 \pm 3.11^{* *}$ \\
$\mathrm{Prol}_{T}(\mathrm{mg})$ & $93.38 \pm 1.41$ & $84.24 \pm 3.11^{* *}$ \\
$\mathrm{~S} \mathrm{w}_{R}\left(\mathrm{~m}^{2}\right)$ & $0.326 \pm 0.008$ & $0.457 \pm 0.027^{*}$ \\
$\mathrm{~S} \mathrm{w}_{T}\left(m^{2}\right)$ & $0.469 \pm 0.013$ & $0.457 \pm 0.027$ \\
$\mathrm{Na}_{R}\left(\times 10^{6}\right)$ & $22.25 \pm 0.74$ & $24.54 \pm 1.20$ \\
$\mathrm{Na}_{T}\left(\times 10^{6}\right)$ & $32.06 \pm 1.12$ & $24.54 \pm 1.20^{*}$ \\
\hline \hline
\end{tabular}

group, absolute parameters would show a smaller compensatory response. Thus, the conclusion might be drawn that incomplete or no compensatory lung growth occurred. On the other hand, in the reverse experiment (female sham-operated group vs male pneumonectomy group) the absolute changes would appear greater and an inference of complete response could be drawn. It is unlikely that such an experiment would be designed, but more realistically, an imbalanced number of both sexes in the shamoperated and pneumonectomy group might occur. Using the data of the present study. two hypothetical experiments $A$ and $B$ were constructed. Experiment $A$ comprised 6 males and 3 females in the sham-operated group and 3 males and 6 females in the pneumonectomy group (see Table 4.5). In this analysis a smaller absolute response would be anticipated. Nonetheless, a significant increase occurred in all parameters. except total number of alveoli, when right lungs of the two groups are compared. When both lungs of the sham-operated group are compared to the right lung of the pneumonectomy group, a complete response is still apparent in terms of $\mathrm{W} l_{T} . \mathrm{W}_{d r y} l_{T}$. $\mathrm{Vl}_{T}$, and $\mathrm{Sw}_{T}$, but incomplete for $\mathrm{DNAl}_{T}$. Prol $l_{T}$ and $\mathrm{Na}_{T}$. In experiment B (see Table 4.6), the sham-operated group consists of 3 males and 6 females, and pneu- 
Table 4.6: Results for hypothetical experiment $[\mathrm{B}]$ using data from the present study.

\begin{tabular}{|c|c|c|}
\hline Variables & $\begin{array}{c}\text { Sham-operated } \\
3 \text { males and } 6 \text { females }\end{array}$ & $\begin{array}{c}\text { Pneumonectomy } \\
6 \text { males and } 3 \text { females }\end{array}$ \\
\hline $\mathrm{W} l_{R}(\mathrm{~g})$ & $0.656 \pm 0.032$ & $1.005 \pm 0.043$ \\
\hline$W l_{T}(\mathrm{~g})$ & $0.959 \pm 0.040$ & $1.005 \pm 0.043$ \\
\hline $\mathrm{V} l_{R}(\mathrm{ml})$ & $6.26 \pm 0.37$ & $9.57 \pm 0.39$ \\
\hline $\mathrm{V} l_{T}(\mathrm{ml})$ & $8.88 \pm 0.52$ & $9.57 \pm 0.39$ \\
\hline$W_{d r y} l_{R}(\mathrm{~g})$ & $0.126 \pm 0.006$ & $0.195 \pm 0.008$ \\
\hline $\mathrm{W}_{d r y} l_{T}(\mathrm{~g})$ & $0.191 \pm 0.009$ & $0.195 \pm 0.008$ \\
\hline $\mathrm{DNAl}_{R}(\mathrm{mg})$ & $3.70 \pm 0.17$ & $4.90 \pm 0.15^{\circ}$ \\
\hline $\mathrm{DNAl}_{T}(\mathrm{mg})$ & $5.63 \pm 0.25$ & $4.90 \pm 0.15^{* *}$ \\
\hline $\operatorname{Prol}_{R}(\mathrm{mg})$ & $60.92 \pm 2.17$ & $85.05 \pm 2.48^{*}$ \\
\hline $\operatorname{Prol}_{T}$ (mg) & $92.76 \pm 2.99$ & $85.05 \pm 2.48$ \\
\hline $\mathrm{Sw}_{R}\left(m^{2}\right)$ & $0.330 \pm 0.016$ & $0.462 \pm 0.014^{*}$ \\
\hline $\mathrm{Sw}_{T}\left(m^{2}\right)$ & $0.469 \pm 0.024$ & $0.462 \pm 0.014$ \\
\hline $\mathrm{Na}_{R}\left(\times 10^{6}\right)$ & $20.51 \pm 0.78$ & $25.10 \pm 0.60^{\circ}$ \\
\hline $\mathrm{Na}_{T}\left(\times 10^{6}\right)$ & $29.10 \pm 1.08$ & $25.10 \pm 0.60^{*}$ \\
\hline
\end{tabular}

Values are means \pm SEM's.

$* \mathrm{P}<0.0005$, ** $\mathrm{P}<0.05$.

monectomy group of 6 males and 3 females. A greater response would be anticipated. Compared to experiment $A$, the number of alveoli is increased in the pneumonectomy group compared to the right lung of the controls. When compared to both lungs of controls, the response is incomplete in terms of DNA $l_{T}$, Prol $_{T}$ and alveolar number. as in experiment $A$. Thus, imbalance number of males and females is not likely to have a major effect, although evidence of alveolar multiplication might be affected. It is noteworthy that some investigators using mixed sexes have observed complete compensatory response with complete alveolar multiplication (Langston et al., 1977: Thurlbeck et al., 1981) while others a complete response without alveolar multiplication (Boatman et al., 1983). On the contrary, investigators have demonstrated a complete response (Boatman. 1977; Rannels et al., 1979; Burri and Sehovic. 1979: Watkins et al., 1985: Bennett et al., 1985), and an incomplete response (Holmes and Thurlbeck. 1979; Buhain and Brody. 1973) using animals of the same sex.

There are other explanations for inter-laboratory result variations. These may include one or more of the following: 
1. The nature of experimental animals has not always been considered. In this study, as in other experiments in our laboratory. littermates from a closely bred strain were used and were divided into control and experimental groups. The largest and the smallest animals of the litter have been discarded in some experiments. Considerable variations in size of animals occur between litters (Weihe. 1987). Therefore, improper matching of experimental and control animals may lead to variation in results.

2. It is also possible that the extent of the response may range from none to complete in individuals, and may vary within a litter. This has not been properly assessed, since it requires measurements to be made on the resected lung and compared to the contralateral lung.

3. As indicated in the introduction, there is evidence that the response is incomplete in older animals. However, an incomplete response has been observed in young animals (Buhain and Brody. 1973; Holmes and Thurlbeck, 1979), and a complete response in older animals (Sery et al., 1969; Nattie et al., 1974: Wandel et al.. 1983).

4. The method of analysis also affects the interpretation of the data. An increase in compensatory response has always been recorded when comparison is made between the right lungs of the sham-operated and pneumonectomy groups (except the study of the effect of long duration by Davies et al.. 1982). On the other hand, if the postpneumoenctomy lung is compared to both lungs of controls. the compensatory response may be less, but this may not reach statistically significant levels. Such an example is in the paper by Burri et al. (1982) who concluded from their experiment that compensatory response following right lobectomy was complete and not influenced by age. Another analysis of this data (Thurlbeck. (editorial) 1983) indicated that the response was always less than complete at 5 points examined from 6 days to 30 days postpneumnonectomy and a paired t-test on the data indicates that the chance of this occurrence is less than 1:100. It is thus possible to conclude that there was not a complete response during this period.

5. The techniques used for pneumonectomy have not been fully investigated. It 
has been observed that if plombage is performed on the thoracic cavity following pneumonectomy. (Cohn. 1939; Tartter and Goss. 1973; Fisher and Simnett. 1973: Cowan and Crystal, 1975; Brody et al., 1978) the compensatory response is either ablated or is much reduced. Pleural effusion is a well known complication of peumonecotomy in humans (Goldstraw, 1980) and probably affects compensatory growth, but this has not been documented in animal experimentation.

6. As noted in the present study. residual blood may lead to a spurious increase in $\mathrm{W} l_{T}, \mathrm{~W}_{d r y} l_{T}$ and $\mathrm{Prol}_{T}$ measurements of the contralateral side following pneumonecotmy.

7. In the present study and some other experiments (Holmes and Thurlbeck, 1979; Thurlbeck et al., 1981; Arnup et al.. 1983) some interlobar differences have been observed, but not in all (Langston et al.. 1977). If interlobar variations do occur. and if a lobe has been considered as a representative of the whole lung (Cohn. 1939; Buhain and Brody. 1973: Brody and Buhain. 1973: Burri and Sehovic. 1979; Wandel et al., 1983; Thet and Law, 1984) and it is not, then conflicting results could arise.

8. The time period required to achieve complete response differs from species to species [i.e. 1 week in rats (Rannels et al.. 1979). 2 weeks in mice (Brody et al., 1978), and 3 weeks in rabbits (Das and Thurlbeck, 1979)]. Thus, if assessments are made before the maximum response is achieved, then the response will appear to be incomplete. On the contrary, it has been suggested that the response is temporary and if a long recovery period is allowed, the response may disappear (Davies et al.. 1982).

9. Some of the technical problems in morphometric studies are generally overlooked. One of the best examples is tissue shrinkage and distortion produced by processing and cutting of tissue, which is often ignored (Buhain and Brody. 1973: Brody and Buhain, 1973; Nattie et al., 1974: Burri and Sehovic. 1979: Wandel et al.. 1983: Thet and Law. 1984). Shrinkage is difficult to measure accurately and variations in shrinkage between blocks of tissue, or even between sections from the same block, has been demonstrated (Thurlbeck, 1967). 
10. As morphometry is a time consuming procedure, sample size is often small and true differences may be obscured. For example. Wandel et al. (1983) used 3 or 4 animals in each group, and Boatman (1977), used only one animal as a control. Another well recognized problem in morphometric measurements is defining an alveolus and large variations occur in interpretation of ducts and alveoli on histological sections (Hensen and Ampaya, 1974).

Thus, besides difference in the male and female postpneumonectomy response, there are sufficient other reasons to help explain the conflicting results in the previous literature.

\subsection{Conclusions}

1. Somatic growth was less in females. Absolute lung variables were higher in males but specific variables were higher in females.

2. Compensatory lung response was complete in terms of lung weight and lung volume but incomplete for DNA and protein content in both males and females.

3. Pneumonectomy resulted mainly in alveolar dilatation in both sexes, but there was evidence of alveolar multiplication from direct alveolar counting.

4. In general the response to pneumonectomy was similar in males and females. Absolute increases were greater in males than females but specific (per unit body weight) were greater in females. These differences were due to the differences in body weight of the sexes, and the percentage increase was the same. Evidence of simple overinflation was greater in females. who also showed loss of elastic recoil at $50 \%-90 \%$ of total lung capacity.

5. Postpneumonectomy lobar response was in general similar in both sexes. The upper and post-caval lobes in males and the post-caval lobe in females expanded more than other lobes.

6. Morphologically, the lower lobes of sham-operated rats have smaller and more unit structures per unit volume than those of the post-caval lobes. Females had smaller alveoli than males. 
7. In terms of completeness of compensatory lung response, male and female differences would not account for the conflicting results in the literature. 


\section{Bibliography}

[1] Addis. T. Compensatory hypertrophy of the lung after unilateral pneumonectomy. J. Exp. Med. 47: 51-56, 1928.

[2] Aherne. W. A. and Dunnill. M. S. Morphometry. 163-178, 1982.

[3] Amy, R., Bowes, D., Burri, P. H., and Thurlbeck. W. M. Post-natal growth of the mouse lung. J. Anat. 124:131-151. 1977.

[4] Angus. G. E.. and Thurlbeck. W. M. Number of alveoli in the human lung. J. Appl. Physiol. 32: 483-485, 1972.

[5] Arnup. M. E.. Greville. H. W.. Oppenheimer, L., Mink, S. N., and Anthonisen, N. R. Dynamic lung function in dogs with compensatory lung growth. J. Appl. Physiol. 57: 1569-1576, 1984.

[6] Aschinberg. L. C., Koskimies, O.. Bernstein. J.. Nash. M., Edelmann. Jr. M.. and Spitzer. A. The influence of age on the respose to renal parenchymal loss. Yale J. Biol. Med. 51: 341-345, 1978.

[7] Bartlett. D. Postnatal growth of the mammalian lung: Influence of exercise and thyroid activity. Respir. Physiol. 9: 50- 57. 1970.

[8] Bartlett. D. and Remmers. J. E. Effect of high altitude exposure on the lungs of young rats. Respir. Physiol. 13: 116-125. 1971.

[9] Becker. F. F. The normal hepatocyte in division: Regeneration of the mammalian liver In Progress in Liver Diseases. Grune \& Stratton. New York. 3: 60-76, 1969. 
[10] Bennett. R. A., Colony. P. C., Addison, J. L., and Rannels. D. E. Effects of prior adrenalectomy on postpneumonectomy lung growth in the rat. Am. J. Physiol. 248: E70-74. 1985.

[11] Berger, L. C. and Burri. P. H. Timing of the quantitative recovery in the regenerating rat lung. Am. Rev. Respir. Dis. 132: 777-783. 1985.

[12] Boatman. E. S. A morphometric and morphological study of the lungs of rabbits after unilateral pneumonectomy. Thorax. 32: 406- 417, 1977.

[13] Boatman. E. G.. Ward. G., and Martin. C. J. Morphometric changes in rabbit lungs before and after pneumonectomy and exposure to ozone. J. Appl. Physiol. 54: $778-784.1983$.

[14] Bond. A. An analysis of the response of salamander gills to changes in the oxygen concentration of the medium. Develop. Biol. 2: 1-20, 1960.

[15] Bonvalet, J. P.. Champion. M.. Wanstak. F., and Berjal. G. Compensatory renal hypertrophy in young rats: Increase in the number of nephrons. Kidney Int. 1: 391-396. 1972.

[16] Boyden. E. A.. and Tomsett. D. H. The post-natal growth of the lung in the dog. Acta. Anat. (Basel) 47: 185-215, 1961.

[17] Boyden. E. A. Notes on the development of the lung in infancy and childhood. Am. J. Anat. 121: 749, 1967.

[18] Boyden, E. A.-The pattern of the terminal air spaces in a premature infant of 30-32 weeks that lived nineteen and a quarter hours. Am. J. Anat. 126: 31. 1969.

[19] Boyden. E. A. The structure of the pulmonary acinus in a child of six years and eight months. Am. J. Anat. 132: 275, 1971.

[20] Bremer, J. L. Post-natal development of alveoli in the mammalian lung in relation to the problem of the alveolar phagocyte. Contrib. Embryol. Carnegie Inst. 25: 83-118, 1935. 
[21] Bremer, J. L. The fate of the remaining lung tissue after lobectomy or pneumonectomy. J. Thorac. Surg. 6: 336-343, 1937.

[22] Brody. J. S. Time course of and stimuli to compensatory growth of the lung after pneumonectomy. J. Clin. Invest. 56: 897-904. 1975.

[23] Brody. J. S. and Buhain. W. J. Hormone-induced growth of the adult rat lung. Am. J. Physiol. 223: 1444-1450. 1972.

[24] Brody. J. S.. and Buhain. W.J. Hormonal influence on postpneumonectomy lung growth in the rat. Respir. Physiol. 19: 344- 355. 1973.

[25] Brody. J. S.. Burki, R., Kaplan. N. Deoxyribonucleic acid synthesis in lung cells during compensatory lung growth after pneumonectomy. Am. Rev. Respir. Dis. 117: 307-316. 1978.

[26] Brody. J. S.. Kagan. H., and Manalo. A. Lung lysyl oxidase activity: relation to lung growth. Am. Rev. Respir. Dis. 120: 1289-1295. 1979.

[27] Brody, J. S., and Thurlbeck. W. M. Development, growth, and aging of the lung. In Handbook of physiology. Section 3. The respiratory system. Ed. Peter T. Macklem, and Jere Mead. American Physiological Society, Bethesda. Maryland. 1986

[28] Buhain, W. J., and Brody. J. S. Compensatory growth of the lung following pneumonectomy. J. Appl. Physiol. 35: 898-902, 1973.

[29] Burri. P. H. The post-natal growth of the rat lung. III. Morphology. Anat. Rec. 180: 77-98, 1974.

[30] urri. P. H., Dbaly. J., and Weibel, E. R. The post-natal growth of the rat lung. I. Morphometry Anat. Rec. 178: 711- 730. 1974.

[31] Burri. P. H.. Pfrunder, H. B.. and Berger. L. C. Reactive changes in pulmonary parenchyma after bilobectomy: a scanning electron microscopic investigation. Exp. Lung Res. 4: 11-28, 1982.

[32] Burri P. H.. and Sehovic, S. The adaptive response of the rat lung after bilobectomy. Am. Rev. Respir. Dis. 119: 769-777, 1979. 
[33] Burri, P. H. and Weibel, E. R. Morphometric estimation of the diffusion capacity. II Effect of $\mathrm{PO}_{2}$ on the growing lung. Respir. Physiol. 11: 247-264. 1971.

[34] Burton. L. Study of conditions and mechanism of diphenylamine reaction for colorimetric determination of deoxyribonucleic acid. Biochem. J. 62: 315-323. 1956.

[35] Cagle. P. T. and Thurlbeck. W. M. The effect of age on the postpne umonectomy adaptive response in rabbits. In press Am. Rev. Respir. Dis., 1988.

[36] Cagle. P. T. and Thurlbeck. W. M. State of the art: Postpneumonectomy compensatory growth. In press Thorax.. 1988.

[37] Carter. B. N., Longacre. J. J.. and Quill. L. Mc. G. A study of the changes in the cardiorespiratory physiology following total pneumonectomy in young developing animals. J. Thorac. Surg. 7: 326-337. 1938.

[38] Cohn. R. Factors affecting the postnatal growth of the lung. Anatomical Record 75: 195-205, 1939.

[39] Cohn. R. The post-natal growth of the lung. J. Thorac. Surg. 9: 272-277. 1940.

[40] Colebatch. H. J. H.. Ng. C. K. Y., and Nikov. N. Use of an exponential function for elastic recoil. J. Appl. Physiol. 46(2): 387-393. 1979.

[41] Cowan, M. J., and Crystal, R. G. Lung growth after unilateral pneumonectomy: quantitation of collagen synthesis and content. Am. Rev. Respir. Dis. 111: 267-277, 1975.

[42] Cunningham, E. L., Brody. J. S., and Jain. B. P. Lung growth induced by hypoxia. J. Appl. Physiol. 37: 363-366. 1974.

[43] Das, R. M., and Thurlbeck. W. M. The events in the contralateral lung following pneumonectomy in the rabbit. Lung 156: 165-172, 1979.

[44] Davies, P., McBride, J., Murray, G. F., Wilcox, B. R., Shallal, J. A., and Reid, L. Structural changes in the canine lung and pulmonary arteries after pneumonectomy. J. Appl. Physiol. 53(4): 859-864. 1982. 
[45] Dunnill. M. S. Postnatal growth of the lung. Thorax. 17: 329-333, 1962.

[46] Enesco. M., and LeBlond. C. P. Increase in cell number as a factor in the growth of the organs and tissues of the young male rat. J. Embryol. Exp. Morphol. 10: 530-562, 1962.

[47] Engel. S. The structure of the respiratory tissue in the newly born. Acta. Anat. 19: 353-365, 1953.

[48] Fisher, J. M., and Simnett. J. D. Morphogenetic and proliferative changes in the regenerating lung of the rat. Anat. Rec. 176: 389-396, 1973.

[49] Ford. G. T. Galaugher, W.. Forkert, L., Fleetham. J. A., Thurlbeck. W. M., and Anthonisen. N. R. Static lung function in puppies after pneumonectomy. J. Appl. Physiol. 50: 1146-1150. 1981.

[50] Galla, J. H., Klein-Robbenhaar, T., and Hayslett. J. P. I nfluence of age on the compensatory response in growth and function to unilateral nephrectomy. Yale J. Biol. Med. 47: 218-226, 1974.

[51] Geelhaar, A. and Weibel, E. R. Morphometric estimation of pulmonary diffusion capacity. III The effect of increased oxygen consumption in Japanese waltzing mice. Respir. Physiol. 11: 354-366. 1971.

[52] Gnavi, M.. Pansa. E., and Anselmetti, G. L'accrescimento e la rigenerazione del polmone. Minerva. Chir. 25: 1491-1504, 1970.

[53] Goldstraw. P. Postpneumonectomy empyema: The cloud with a silver lining. J. Thorac. Cardiovasc. Surg. 79: 851-855, 1980.

[54] Greville. H. W., Arnup, M. E., Mink, S. N., Oppenheimer, L., and Anthonisen, N. R. Mechanism of reduced maximum expiratory flow in dogs with compensatory lung growth. J. Appl. Physiol. 60: 441-448, 1986.

[55] Haber. P. S., Colebatch. H. J. H., Ng. C. K. Y., and Greaves. I. A. Alveolar size as a determinant of pulmonary distensibility in mammalian lungs. J. Appl. Physiol. 54(3): 837-845. 1983. 
[56] Hayslett, J. P. Functional adaptation to reduction in renal mass. Physiol. Rev. 59(1): 137-164, 1979 .

[57] Hislop. A. and Reid. L. Development of the acinus in the human lung. Thorax. 29: 90-94. 1974.

[58] Holmes, C. and Thurlbeck, W. M. Normal lung growth and response after pneumonectomy in rats at various ages. Am. Rev. Respir. Dis. 120: 1125 1136. 1979.

[59] Inselman. L. S., Mellins. R. B.. and Brasel. J. A. Effect of lung collapse on compensatory lung growth. J. Appl. Physiol. Respirat. Environ. Exercise Physiol. 43: 27-31, 1977.

[60] Jerek, V. Pulmonary haemodynamics and blood gases during unilateral pulmonary artery occlusion and after lung resection. Bull. Physio-Pathol. Respirat. 6: 255-264, 1970 .

[61] Karp. R., Brasel. J. A.. Winie. M. D. Compensatory kidney growth after uninephrectomy in adult and infant rats. Am. J. Dis. Childh. 121: 186-192. 1971.

[62] Kauffman, S. L., Burri. P. H., and Weibel, E. R. The postnatal growth of the rat lung. II. Autoradiography. Anat. Rec. 180: 63-76. 1974.

[63] Kaufman. J. M., DiMeola, H. J., Siegel, N. J., Lytton, B., Kashgarian. M., and Hayslett, J. P. Compensatory adaptation of structure and function following progressive renal ablation. Kidney Int. 6: 10-17, 1974.

[64] Keszler. P. Compensatory phenomena in the residual lung following resection. Acta. Med. Acad. Sci. Hung. 9: 181-197, 1955.

[65] Kida, K., and Thurlbeck, W. M. Effects of Beta-aminoproprionitrile on the growing rat lung. Am. J. Pathol. 101: 693-710, 1980.

[66] Langston. C.. Sachdeva. P.. Cowan. M. J.. Haines, J.. Crystal. R. J.. and Thurlbeck. W. M. Alveolar multiplication in the contralateral lung after unilateral pneumonectomy in the rabbit. Am. Rev. Respir. Dis. 115: 7-13. 1977. 
[67] Langston, C., and Thurlbeck. W. M. Lung growth and development in late gestation and early postnatal life (Lung growth in utero and in the neonate). Year Book Medical Publishers. Chicago, 111.

[68] Lechner. A. J.. and Banchero. N. Lung morphometry in guinea pigs acclimated to hypoxia during growth. Respir. Physiol. 42(2): 155-169. 1980.

[69] Lewan, L., Yngner, T., and Engelbrecht, C. Minireview: The biochemistry of the regenerating liver. In. J. BBiochem. 8: 477-487, 1977.

[70] Longacre. J. J., and Johansman. R. An experimental study of the fate of the remaining lung following total pneumonectomy. J. Thorac. Surg. 10: 131-149. 1940.

[71] Loosli, C. G. and Potter. E. L. Pre and postnatal development of the respiratory portion of the human lung. Am. Rev. Respir. Dis. 80: 5-23, 1959.

[72] Lowry, O. H., Rosebrough, N. J., Farr. A. L., and Randall, R. J. Protein measurement with the Folin phenol reagent. J. Biol. Chem. 193: 265-275. 1951.

[73] Massion, W. H. and Schilling. J. A. Physiological effects of lung resection in adult and puppy dogs. J. Thorac. Cardiovasc. Surg. 48: 239-250, 1964.

[74] McBride. J. T. Postpneumonectomy airway growth in the ferret. J. Appl. Physiol. 58: 1010-1014, 1985.

[75] Mead. J. Mechanical properties of lungs. Physiol. Rev. 41: 281-330, 1961.

[76] Nardell. E. A., and Brody. J. S. Determinants of mechanical properties of rat lung during postnatal development. J. Appl. Physiol. 53: 140-148. 1982.

[77] Nattie. E. E., Wiley. C. W.. and Bartlett Jr., D. Adaptive growth of the lung following pneumonectomy in rats. J. Appl. Physiol. 37: 491-495. 1974.

[78] Nijjar, M. S. and Thurlbeck. W. M. Alterations in enzymes related to adenosine 9', 5'-monophosphate during compensatory growth of rat lung. Eur. J. Biochem. 105: 403-407. 1980. 
[79] Pepelko. W. E. Effects of hypoxia and hypercapnia, singly and combined, on growing rats. J. Appl. Physiol. 28: 646-651, 1970.

[80] Rannels, D. E., Addison. J. L., and Bennett. R. A. Increased pulmonary uptake of exogenous polyamines after unilateral pneumonectomy. Am. J. Physiol. 250: E435-440, 1986.

[81] Rannels. D. E.. Burkhart. L. R.. and Watkins. C. A. Effect of age on the accumulation of lung protein following unilateral pneumonectomy in rats. Growth 48: 297-308, 1984.

[82] Rannels, D. E., White. D. M., and Watkins, C. A. Rapidity of compensatory lung growth following pneumonectomy in adult rats. J. Appl. Physiol. 46: 326333. 1979.

[83] Reid. L. The embryology of the lung. In Ciba foundation symposium and development of the lung. J. and A. Churchill. A. V. S. de Rueck and R. Porter (eds.). London, 109-124, 1967.

[84] Reinhoff, W. F.. Reichert, F.L., and Heuer, G. J. Compensatory changes in the remaining lung following total pneumonectomy: an experimental study. Bull. Johns Hopkins Hosp. 57: 373-383, 1935.

[85] Romanova, L. K. Regenerative hypertrophy of the lungs in rats after one-stage removal of the entire left lung and the diaphragmatic lobe of the right lung. Bull. Exp. Biol. Med. 50: 100-105. 1960.

[86] Romanova. L. K.. Leikina. E. M., and Antipova. K. K. Nucleic acid synthesis and mitotic activity during development of compensatory hypertrophy of the lung in rats. Bull. Exp. Biol. Med. 63: 96-100. 1967.

[87] Romanova, L. K., Leikina, E. M., Antipova, K. K. and Sokolova, T. N. The role of function in the restoration of damaged viscera. Soviet. J. Develop. Biol. 1-2: 384-390, 1970-1.

[88] Romanova. L. K., and Zhikhareva. I. A. Humoral regulation of regeneration in the lungs, kidneys and liver. Bull. Exp. Biol. Med. 73: 84-87, 1972. 
[89] Saetren, H. A principle of autoregulation of growth: Production of organ specific mitosis inhibitors in kidney and liver. Exptl. Cell Res. 11: 229-232. 1956.

[90] Sery, Z., Keprt. E., and Obrucnik. M. Morphometric analysis of late adaptation of the residual lung following pneumonectomy in young and adult rabbits. J. Thorac. Cardiovasc. Surg. 57: 549-557, 1969.

[91] Short. R. H. D. Aspects of comparative lung growth. Proc. R. Soc. Lond. [Biol] 140: 432. 1952.

[92] Simnett, J. D. Stimulation of cell division following unilateral collapse of the lung. Anat. Rec. 180: 681-686, 1974.

[93] Simnett, J. D., Fisher. J. M., and Heppleston. A. G. Tissue-specific inhibition of lung alveolar cell mitosis in organ culture. Nature 223: 944-946, 1969.

[94] Smith. B. T.. Galaugher. W.. and Thurlbeck. W. M. Serum from pneumonectomized rabbits stimulates alveolar type II cell proliferation in vitro. Am. Rev. Respir. Dis. 121: 701-707. 1980.

[95] Sosenko, I. R. S. and Frank. L. Endotoxin alters biochemical and morphological responses to pneumonectomy in adult rats. Am. J. Physiol. 249: R125-132. 1985.

[96] Stiles, Q. R., Meyer. B. W.. Lindesmith, G. G., and Jones. J. C. The effects of pneumonectomy in children. J. Thorac. Cardiovasc. Surg. 58: 394-400, 1969.

[97] . Tartter, P. I., and Goss, R. J. Compensatory pulmonary hypertrophy after incapacitation of one lung in the rat. J. Thorac. Cardiovasc. Surg. 66: 147-152. 1973.

[98] Thet. L. A. and Law, D. J. Changes in cell number and lung morphology during early postpneumonectomy lung growth. J. Appl. Physiol. 56: 975-978, 1984.

[99] Thurlbeck, W. M. Measurements of pulmonary emphysema. Am. Rev. Respir. Dis. 95(5): 752-764, 1967.

[100] Thurlbeck. W. M. Postnatal growth and development of the lung. Am. Rev. Respir. Dis. 111: 803-844, 1975. 
[101] Thurlbeck. W. M. Structure of the Lungs, in Respiratory physiology II. University Park Press. Baltimore Vol.14: 1-36. 1977.

[102] Thurlbeck. W. M. Postnatal human lung growth. Thorax. 37: 564-571, 1982.

[103] Thurlbeck. W. M. Editorial: Postpneumonectomy compensatory lung growth. Am. Rev. Respir. Dis. 128: 965-967. 1983.

[104] Thurlbeck. W. M. and Angus. G. B. Growth and aging of the normal lung. Chest. 67: 3S-7S. 1975.

[105] Thurlbeck. W. M.. D'Ercole. A. J., and Smith. B. T. Serum somatomedin C concentrations following pneumonectomy. Am. Rev. Respir. Dis. 130: 499-500. 1984.

[106] Thurlbeck. W. M.. Galaugher, W., Mathers, J. Adaptive response to pneumonectomy in puppies. Thorax. 36: 424-427, 1981.

[107] Tsanev. R. Cell cycle in liver function. In Cell cycle and cell differentiation. Springer. New York 197-248, 1975.

[108] Wandel. G.. Berger, L. C.. and Burri, P. H. Morphometric analysis of adult rat lung after bilobectomy. Am. Rev. Respir. Dis. 128: 968-972, 1983.

[109] Wannemacher Jr.. R. W.. Banks Jr., W. L., and Wunner. W. H. Use of a single tissue extract to determine cellular protein and nucleic acid concentrations and rate of amino acid incorporation. Anal. Biochem. 11: 320-326, 1965.

[110] Watkins. C. A.. Burkhart. L. A.. and Rannels. D. E. Lung growth in response to unilateral pneumonectomy in rapidly growing rats. Am. J. Physiol. 248: E162-169, 1985.

[111] Weibel, E. R. Practical methods for biological morphometry in stereological methods. Vol. I. Academic Press, London, 1979.

[112] Weibel. E. R. Looking into the lung: What can it tell us? Am. J. Roentgenol. 133: 1021-1031. 1979. 
[113] Weibel. E. R. Fleischner lecture. How does lung structure affect gas exchange? Chest. 83(4): 657-665. 1983.

[114] Weibel, E. R. The pathway for oxygen. Structure and function of the mammalian respiratory system. Harvard University Press. 1984.

[115] Wigglesworth, V. B. Growth and regeneration in the tracheal system of an insect, Rhodnius prolixus (Hemiptera). Quart. J. Microscop. Sci. 95: 115-137. 1954.

[116] Wilcox, B. R., Murray, G. F., Friedman. M., and Pimmel. R. L. The effects of early pneumonectomy on the remaining pulmonary parenchyma. Surgery 86 : 294-300, 1979.

[117] Winick. M., and Noble. A., Quanitative changes in $D N A, R N A$, and protein during prenatal and postnatal growth in the rat. Develop. Biol. 12: 451-466. 1965.

[118] Yee. N. M.. Hyatt. R. E. Effect of left pneumonectomy on lung mechanics in rabbits. J. Appl. Physiol. 54: 1612-1617, 1983.

[119] Zar. J. H. Biostatistical analysis. Prentice-Hall, Englewood Cliffs, New Jersey. 1974. 


\section{Appendix A}

\section{APPENDIX}

Table A.1: Somatic growth results for male sham-operated vs male pneumonectomy, female sham operated and female pnuemonectomy groups.

\begin{tabular}{||l|c|c||c|c||}
\hline \hline Variable & $\begin{array}{c}\text { Male } \\
\text { sham }\end{array}$ & $\begin{array}{c}\text { male } \\
\text { pneumo }\end{array}$ & $\begin{array}{c}\text { female } \\
\text { sham }\end{array}$ & $\begin{array}{c}\text { Female } \\
\text { pneumo }\end{array}$ \\
\hline \hline Wb (g) & $86 \pm 1.6$ & $90 \pm 1.8$ & $80 \pm 1.9$ & $80 \pm 1.1$ \\
$\begin{array}{l}\text { (4 weeks) } \\
\begin{array}{l}\text { Wb (g) } \\
\text { (7 weeks) }\end{array}\end{array}$ & $250 \pm 4.9$ & $252 \pm 3.4$ & $177 \pm 3.1$ & $170 \pm 2.4$ \\
NTL (cm) & $37 \pm 0.3$ & $38 \pm 0.2$ & $34 \pm 0.2$ & $35 \pm 0.1$ \\
\hline
\end{tabular}

Values are means \pm SEM's. 
Table A.2: Extent of compensatory lung growth results for male sham-operated group compared to female sham-operated group.

\begin{tabular}{|c|c|c|}
\hline Variables & Male sham & Female sham \\
\hline$W l_{R}(\mathrm{~g})$ & $0.728 \pm 0.02$ & $0.590 \pm 0.01^{*}$ \\
\hline$W l_{T}(\mathrm{~g})$ & $1.068 \pm 0.02$ & $0.877 \pm 0.02^{*}$ \\
\hline$W_{d r y} l_{R}(\mathrm{~g})$ & $0.144 \pm 0.003$ & $0.118 \pm 0.003^{*}$ \\
\hline$W_{d r y} l_{T}(\mathrm{~g})$ & $0.220 \pm 0.004$ & $0.181 \pm 0.004^{*}$ \\
\hline$V l_{R}(\mathrm{ml})$ & $6.57 \pm 0.32$ & $5.83 \pm 0.19$ \\
\hline $\mathrm{V} l_{T}(\mathrm{ml})$ & $9.34 \pm 0.46$ & $8.42 \pm 0.31$ \\
\hline $\mathrm{DNAl}_{R}(\mathrm{mg})$ & $4.15 \pm 0.09$ & $3.44 \pm 0.10^{*}$ \\
\hline $\mathrm{DNAl}_{T}(\mathrm{mg})$ & $6.32 \pm 0.12$ & $5.27 \pm 0.13^{*}$ \\
\hline $\operatorname{Prol}_{R}(\mathrm{mg})$ & $63.19 \pm 1.00$ & $59.69 \pm 1.6$ \\
\hline $\operatorname{Prol}_{T}(\mathrm{mg})$ & $96.29 \pm 1.43$ & $91.48 \pm 2.22$ \\
\hline$W l_{T} / 100 \mathrm{~g} \mathrm{~Wb}(\mathrm{~g})$ & $0.430 \pm 0.009$ & $0.496 \pm 0.008^{*}$ \\
\hline $\mathrm{W}_{d r y} l_{T} / 100 \mathrm{~g} \mathrm{~Wb}(\mathrm{~g})$ & $0.084 \pm 0.001$ & $0.101 \pm 0.001^{*}$ \\
\hline $\mathrm{V} l_{T} / 100 \mathrm{~g} \mathrm{~Wb}(\mathrm{ml})$ & $4.01 \pm 0.11$ & $4.83 \pm 0.18^{* *}$ \\
\hline $\mathrm{DNAl}_{T} / 100 \mathrm{~g} \mathrm{~Wb}(\mathrm{mg})$ & $2.41 \pm 0.05$ & $2.95 \pm 0.04^{*}$ \\
\hline Prol $_{T} / 100 \mathrm{~g} \mathrm{~Wb}(\mathrm{mg})$ & $36.79 \pm 0.66$ & $51.18 \pm 0.87^{*}$ \\
\hline
\end{tabular}

Values are means \pm SEM's.

$* \mathrm{P}<0.0005 ; * * \mathrm{P}<0.005$.

Table A.3: Extent of compensatory lung growth results for male pneumonectomy group compared to female pneumonectomy group.

\begin{tabular}{|c|c|c|}
\hline Variables & Male pneumo & Female pneumo \\
\hline$W l_{R}(\mathrm{~g})$ & $1.094 \pm 0.03$ & $0.893 \pm 0.02^{*}$ \\
\hline$W_{d r y} l_{R}(\mathrm{~g})$ & $0.207 \pm 0.006$ & $0.167 \pm 0.005^{*}$ \\
\hline $\mathrm{V} l_{R}(\mathrm{ml})$ & $10.49 \pm 0.34$ & $8.57 \pm 0.40^{* *}$ \\
\hline $\mathrm{DNAl}_{R}(\mathrm{mg})$ & $5.25 \pm 0.14$ & $4.31 \pm 0.14^{*}$ \\
\hline $\operatorname{Prol}_{R}(\mathrm{mg})$ & $87.36 \pm 2.77$ & $80.19 \pm 1.90^{* * *}$ \\
\hline $\mathrm{W} l_{R} / 100 \mathrm{~g} \mathrm{~Wb}(\mathrm{~g})$ & $0.433 \pm 0.011$ & $0.525 \pm 0.015^{*}$ \\
\hline$W_{d r y} l_{R} / 100 \mathrm{~g} \mathrm{~Wb}(\mathrm{~g})$ & $0.082 \pm 0.001$ & $0.098 \pm 0.002^{*}$ \\
\hline $\mathrm{V} l_{R} / 100 \mathrm{~g} \mathrm{~Wb}(\mathrm{ml})$ & $4.17 \pm 0.14$ & $5.13 \pm 0.16^{*}$ \\
\hline $\mathrm{DNA}_{R} / 100 \mathrm{~g} \mathrm{~Wb}(\mathrm{mg})$ & $2.07 \pm 0.03$ & $2.54 \pm 0.05^{*}$ \\
\hline Prol $_{R} / 100 \mathrm{~g} \mathrm{~Wb}(\mathrm{mg})$ & $34.47 \pm 0.82$ & $47.31 \pm 0.81^{\circ}$ \\
\hline
\end{tabular}

Values are means \pm SEM's.

$* \mathrm{P}<0.0005, * * \mathrm{P}<0.005, * * * \mathrm{P}<0.05$. 
Table A.4: Lobar morphometric results for male sham-operated group compared to female sham-operated group.

\begin{tabular}{||l|c|c||}
\hline \hline Variables & Male sham & Female sham \\
\hline \hline L $_{m}(\mu)$ & & \\
Upper lobe & $74.6 \pm 2.6$ & $72.1 \pm 2.9$ \\
Middle lobe & $77.0 \pm 3.0$ & $72.8 \pm 2.1$ \\
Post-caval lobe & $82.9 \pm 2.1$ & $75.4 \pm 1.1^{*}$ \\
Lower lobe & $74.4 \pm 2.2$ & $71.3 \pm 1.8$ \\
$\bar{l}_{\text {alv }(\mu)}$ & & \\
Upper lobe & $38.4 \pm 0.9$ & $37.3 \pm 0.7$ \\
Middle lobe & $40.4 \pm 0.9$ & $36.6 \pm 0.7$ \\
Post-caval lobe & $41.4 \pm 1.0$ & $38.9 \pm 0.4$ \\
Lower lobe & $40.2 \pm 1.2$ & $37.5 \pm 1.0$ \\
Sw ${ }_{L B E}\left(m^{2}\right)$ & & \\
\hline Upper lobe & $0.057 \pm 0.002$ & $0.049 \pm 0.001^{*}$ \\
Middle lobe & $0.071 \pm 0.003$ & $0.068 \pm 0.003$ \\
Post-caval lobe & $0.061 \pm 0.002$ & $0.059 \pm 0.001$ \\
Lower lobe & $0.155 \pm 0.008$ & $0.147 \pm 0.006$ \\
Nv $\left(\times 10^{6}\right)$ & & \\
Upper lobe & $3.39 \pm 0.20$ & $3.38 \pm 0.16$ \\
Middle lobe & $3.31 \pm 0.18$ & $3.41 \pm 0.11$ \\
Post-caval lobe & $3.17 \pm 0.12$ & $3.24 \pm 0.13$ \\
Lower lobe & $3.90 \pm 0.18$ & $3.57 \pm 0.14$ \\
\hline Values aremeans
\end{tabular}

Values are means \pm SEM's.

$* P<0.05$. 
Table A.5: Lobar morphometric results for male pneumonectomy group compared to female pneumonectomy group.

\begin{tabular}{||l|c|c|}
\hline \hline Variables & Male pneumo & Female pneumo \\
\hline \hline $\mathrm{L}_{m}(\mu)$ & & \\
Upper lobe & $74.3 \pm 2.0$ & $80.0 \pm 2.6$ \\
Middle lobe & $83.1 \pm 2.2$ & $81.8 \pm 2.0$ \\
Post-caval lobe & $88.8 \pm 2.2$ & $86.2 \pm 2.1$ \\
Lower lobe & $81.0 \pm 1.6$ & $78.8 \pm 2.2$ \\
$\bar{T}_{\text {alv }(\mu)}$ & & \\
\hline Upper lobe & $41.0 \pm 1.1$ & $41.9 \pm 1.2$ \\
Middle lobe & $44.8 \pm 0.8$ & $43.9 \pm 0.8$ \\
Post-caval lobe & $46.2 \pm 1.2$ & $46.1 \pm 1.1$ \\
Lower lobe & $42.7 \pm 0.7$ & $42.7 \pm 1.3$ \\
Sw $w_{\text {LOBE }\left(m^{2}\right)}$ & & \\
Upper lobe & $0.100 \pm 0.004$ & $0.067 \pm 0.002^{*}$ \\
Middle lobe & $0.100 \pm 0.004$ & $0.089 \pm 0.003$ \\
Post-caval lobe & $0.098 \pm 0.005$ & $0.088 \pm 0.004$ \\
Lower lobe & $0.216 \pm 0.009$ & $0.176 \pm 0.008^{*} *$ \\
Nv $\left(\times 10^{6}\right)$ & & \\
Upper lobe & $2.84 \pm 0.12$ & $2.95 \pm 0.15$ \\
Middle lobe & $2.51 \pm 0.09$ & $2.62 \pm 0.11$ \\
Post-caval lobe & $2.03 \pm 0.09$ & $2.04 \pm 0.07$ \\
Lower lobe & $2.83 \pm 0.14$ & $3.25 \pm 0.13$ \\
\hline
\end{tabular}

Values are means \pm SEM's.

${ }^{*} \mathrm{P}<0.0005$. ${ }^{* *} \mathrm{P}<0.005$. 
Table A.6: Global morphometric response results for male sham-operated group compared to female sham-operated group.

\begin{tabular}{||l|c|c||}
\hline \hline Variable & Male sham & Female sham \\
\hline \hline $\mathrm{L}_{m}(\mu)$ & $76.6 \pm 2.0$ & $72.6 \pm 1.5$ \\
$\mathrm{I}_{a l v}(\mu)$ & $39.9 \pm 0.6$ & $37.6 \pm 0.6^{* *}$ \\
$\mathrm{Nv}\left(\times 10^{6}\right)$ & $3.64 \pm 0.15$ & $3.44 \pm 0.07$ \\
$\mathrm{~S} w_{R}\left(m^{2}\right)$ & $0.340 \pm 0.010$ & $0.320 \pm 0.010$ \\
$\mathrm{Sw}_{T}\left(m^{2}\right)$ & $0.485 \pm 0.020$ & $0.462 \pm 0.017$ \\
$\mathrm{Na}_{R}\left(\times 10^{6}\right)$ & $23.2 \pm 0.4$ & $19.8 \pm 0.5^{*}$ \\
$\mathrm{Na}_{T}\left(\times 10^{6}\right)$ & $33.0 \pm 0.7$ & $28.6 \pm 0.9^{*}$ \\
$\mathrm{Sw}_{R} / 100 \mathrm{~g} \mathrm{~Wb}\left(\mathrm{~m}^{2}\right)$ & $0.146 \pm 0.003$ & $0.184 \pm 0.008^{*}$ \\
$\mathrm{Sw}_{T} / 100 \mathrm{~g} \mathrm{~Wb}\left(m^{2}\right)$ & $0.208 \pm 0.006$ & $0.266 \pm 0.013^{*}$ \\
$\mathrm{Na}_{R} / 100 \mathrm{~g} \mathrm{~Wb}\left(\times 10^{6}\right)$ & $10.07 \pm 0.31$ & $11.42 \pm 0.48^{* *}$ \\
$\mathrm{Na}_{T} / 100 \mathrm{~g} \mathrm{~Wb}\left(\times 10^{6}\right)$ & $14.33 \pm 0.52$ & $16.47 \pm 0.73^{* *}$ \\
\hline \hline
\end{tabular}

Values are means \pm SEM's.

$* \mathrm{P}<0.002, * * \mathrm{P}<0.05$.

Table A.7: Global morphometric response results for male pneumonectomy group compared to female pneumonectomy group.

\begin{tabular}{||l|c|c||}
\hline \hline Variable & Male pneumo & Female pneumo \\
\hline \hline $\mathrm{L}_{m}(\mu)$ & $82.0 \pm 1.2$ & $81.6 \pm 1.7$ \\
$\mathrm{I}_{a l v}(\mu)$ & $43.6 \pm 0.5$ & $43.6 \pm 0.9$ \\
$\mathrm{Nv}\left(\times 10^{6}\right)$ & $2.59 \pm 0.09$ & $2.82 \pm 0.08$ \\
$\mathrm{Sw}_{R}\left(m^{2}\right)$ & $0.514 \pm 0.018$ & $0.418 \pm 0.014^{*}$ \\
$\mathrm{Na}_{R}\left(\times 10^{6}\right)$ & $26.6 \pm 0.7$ & $23.3 \pm 0.5^{*}$ \\
$\mathrm{Sw}_{R} / 100 \mathrm{~g} \mathrm{~Wb}\left(m^{2}\right)$ & $0.204 \pm 0.008$ & $0.251 \pm 0.007^{*}$ \\
$\mathrm{Na}_{R} / 100 \mathrm{~g} \mathrm{~Wb}\left(\times 10^{6}\right)$ & $10.66 \pm 0.47$ & $14.66 \pm 0.38^{*}$ \\
\hline \hline
\end{tabular}

Values are means \pm SEM's

$* \mathrm{P}<0.003$.

Table A.8: Nature of lung growth, a biochemical aspect: Male sham-operated vs female sham-operated group, and male pneumonectomy vs female pneumonectomy group.

\begin{tabular}{||l|c|c||c|c||}
\hline Variables & $\begin{array}{c}\text { Male } \\
\text { sham }\end{array}$ & $\begin{array}{c}\text { Female } \\
\text { sham }\end{array}$ & $\begin{array}{c}\text { Male } \\
\text { pneumo }\end{array}$ & $\begin{array}{c}\text { Female } \\
\text { pneumo }\end{array}$ \\
\hline DNA/g W dry $_{\text {l }}(\mathrm{mg})$ & 28.68 & 29.12 & 25.33 & 25.82 \\
& \pm 0.36 & \pm 0.36 & \pm 0.37 & \pm 0.33 \\
Protein/DNA (mg/mg) & 15.2 & $17.3^{*}$ & 16.6 & $18.6^{*}$ \\
& \pm 0.25 & \pm 0.17 & \pm 0.22 & \pm 0.29 \\
\hline
\end{tabular}

Values are means \pm SEM's.

$* \mathrm{P}<0.003$. 
Table A.9: Static pressure-volume curve results for male sham-operated vs female sham-operated group, and male pneumonectomy vs female pneumonectomy group.

\begin{tabular}{||l|c|c||c|c||}
\hline \hline Variables & $\begin{array}{c}\text { male } \\
\text { sham }\end{array}$ & $\begin{array}{c}\text { female } \\
\text { sham }\end{array}$ & $\begin{array}{c}\text { male } \\
\text { pneumo }\end{array}$ & $\begin{array}{c}\text { female } \\
\text { pneumo }\end{array}$ \\
\hline \hline TLC $(\mathrm{ml})$ & 8.1 & $6.6^{*}$ & 8.1 & $6.8^{*}$ \\
& \pm 0.63 & \pm 0.18 & \pm 0.49 & \pm 0.3 \\
TLC $/ 100 \mathrm{~g} \mathrm{~Wb}(\mathrm{ml})$ & 3.45 & 3.83 & 3.23 & $4.05^{*}$ \\
& \pm 0.25 & \pm 0.12 & \pm 0.17 & \pm 0.19 \\
TLC / g W $(\mathrm{ml})$ & 7.31 & 7.3 & 6.79 & 7.14 \\
& \pm 0.47 & \pm 0.3 & \pm 0.38 & \pm 0.34 \\
Constant K & 0.125 & 0.114 & 0.139 & 0.139 \\
& \pm 0.005 & \pm 0.005 & \pm 0.006 & \pm 0.004 \\
\hline \hline
\end{tabular}

Values are means \pm SEM's.

$* P<0.05$. 